
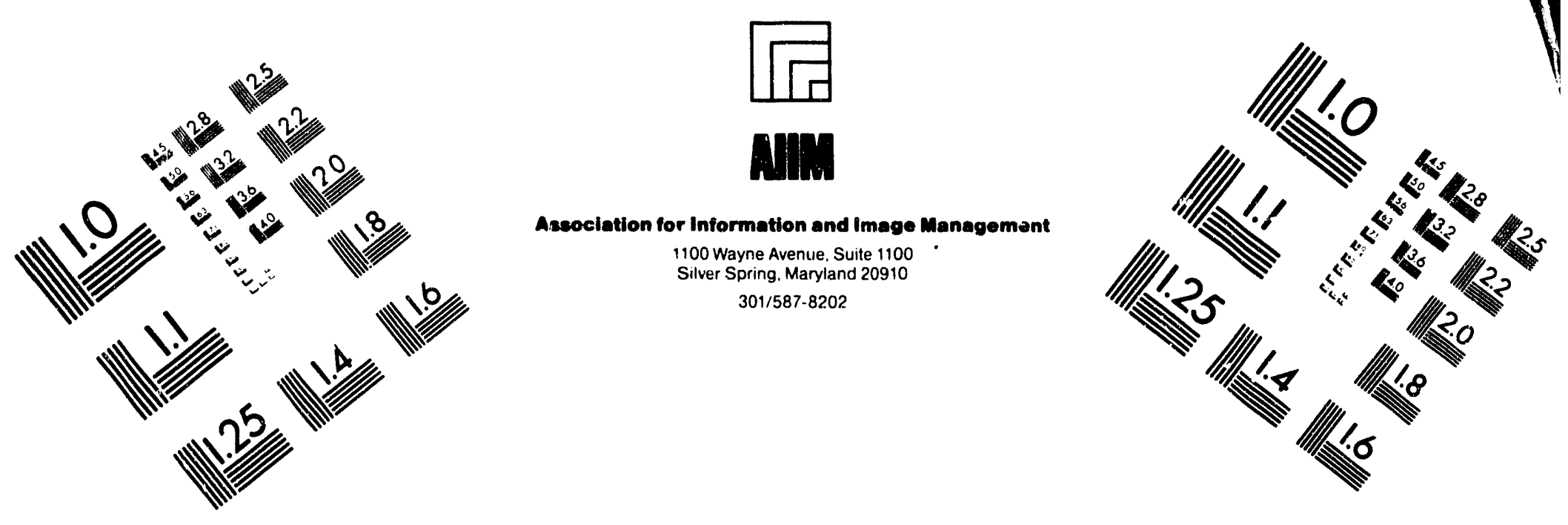

\title{
Centimeter
}

$\begin{array}{llllllllllllllll}1 & 2 & 3 & 4 & 5 & 6 & 7 & 8 & 9 & 10 & 11 & 12 & 13 & 14 & 15 & \mathrm{~mm}\end{array}$ $\left.\right|_{1}$ Inches
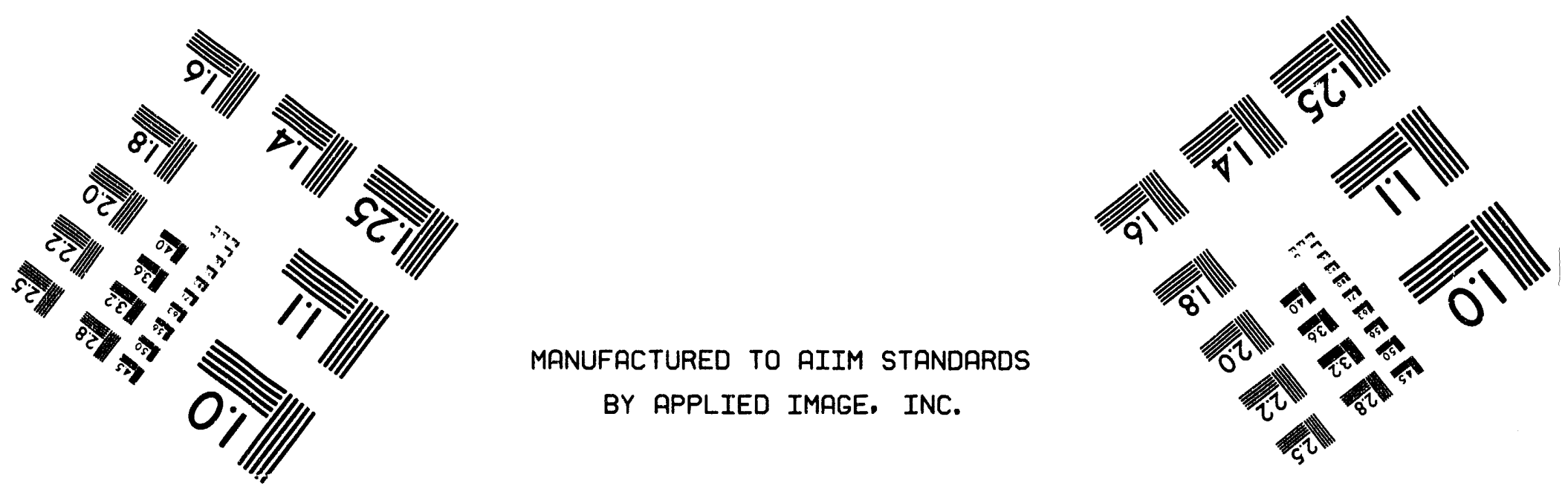

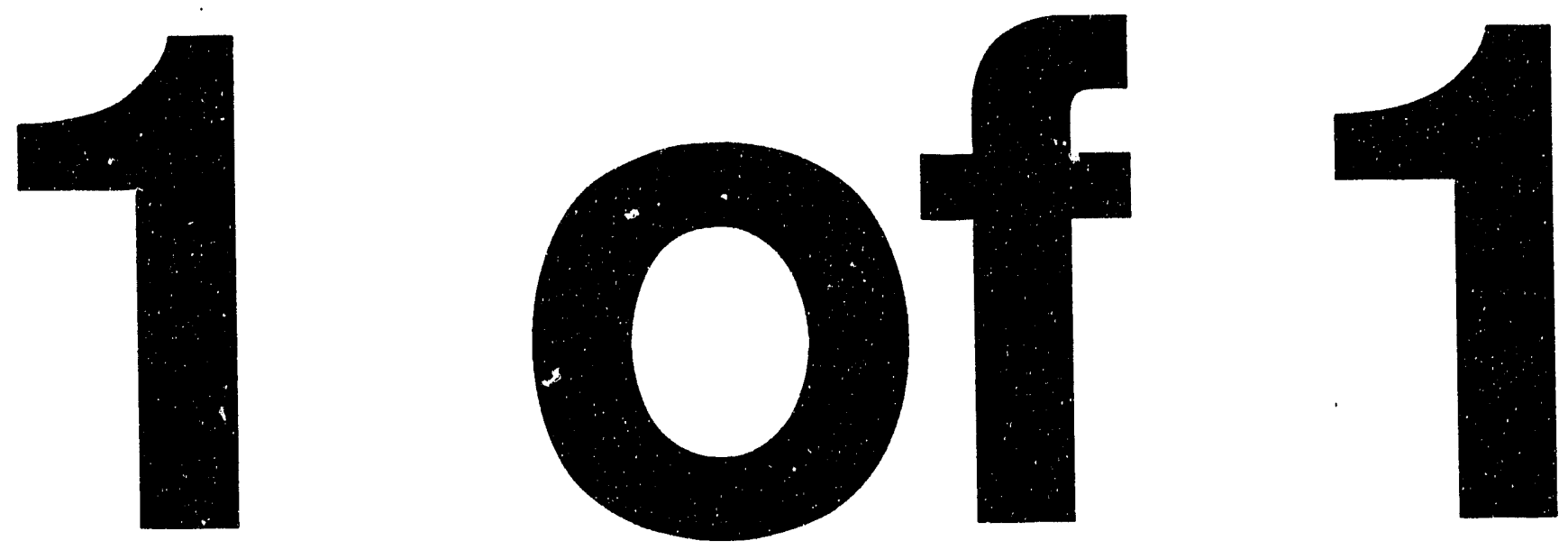
PNL-SA-22634

\section{CARBON DIOXIDE CONTROL COSTS FOR GASIFICATION COMBINED-CYCLE PLANTS IN THE UNITED STATES}
D. R. Brown
K. K. Humphreys
L. W. Vail

June 1993

Prepared for the U.S. Department of Energy under Contract DE-ACO6-76RLO 1830

Pacific Northwest Laboratory Richland, Washington 99352 


\section{SUMMARY}

The objective of this study, conducted for the U.S. Department of Energy by the Pacific Northwest Laboratory's (PNL) Global Studies Program, was to initiate the development of a carbon dioxide $\left(\mathrm{CO}_{2}\right)$ control "suppiy curve." The curve would relate the amount of $\mathrm{CO}_{2}$ controlled as a function of the cost of control in the electric utility sector. This information, along with similar characterizations of other options, could be used in general planning studies evaluating alternative responses to the potential global warming problem.

This study focused on evaluating the cost of recovering $\mathrm{CO}_{2}$ from coal gasification, combined-cycle (GCC) power plants and transporting the $\mathrm{CO}_{2}$ in pipelines for disposal in deep ocean water, depleted $0 i 1$ and gas reservoirs, or aquifers. Other fuels and conversion technologies were not evaluated. Technical feasibility, environmental acceptability, and other implementation issues were not addressed in detail.

Ocean disposa? of $\mathrm{CO}_{2}$ offers essentially unlimited capacity, but is distant from most U.S. coal-fired power plants and presents environmental concerns at the disposal point. Depleted $0 i 1$ and gas reservoirs are also distant from most U.S. coal-fired power plants and have a more limited disposal capacity, but were calculated to have a potential capacity more than double that required to dispose of all $\mathrm{CO}_{2}$ from $830 \mathrm{GCC}$ power plants (380-MWe each) for a period of 40 years. The existence of $0 i 1$ and gas reservoirs provides "proof" of the long-term $\mathrm{CO}_{2}$ confinement potential in these formations. In contrast, aquifer disposal is believed to be significantly riskier. Key concerns are lack of geologic knowledge at depths adequate for $\mathrm{CO}_{2}$ disposal; uncertainty about geochemical impacts from decreased water $\mathrm{pH}$; and long-term confinement, which is unproven for non-petroleum formations.

Carbon dioxide recovery at GCC plants increased the levelized energy cost (LEC) by about one third relative to a reference GCC plant without $\mathrm{CO}_{2}$ recovery. The transmission distance is the key factor affecting total $\mathrm{CO}_{2}$ control costs. The LEC with $\mathrm{CO}_{2}$ recovery and disposal increased by one third to more than a factor of two, depending on the transmission distance, which 
ranged from about 25 to nearly $2000 \mathrm{mi}$. While $\mathrm{CO}_{2}$ recovery and disposal would likely be too expensive to implement on a national basis, regional or sitespecific applications may be competitive with other $\mathrm{CO}_{2}$ control strategies.

The significant impact of transmission on the cost-effectiveness of $\mathrm{CO}_{2}$ recovery and disposal suggests that the following topics are worthy of further examination:

1. The impact of locational and seasonal variation in ambient temperature on $\mathrm{CO}_{2}$ properties, hence pipeline design.

2. $\mathrm{CO}_{2}$ distribution equipment within oil and gas reservoirs.

3. Integrated pipelines from multiple GCC units or power plants.

4. Specific design requirements for $\mathrm{CO}_{2}$ pipelines.

5. Impact of elevation drop on recompression requirements in overland pipelines.

Carbon dioxide control costs for the GCC power plant should be compared with other control options, such as increased efficiency of energy supply and end-use equipment, reforestation, and carbon taxes. $\mathrm{CO}_{2}$ control costs for other fossil fuels and combustion technologies should also be evaluated to complete the development of a $\mathrm{CO}_{2}$ control "supply curve" for U.S. electric utilities. 


\section{CONTENTS}

SUMMARY . . . . . . . . . . . . . . . . . . . . . . . i i

1.0 INTRODUCTION . . . . . . . . . . . . . . . . . . . . . 1.1

2.0 RECOVERY . . . . . . . . . . . . . . . . . . . . . 2.1

2.1 REFERENCE PLANT SELECTION . . . . . . . . . . . . 2.1

2.2 REFERENCE PLANT DESCRIPTION . . . . . . . . . . . . . 2.2

3.0 DISPOSAL . . . . . . . . . . . . . . . . . . . . 3.1

3.1 OCEAN DISPOSAL . . . . . . . . . . . . . . . . . 3.1

3.2 DEPLETED OIL AND GAS RESERVOIR DISPOSAL . . . . . . . . . 3.3

3.2.1 Historical Approaches to Estimating $\mathrm{CO}_{2}$ Disposal
Capacity ............................ 3.5

3.2.2 Current Approach to Estimating $\mathrm{CO}_{2}$ Disposal
Capacity ......................... 3.7

3.3 AQUIFER DISPOSAL . . . . . . . . . . . . . . 3.9

4.0 TRANSMISSION . . . . . . . . . . . . . . . . . . . 4.1

4.1 TRANSMISSION DISTANCE . . . . . . . . . . . . . 4.1

4.2 PIPELINE DESIGN AND COST . . . . . . . . . . . . . 4.7

5.0 SYSTEM RESULTS . . . . . . . . . . . . . . . . . . 5.1

5.1 LEC AND LCCC CALCULATION . . . . . . . . . . . . 5.2

5.2 LEC AND LCCC RESULTS . . . . . . . . . . . . . . 5.3

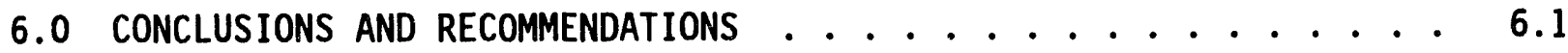

APPENDIX A - CALCULATIONS OF $\mathrm{CO}_{2}$ STORAGE CAPACITY . . . . . . . . . A. 1

APPENDIX B - PIPELINE DESIGN DETAILS . . . . . . . . . . . . . . . B. 1

REFERENCES . . . . . . . . . . . . . . . . . . . . R.1 


\section{FIGURES}

$3.1500 \mathrm{~m}$ and $3000 \mathrm{~m}$ 0cean Depth Contcurs . . . . . . . . . . . 3.4

3.2 Comparison of Total Petroleum Resources and Proved Reserves . . . 3.6

3.3 Idealized Volume Relations of Petroleum Fluid at Reservoir and Surface Conditions . . . . . . . . . . . . . . 3.8

3.4 California Petroleum Production Regions . . . . . . . . . . 3.12

3.5 Louisiana Petroleum Production Regions . . . . . . . . . . . 3.12

3.6 New Mexico Petroleum Production Regions . . . . . . . . . . 3.13

3.7 Texas Petroleum Production Regions . . . . . . . . . . . 3.13

3.8 Major U.S. Aquifers .................... 3.14

4.1 GCC Units with $\mathrm{CO}_{2}$ Recovery ................. 4.3

4.2 Transmission Distance Summary . . . . . . . . . . . . 4.6

5.1 LEC Summary, Cumulative Units . . . . . . . . . . . 5.5

5.2 LCCC Summary, Cumulative Units . . . . . . . . . . . . 5.5

5.3 LEC Summary, Cumulative Emission Reductions . . . . . . . . 5.6

5.4 LCCC Summary, Cumulative Emission Reductions . . . . . . . . 5.6 
TABLES

2.1 GCC Power Plant Characteristics . . . . . . . . . . . 2.3

2.2 Startup and Working Capital . . . . . . . . . . . . 2.3

3.1 Cumulative $\mathrm{CO}_{2}$ Storage Capacity Resulting from Petroleum

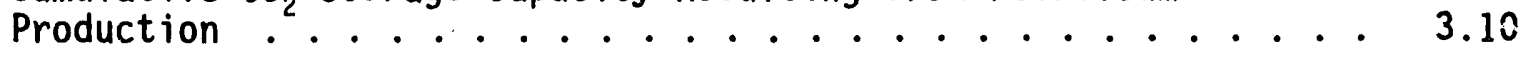

4.1 Transmission Distance Summary . . . . . . . . . . . 4.6

4.2 Overland Pipeline Temperature and Pressure Profile . . . . . 4.8

4.3 Pipeland Size and Cost Assumptions . . . . . . . . . . 4.11

5.1 Financial Assumptions . . . . . . . . . . . . . . 5.1

5.2 LEC Summary . . . . . . . . . . . . . . . . . . 5.4

5.3 LCCC Summary . . . . . . . . . . . . . . . 5.4

vii 


\subsection{INTRODUCTION}

The concentration of $\mathrm{CO}_{2}$ in the atmosphere has been rising steadily for several decades. Predictions of global warming and related deleterious effects give cause for considering potential responses. Electric utilities account for approximately one third of U.S $\mathrm{CO}_{2}$ emissions via the combustion of coal, oil, and natural gas. One option for reducing atmospheric $\mathrm{CO}_{2}$ emissions is to capture $\mathrm{CO}_{2}$ at power $\mathrm{plants}$ and transport it for disposal in an alternative "sink."

Carbon dioxide control (capture and disposal) costs would vary significantly depending on the fuel, conversion technology, and location of the electric power plant. Coal, oil, and gas produce different amounts and concentrations of $\mathrm{CO}_{2}$ per Btu of energy released during combustion. For a given fuel, such as coal, the best control technology for a pulverized coal plant would differ from that for a gasification type plant. Carbon dioxide transportation costs are extremely site-specific, depending on the proximity to a disposal location.

The objective of this study, conducted for the U.S. Department of Energy (DOE) by the Pacific Northwest Laboratory's (PNL) Global Studies Program, (a) was to initiate the development of a $\mathrm{CO}_{2}$ control "supply curve" relating the amount of $\mathrm{CO}_{2}$ controlled as a function of the cost of control in the electric utility sector. This information could be used (along with similar characterizations of other options) in general planning studies evaluating alternative responses to the potential global warming problem.

The scope of this study was limited to coal-fired power plants employing gasification, combined-cycle technology. Other fuels and conversion technologies were not evaluated. Deep ocean water, depleted $0 i 1$ and gas reservoirs, and/or aquifers were considered as potential disposal locations. Emphasis was placed on determining the cost impact of varying the coal-fired power plant

(a) Pacific Northwest Laboratory is operated for the U.S. Department of Energy by Battelle Memorial Institute under Contract DE-AC06-76RLO 1830. 
location and disposal concept. Technical feasibility, environmental acceptability, and other implementation issues were not addressed in detail.

The following three sections on recovery, disposal, and transmission define the analytical procedure and resultant characterization of the major $\mathrm{CO}_{2}$ control system elements. The final two sections in the main body of the report summarize the system results, conclusions, and recommendations. Supporting detail describing the calculation of $\mathrm{CO}_{2}$ storage capacity in depleted $0 i 1$ and gas reservoirs is presented in Appendix A. Appendix B describes design details of the $\mathrm{CO}_{2}$ pipeline. 


\subsection{RECOVERY}

As indicated in the Introduction, $\mathrm{CO}_{2}$ recovery was based on coal-fired power plants employing gasification, combined-cycle technology. Coal-fired power plants were chosen for evaluation because coal produces more $\mathrm{CO}_{2}$ per Btu of energy released during combustion and is the predominant fossil fuel consumed by U.S. utilities. Currently, practically all large-scale coal-fired power plants use pulverized coal (PC) combustion technology. However, more advanced coal combustion technologies such as fluidized bed (atmospheric or pressurized) or gasification, combined-cycie (GCC) (integrated or nonintegrated) that are less polluting and more efficient are more likely to be employed in the future. In addition, several previous studies (e.g., Smelser and Boeras 1990) have indicated that $\mathrm{CO}_{2}$ capture from PC plants would be more costly, particularly in a retrofit situation, than $\mathrm{CO}_{2}$ capture from $\mathrm{GCC}$ plants.

\subsection{REFERENCE PLANT SELECTION}

Three reports describing evaluations of $\mathrm{CO}_{2}$ recovery from GCC plants were reviewed to define the specific design and cost characteristics (Smelser and Booras 1990; Shell Internationale 1990; Hendriks, Blok and Turkenburg 1990). In each of these evaluations, carbon monoxide in the fuel gas is converted to carbon dioxide via the water/gas shift reaction. Carbon dioxide is subsequently scrubbed from the fuel gas prior to combustion of the hydrogen in the gas turbine. Each of the three studies is briefly described below.

Smelser and Booras evaluated a 400-MWe GCC plant that used Texaco's total quench gasification technology. The water/gas shift reaction was accomplished in two stages. Ninety percent of the $\mathrm{CO}_{2}$ was recovered by washing the syngas at pressure with Selexol after first using the same solvent to preferentially remove hydrogen sulfide. The $\mathrm{CO}_{2}$ was compressed and dried for transport in a pipeline presumed to be $400 \mathrm{mi}$ long. Current technology was employed.

The analysis by Hendriks, Blok and Turkenburg evaluated a 600-MWe integrated GCC plant that was based on Shell's gasification technology. Fuel 
gases were partially cooled by generating steam rather than quenching. The water/gas shift reaction was conducted after sulfur removal to protect the catalyst in the shift reactors from becoming poisoned. Selexol was used to recover $88 \%$ of the $\mathrm{CO}_{2}$, which was compressed and dried for pipeline transport. The hydrogen sulfide solvent was not specified. Design and performance assumptions were based on capabilities expected to be available by the year 2000.

As might be expected, Shell employed its own gasification technology in its evaluation of a 750-MWe IGCC plant. Sulfur removal and $\mathrm{CO}_{2}$ separation followed the water/gas shift reaction similar to the Smelser and Booras study, but SUIFerox and DEMEA (two licensable Shell processes) were used for hydrogen sulfide removal and $\mathrm{CO}_{2}$ separation, respectively. Higher conversion in the water/gas shift reactions allowed recovery of $94 \%$ of the $\mathrm{CO}_{2}$, which was compressed and dried for pipeline transport. Currently available technology was emplicyed.

The evaluation described by Smelser and Booras was selected as the reference for defining GCC plant cost and performance characteristics. The results presented in Smelser and Booras were consistent with the Shell study while results from Hendriks, Blok, and Turkenburg were considerably more optimistic. Factors favoring selection of the Smelser and Booras data were greater cost and performance detail, U.S. design conditions, and a moderate plant size.

\subsection{REFERENCE PLANT DESCRIPTION}

Smelser and Booras presented design, cost, and performance data for GCC plants with and without $\mathrm{CO}_{2}$ recovery. The $\mathrm{CO}_{2}$ was initially pressurized to 2200 psia for transmission through a 400-mi pipeline. The pipeline was eliminated and the initial pressurization was reduced in order to create a common plant design independent of the actual transmission distance.

A minimum pipeline pressure of 1200 psia was selected based on advice presented in Decker (1986), which described an actual $\mathrm{CO}_{2}$ pipeline running from Colorado to Texas. The critical pressure for $\mathrm{CO}_{2}$ is about 1070 psia. Therefore, operation at 1200 psia or above eliminates two-phase flow. The 
amount of additional pressurization required beyond 1200 psia depends on the pipeline length and pressure drop per unit of length. Pipeline pressure losses and incremental pressurization requirements are discussed in more detail in Section 4 and Appendi $\because B$.

Besides eliminating the costs associated with the pipeline, the reduction of initial $\mathrm{CO}_{2}$ pressure reduced the size, cost, and power consumption of the compression equipment. The resultant plant characteristics for a GCC plant, with and without $\mathrm{CO}_{2}$ recovery, are shown in Table 2.1. The "total plant cost" shown in Table 2.1 represents construction costs. Startup and working capital costs were estimated for each plant based on the relationships shown in Table 2.2. All cost data were adjusted to mid-1990 dollars.

Many different technologies have been considered for coupling $\mathrm{CO}_{2}$ recovery with coal-fired power plants (Blok et al. 1992). While several of these

IABLE 2.1. GCC Power Plant Characteristics

Characteristic

Gross Power Output, kWe

Net Power Output, kWe

Total Plant Cost $\$ 1000^{(a)}$

Annual 0\&M Costs $(a)$

Labor, $\$ 1000$

Fixed Materials, $\$ 1000$

Consumables, mi11s/kWh

Heat Rate, Btu/kWh

Annual Power Production 0

65\% Capacity Factor, MWh
Reference GCC Plant

501,656

431,647

705,911

20,092

12,707

0.432

9,639

$2,457,798$
GCC Plant with $90 \% \mathrm{CO}_{2}$ Recovery (b)

496,600

381,500

832,902

23,681

18,081

0.826

11,894

$2,172,261$

(a) All costs are in mid-1990 dollars.

(b) Does not include $\mathrm{CO}_{2}$ transmission and disposal.

IABLE 2.2. Startup and Working Capital

$\begin{aligned} \text { Startup }= & 0.02 * \text { Total Plant Cost }+ \\ & 1 / 12 * \text { Total Annual 08M Cost }+ \\ & 1 / 52 * \text { Total Annual Fuel Cost }\end{aligned}$

Working Capital $=0.005 *$ Total P1ant Cost + $1 / 6$ * Total Annual 08M Cost + $1 / 6$ * Total Annual Fuel cost 
technologies may eventually prove to be better, the gasification plant and $\mathrm{CO}_{2}$ recovery described above is a reasonable option using proven technology that could be constructed today. 


\subsection{DISPOSAL}

Three possible disposal options were considered in this study: deep ocean water, depleted oil and gas reservoirs, and aquifers. The first two options have been given the most attention by researchers considering $\mathrm{CO}_{2}$ recovery and disposal. By comparison, the possibility of disposing $\mathrm{CO}_{2}$ in aquifers has been less vigorously investigated. The following three subsections present discussions of each of these options.

\subsection{OCEAN DISPOSAL}

Deep ocean water has several characteristics that make it a potentially attractive alternative to atmospheric release of $\mathrm{CO}_{2}$. The deep ocean has a tremendous $\mathrm{CO}_{2}$ storage capacity compared with global $\mathrm{CO}_{2}$ emission rates. The ocean is a relatively homogeneous medium, which reduces the site-specific technical uncertainty, particularly when compared with terrestrial disposal options such as depleted $0 \mathrm{il}$ and gas reservoirs and aquifers. Ultimately, $\mathrm{CO}_{2}$ released to the atmosphere will dissolve in the ocean. Deep ocean injection of $\mathrm{CO}_{2}$ serves to speed the long-run (hundreds of years) equilibrating processes. Nevertheless, there are legitimate concerns about the potential negative impact on the local aquatic environment near disposal points. Differences of opinion also exist with regard to the $\mathrm{CO}_{2}$ retention period.

Several different ocean disposal concepts have been proposed. These include 1) dissolution of liquid $\mathrm{CO}_{2}$ into moderately deep water; 2) injection of $\mathrm{CO}_{2}$-rich sea water into moderately deep water; 3 ) sinking of liquid $\mathrm{CO}_{2}$ into very deep water; 4 ) injection of $\mathrm{CO}_{2}$ into naturally sinking currents; 5) surface injection of solid $\mathrm{CO}_{2}$; and 6 ) surface injection of solid $\mathrm{CO}_{2}$ hydrate. Each of these concepts is described below.

In the first concept, liquid $\mathrm{CO}_{2}$ is injected into the ocean at a depth of approximately $500 \mathrm{~m}$ and dissolves in the surrounding water. The $\mathrm{CO}_{2}$ is injected via a pipeline extending from the nearest shore or from a platform on the ocean's surface. The required injection depth is subject to some debate. Essentially all sources agree that the upper layer of the ocean in relatively intimate contact with the atmosphere is about $100 \mathrm{~m}$ deep. This upper layer is 
well-mixed and subsequently maintains a fairly uniform temperature. In the next few hundred meters, water temperature drops very quickly. Below the thermocline, which varies in depth depending on location, the ocean water is uniformly a few degrees above the freezing point. At a depth of $500 \mathrm{~m}, \mathrm{CO}_{2}$ is less dense than the surrounding ocean water and will bubble up towards the surface before it dissolves. At issue is the depth at which the $\mathrm{CO}_{2}$ would dissolve and the amount of interaction water at this depth actually has with the well-mixed upper $100 \mathrm{~m}$.

In the second concept, $\mathrm{CO}_{2}$ is first dissoived in a stream of sea water near the ocean shore. The $\mathrm{CO}_{2}$-rich stream is then injected via pipeline to a depth of approximately $500 \mathrm{~m}$. This approach eliminates $\mathrm{CO}_{2}$ bubbling concerns at the injection point, but requires a much larger pipe or multiple pipes to handle the significant increase in fluid volume.

The third concept is similar to the first, except the $\mathrm{CO}_{2}$ is injected at a greater depth. At a depth of $3000 \mathrm{~m}$, liquid $\mathrm{CO}_{2}$ has a density greater than sea water and will sink to the ocean floor where it will slowly dissolve over time. Presumably, this disposal approach results in a considerably longer retention period than injection at $500 \mathrm{~m}$. Of course, a longer, more costly pipeline would be required.

In the fourth concept, $\mathrm{CO}_{2}$ is injected directly into a near-surface sinking current that transports the $\mathrm{CO}_{2}$ into the deep ocean. Several locations in the world have naturally sinking currents that originate relatively close to shore and are relatively shallow. One example of this is the thermohaline current that exits to the Atlantic from the Mediterranean Sea. Surface evaporation of Mediterranean waters exceeds the inflow of water from rivers, causing the Sea to be saltier than the ocean. This creates two different currents crossing the entrance to the Mediterranean at the Straits of Gibraltar. Near the floor of the sea, the denser salt water flows out to the Atlantic and sinks below the lighter ocean water. At the surface, a larger current flows into the Mediterranean, making up for the net water lost via evaporation and the subsurface outflow. This concept, while interesting, has obvious geographic limitations. No similar currents exist close to the shore in the United States. 
The fifth and sixth ocean disposal concepts are based on solidified $\mathrm{CO}_{2}$ that can be transported via refrigerated ocean freighter and dropped directly in the ocean. Both solid $\mathrm{CO}_{2}$ and solid $\mathrm{CO}_{2}$ hydrate $\left(\mathrm{CO}_{2} \cdot 6 \mathrm{H}_{2} \mathrm{O}\right)$ are denser than sea water and sink when dropped onto the ocean surface. Initially, some $\mathrm{CO}_{2}$ is released as the cube sinks, but sublimation ceases at a pressure corresponding to a depth of about $500 \mathrm{~m}$. Below $500 \mathrm{~m}$, the cube continues to meli on its way to the ocean floor. Because it is denser than $\mathrm{CO}_{2}$ hydrate, solid $\mathrm{CO}_{2}$ sinks more quickly and should lose less $\mathrm{CO}_{2}$ to sublimation. The principal drawback of solid $\mathrm{CO}_{2}$ disposal is the energy required for solidification, which is several times that required for liquefaction.

The ocean disposal concepts selecied for evaluation in this study were injection of liquid $\mathrm{CO}_{2}$ at either $500-\mathrm{m}$ or $3000-\mathrm{m}$ depth. The other concepts are either significantly more expensive (concepts 2, 5, and 6) or have 1 imited geographic applicability (concept 4). Examination of the two depths should help identify the economic importance of resolving the injection depth issue. Bathymetric maps prepared by the National Oceanic and Atmospheric Administration were used to locate $500-\mathrm{m}$ and $3000-\mathrm{m}$ deep water off the U.S. coastlines (see Figure 3.1). Ocean disposal capacity was assumed to be a non-issue, i.e., the deep ocean water was assumed to have adequate capacity to absorb all the $\mathrm{CO}_{2}$ recovered from the GCC power plants. For further discussion of ocean disposal issues and prospects, the reader is referred to several papers presented in Blok et al. (1992).

\subsection{DEPLETED OIL AND GAS RESERVOIR DISPOSAL}

In general, petroleum (natural gas and crude oil) is found in sedimentary (e.g., sandstone and 1 imestone) rock formations at depths as shallow as $40 \mathrm{ft}$ and as deep as 21,000 ft. Petroleum is not found in a11 geographical regions, but rather in localized accumulations under certain geologic conditions (Amyx, Bass and Whiting 1960). The concept of $\mathrm{CO}_{2}$ disposal in abandoned 


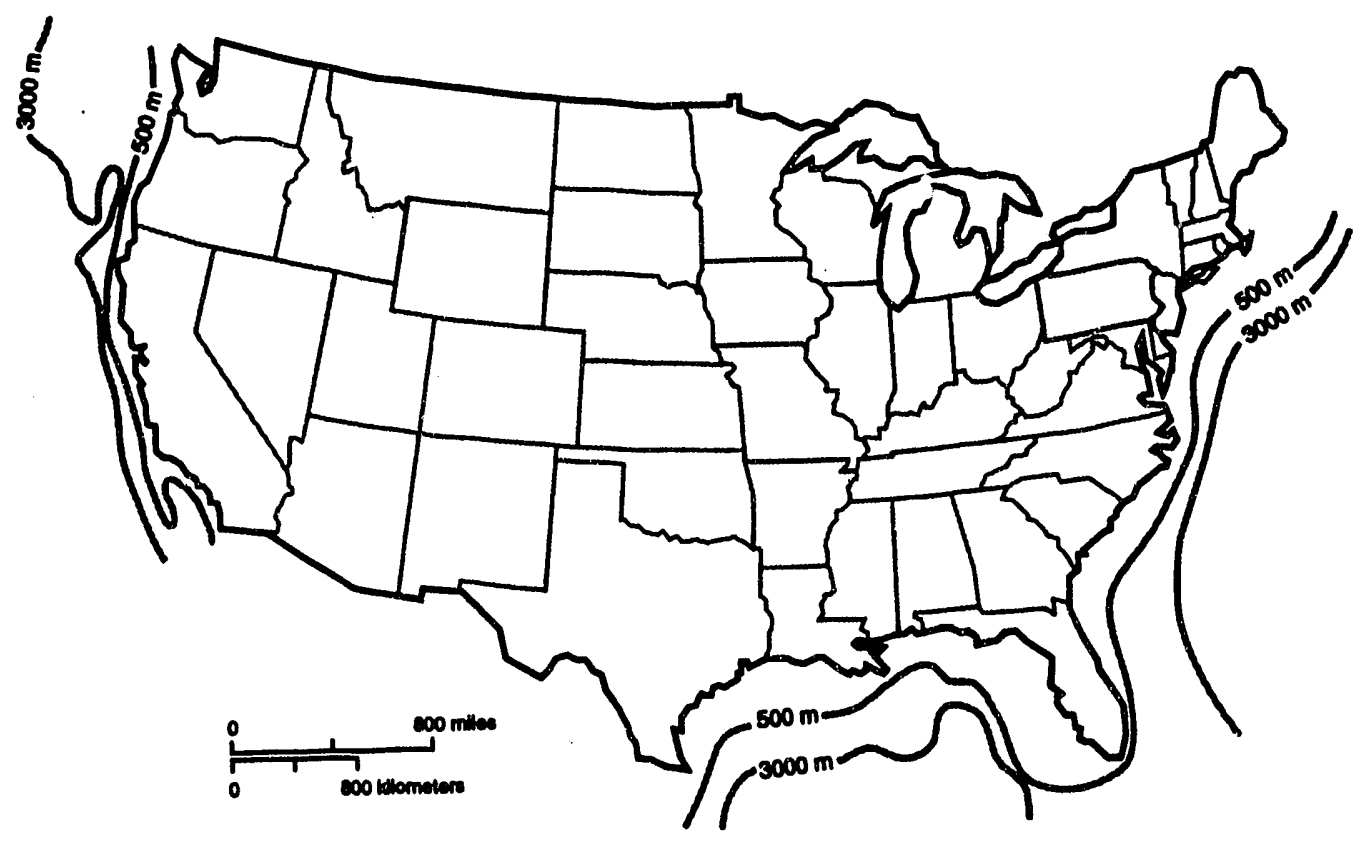

FIGURE 3.1. $500 \mathrm{~m}$ and $3000 \mathrm{~m}$ Ocean Depth Contours

reservoirs is that once petroleum has been evacuated from the reservoir (a) rock, the void space can be filled with compressed $\mathrm{CO}_{2}$.

In addition to the basic presence of a reservoir, factors that must be considered in order to determine the technical and economic feasibility of $\mathrm{CO}_{2}$ disposal in an abandoned reservoir include the following:

- the ability of the reservoir to accommodate an acceptable quantity of $\mathrm{CO}_{2}$

- the presence of an impermeable cap rock to prevent upward migration of $\mathrm{CO}_{2}$, leakage, and pressure loss

- sufficient reservoir depth to allow for a safe pressure

- the ability (legally and economically) of the disposal system operator to obtain a lease for the entire reservoir

(a) A reservoir is defined as a porous and permeable underground formation containing a natural accumulation of hydrocarbon ( $0 i 1$ and/or gas) which is confined by impermeable rock or water barriers and is characterized by a single natural pressure system. 
- the physical tightness of the reservoir (i.e., lateral sealing by formations with a minimal number of unusable abandoned wells [which promote leakage])

- the extent of reconditioning required because of water encroachment, corrosion of tubing, or deposition of mud on the well bore

- the number and size of injection wells required for an acceptable disposal rate

- proximity to major $\mathrm{CO}_{2}$ transmission lines and the auxiliary equipment required.

This analysis estimates the total volume of abandoned petroleum reservoirs, including offshore reservoirs, available for $\mathrm{CO}_{2}$ disposal through the year 2030 for the lower 48 states. It is assumed that any reservoir capable of producing petroleum could ultimately be capable of storing compressed $\mathrm{CO}_{2}$. The result of this analysis is an estimated theoretical $\mathrm{CO}_{2}$ storage capacity. For the technical and economic considerations listed above, this theoretical capacity represents an upper bound of available capacity and subsequently should be reduced to incorporate the impact of each of the considerations.

\subsubsection{Historical Approaches to Estimating $\mathrm{CO}_{2}$ Disposal Capacity}

Several studies have previously estimated the available $\mathrm{CO}_{2}$ storage capacity (Hamilton 1989; Horn and Steinberg 1982; Steinberg, Lee and Morris 1991) in abandoned petroleum reservoirs. These studies used two basic approaches to approximate storage capacity. The two approaches have the advantage of being relatively quick and straightforward; however, they do not fully incorporate some critical factors that affect storage capacity. Each approach is outlined below.

The first historical approach has been to assume that reservoirs are depleted at a rate close to the rate of U.S. consumption and that the depleted reservoir volume is available for $\mathrm{CO}_{2}$ storage. This approach has two very important limitations which result in an imprecise estimation of storage capacity: 1) U.S. consumption is not a very good proxy for U.S. reservoir depletion because imports and petroleum storage systems supply a large segment of U.S. consumption, and 2) because of compressibility, the relationship between the volume of petroleum extracted from a reservoir and the volume of 
$\mathrm{CO}_{2}$ that can be injected for disposal is complex and cannot be accurately estimated without reservoir temperature and pressure data, which this approach does not fully incorporate.

The second historical approach has been to assume that the available volume for $\mathrm{CO}_{2}$ disposal is represented by the total volume (at reservoir conditions) of proved U.S. petroleum reserves. As applied by organizations that report reserve volume, the term "proved reserves" means "the volume of petroleum that can with reasonable certainty be recovered in future years from known reservoirs under existing economic and operating conditions." Figure 3.2 illustrates the difference between "proved reserves" and the available petroleum resources that underlie the lower 48 states.

The use of proved reserves to estimate total $\mathrm{CO}_{2}$ disposal capacity results in a significant limitation. U.S. reserves have historically and will continue to increase significantly as technology improves and the economic climate changes. Given the current rate of 10 wer 48 production, current reserves will be expended in ten years; however, in the meantime, many more reserves will be identified and will allow the lower 48 states to produce well

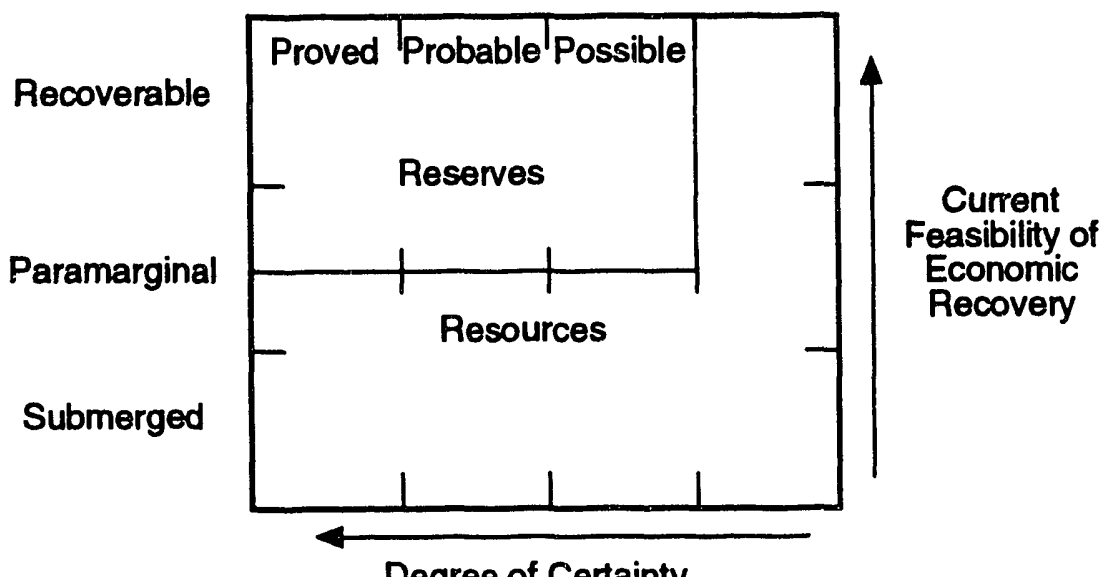

Degree of Certainty

S9209068.12

FIGURE 3.2. Comparison of Total Petroleum Resources and Proved Reserves (after Ikoku 1984) 
beyond the year 2030 (DOE 1991). Consequently, the approach of assuming future available volume is equivalent to current reserves underestimates the potential volume several times.

Similar to the first historical approach, the second historical approach makes some significant assumptions regarding the relationship of petroleum volume at standard surface temperature and pressure and the resulting reservoir void volume at reservoir temperature and pressure. The non-proportional relationship between petroleum and $\mathrm{CO}_{2}$ compressibility results in complex relationships between surface volume and reservoir volume. For example, for the pressure and temperature ranges examined in this analysis, if $1 \mathrm{cu} f t$ of gas is produced, the amount of $\mathrm{CO}_{2}$ that can be stored in the corresponding reservoir void varies from 1 to $3 \mathrm{cu} f \mathrm{ft}$.

\subsubsection{Current Approach to Estimating $\mathrm{CO}_{2}$ Disposal Capacity}

Some of the limitations of the above two historical approaches are addressed in an approach that incorporates the procedures described below.

- Petroleum reservoir volume that has been or will be produced by the year 2030 was assumed to become available for $\mathrm{CO}_{2}$ disposal. The production basis was derived from DOE production statistics (Energy Information Administration [EIA] 1990) and the National Energy Strategy's (NES) base case for crude oil and natural gas production through the year 2030 (DOE 1991).

- A reservoir capacity profile for $\mathrm{CO}_{2}$ disposal by depth and geographical region was developed. Separate profiles were developed for capacity generated by gas production and by oil production. Subsequently, average temperature and pressure gradients were used to add reservoir temperature and pressure attributes to the capacity profiles.

- The differing compressibilities of gas and $\mathrm{CO}_{2}$ were factored into the ultimate $\mathrm{CO}_{2}$ storage capacity estimate.

To segment the analysis, $\mathrm{CO}_{2}$ storage capacity generated by $0 \mathrm{il}$ and gas production are discussed separately. In reality, the vast majority of oil and 
gas fields ${ }^{(a)}$ produce both products. For example, of the 45,120 petroleum fields identified in the United States (EIA 1991b), 33,495 fields (74\%) produce significant quantities of $0 i 1$ and $30,161(67 \%)$ produce significant quantities of gas.

The approach used to segment the analysis is based on the concept that a reservoir has a volume $\left(V_{R}\right)$ of hydrocarbon at reservoir temperature $\left(T_{R}\right)$ and reservoir pressure $\left(P_{R}\right)$. As the hydrocarbon is produced, ${ }^{(b)}$ its temperature and pressure decrease. A significant amount of gas is released, resulting in a volume of gas $\left(V_{\text {gsc }}\right)$ and volume of oil $\left(V_{\text {osc }}\right)$ at standard surface conditions (i.e., $60^{\circ} \mathrm{F}, 14.73 \mathrm{psia}$ ). Figure 3.3 illustrates this concept.

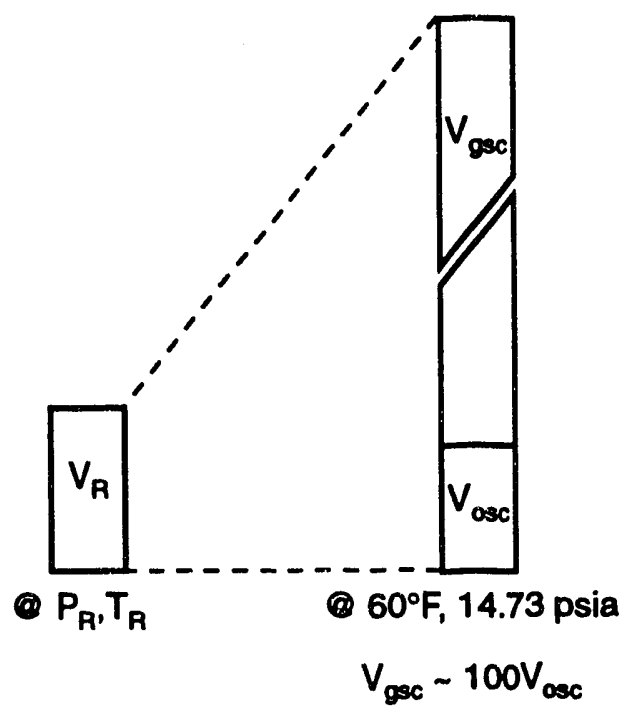

59209068.13

FIGURE 3.3. Idealized Volume Relations of Petroleum Fluid at Reservoir and Surface Conditions (adapted from Amyx, Bass and Whiting 1960)

(a) An area consisting of a single reservoir or multiple reservoirs all grouped on or related to the same individual geological structural feature and/or stratigraphic condition. A field may have two or more reservoirs which are separated vertically by intervening impervious strata, laterally by local geologic barriers, or both.

(b) Produced refers to the process of allowing a hydrocarbon to escape from its resident formation into a wellbore at which point, through natural or human applied forces, it travels to the surface, passing through the wellhead into surface equipment (i.e., separators, heaters, filters, stock tanks, etc.). 
Regional oil and gas production figures reported by organizations such as the DOE are based on the produced volume of $0 i 1$ and gas at standard conditions. As noted above, without knowing the reservoir-by-reservoir production volumes and the reservoir temperature and pressure data, it is not possible to estimate the total volume of a specific reservoir. However, by defining a representative regional capacity profile by depth and assuming that average temperature and pressure gradients apply, the total volume of oil or gas produced at surface conditions can be used to estimate the corresponding reservoir void volume created during the production process, ${ }^{(a)}$ adjusting as appropriate for compressibility. The specific details describing the implementation of this approach are presented in Appendix $A$. The cumulative $\mathrm{CO}_{2}$ storage capacity resulting from all petroleum production is shown in Table 3.1 for each petroleum production Region. Substate regions are identified in Figures 3.4 through 3.7 .

\subsection{AQUIFER DISPOSAL}

Because of the prevalence of aquifers in the United States, disposal of $\mathrm{CO}_{2}$ in aquifers would significantly reduce the transmission-related costs associated with $\mathrm{CO}_{2}$ recovery and disposal. Roughly two thirds of the country is underlain by aquifers (Reilly, Brown and Huber 1981). The locations of major aquifers are shown in Figure 3.8 .

An aquifer suitable for $\mathrm{CO}_{2}$ disposal would have high porosity and adequate thickness to provide good storage capacity, adequate depth to allow $\mathrm{CO}_{2}$ disposal as a supercritical fluid, high hydraulic conductivity to allow a high injection rate, homogeneous hydraulic conductivity to obtain a high sweep efficiency or high aquifer utilization, and a very low-permeability confining layer without fractures to ensure long-term isolation. Key issues affecting $\mathrm{CO}_{2}$ disposal in aquifers are discussed below.

(a) The term "reservoir void volume" would imply that the reservoir contains empty pore space that is available for $\mathrm{CO}_{2}$ storage. In fact, residual gas, oil and water expand into the voided area. The $\mathrm{CO}_{2}$ injected is assumed to drive back the gas, oil and water that expanded. 


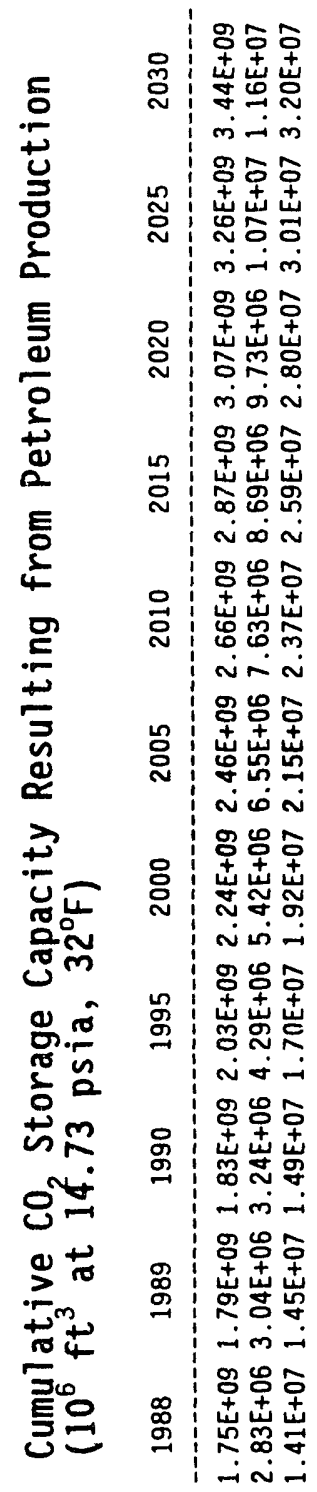

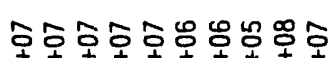

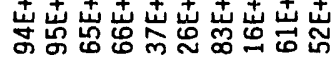

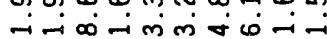

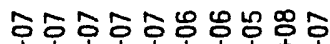

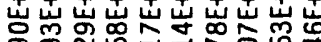
-

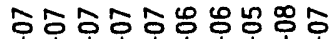

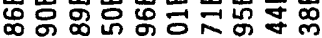
-iñत的的-i

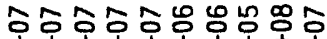
山出山出出出出

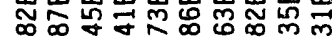

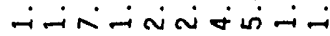

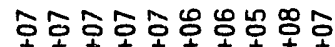
岃山岀岀岃嵌嵌

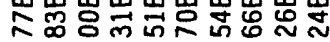

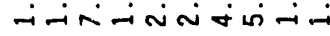

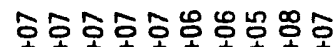

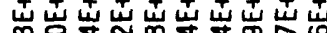
गू TNN

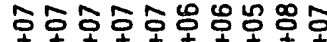

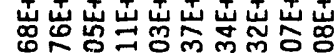
- -i心-iñu-

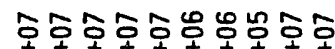

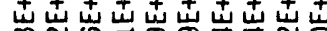

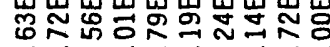
- -

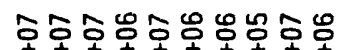

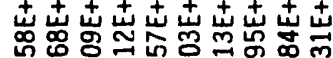

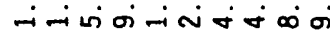

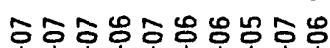

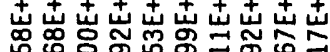

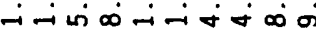

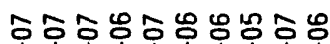

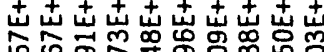
- -

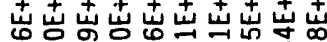

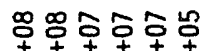

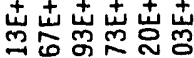
-inin-io

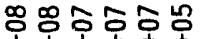
㟧岃岕岕出 -i们-i

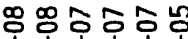
嵌岃吉出岕 年 - inm-in

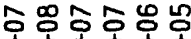
岁出岕㟧岁出

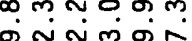

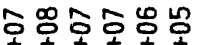
岃岕㟧岁 政品。

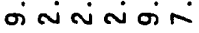
홍ㅇㅇ옹ㅇㅇㄴㅇㅇ 岕志志志志 폿 论 oñति

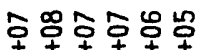

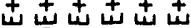

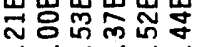

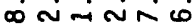

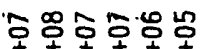

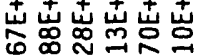
- 옹송ㅇㅇ용 -

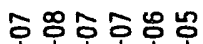
岁岕岁岕岕㟧 -in- in 둥ㅇㅇㅇㅇㅇㅇㅇㅇㅇㅇㅇ 岩岩䓌岕志志

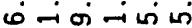

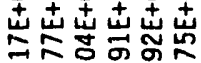

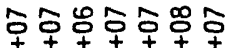
岃岕出岁志志志

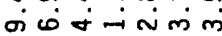
응ㅇㅇㅇㅇㅇㅇㅇㅇㅇㅇㅇ 岩岩岁至岕㟧专 ㅇํㅇㅇㅇㅇㅇㅇㅇㅇㅇㅇㅇㅇ

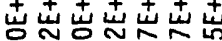

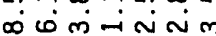

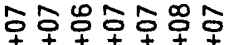
㟧嵌嵌嵌嵌

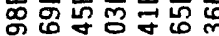

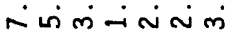
둥ㅇㅇㅇㅇㅇㅇㅇㅇㅇ 岃岕岕出嵌 रालिकर्यां 훙ㅇㅇㅇㅇㅇㅇㅇㅇㅇㅇㅇㅇ 岕岕壱岕岁㟔出

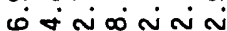

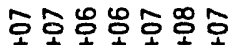
岃出出出出出

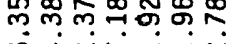
ocono

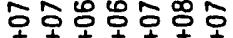

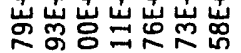
in 훙ㅇㅇㅇㅇㅇㅇㅇㅇㅇㅇ 岕岕岕岁岩岕岁 ज的证位

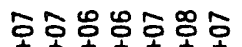

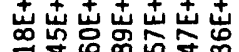

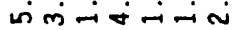
둥ㅇㅇㅇㅇㅇㅇㅇㅇㅇㅇ

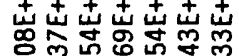
जim-if-ín

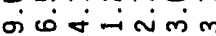

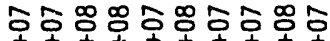

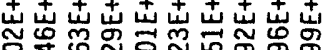

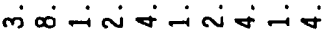

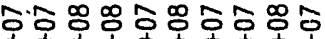

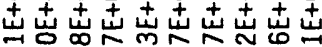

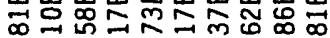

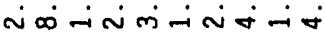

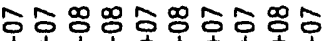

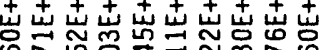

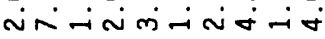

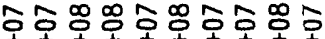

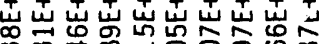
in-im-in-j 송ㅇㅇㅇㅇㅇㅇㅇㅇㅇㅇㅇㅇㅇㅇㅇㅇㅇ

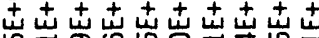

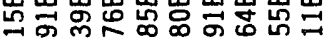

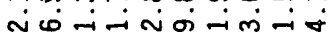

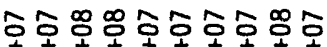

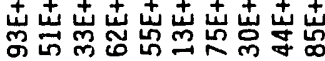
-i山-

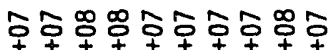

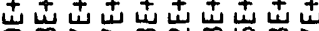

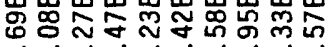
-i山-ino-iñm

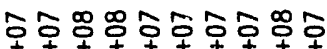

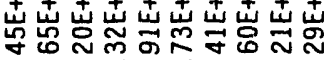

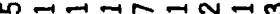

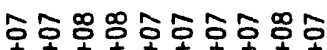

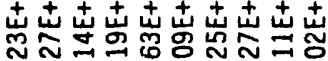
in--irintim

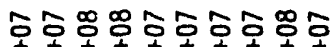

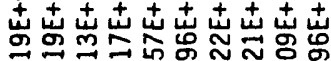
-

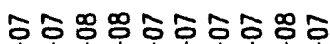

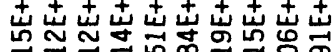
- in-

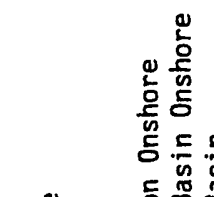

-

苋亮 尊采 


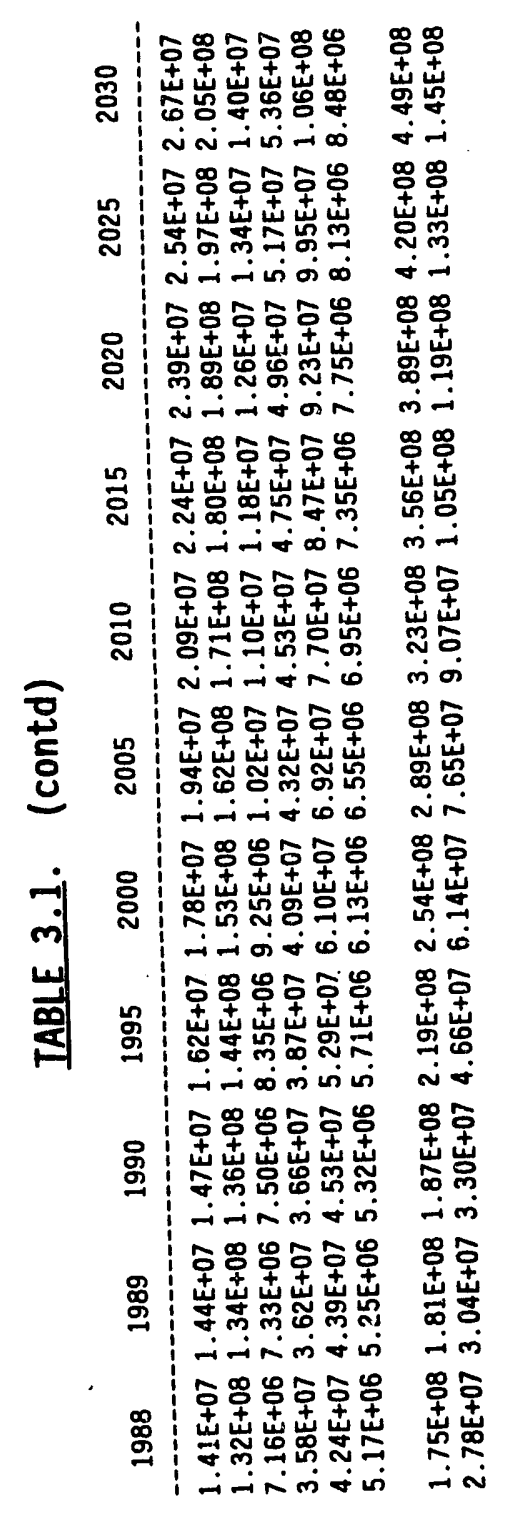

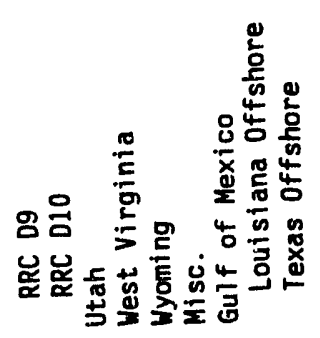




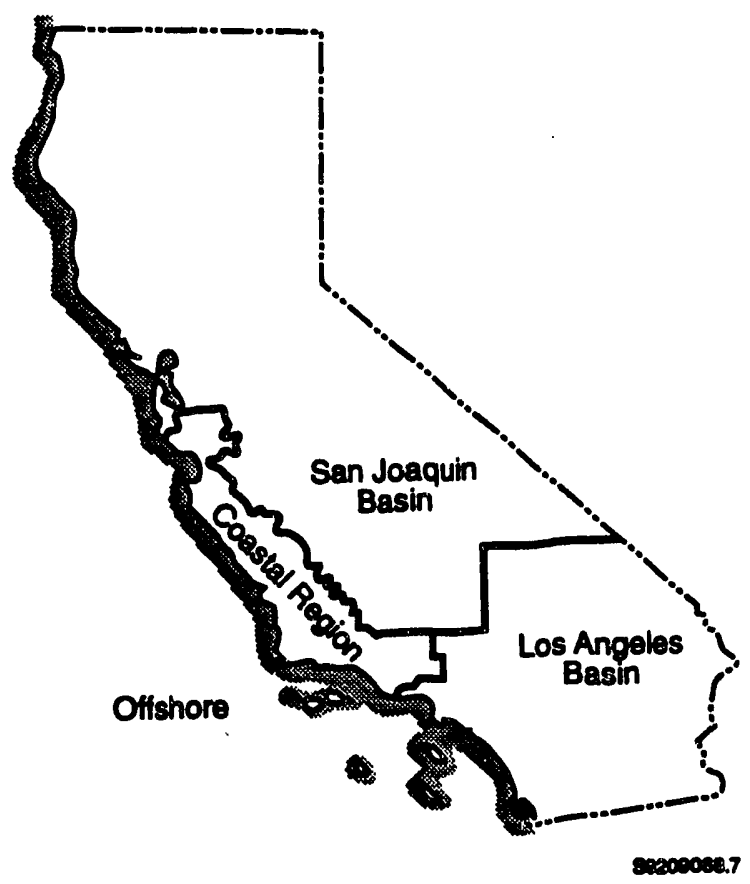

FIGURE 3.4. California Petroleum Production Regions

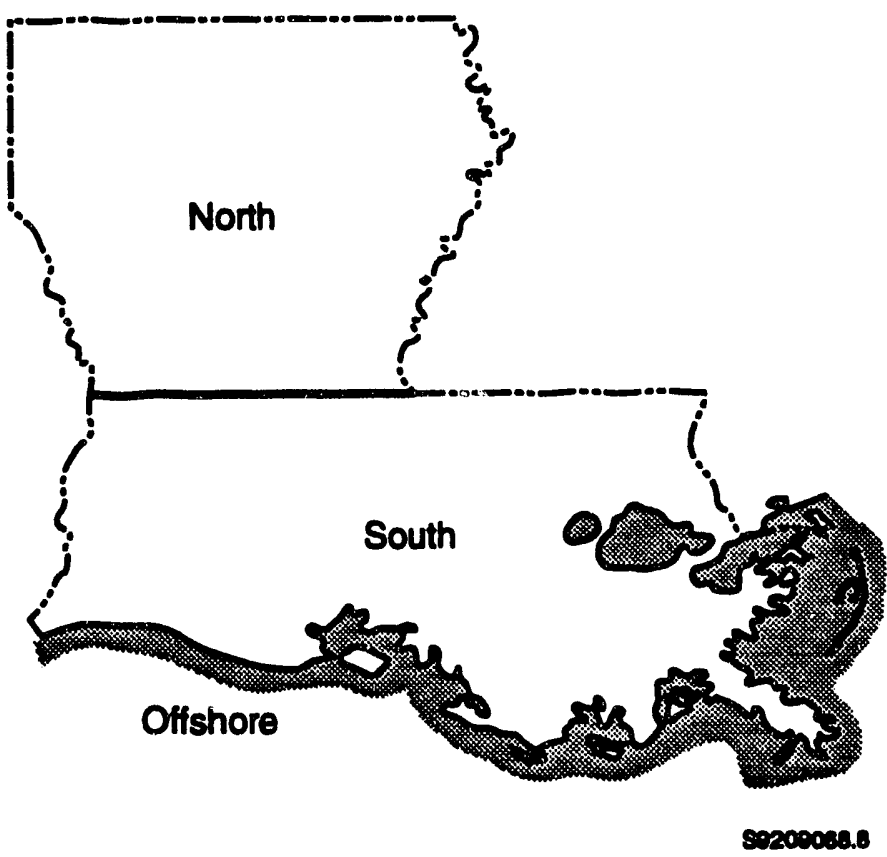

FIGURE 3.5. Louisiana Petroleum Production Regions 


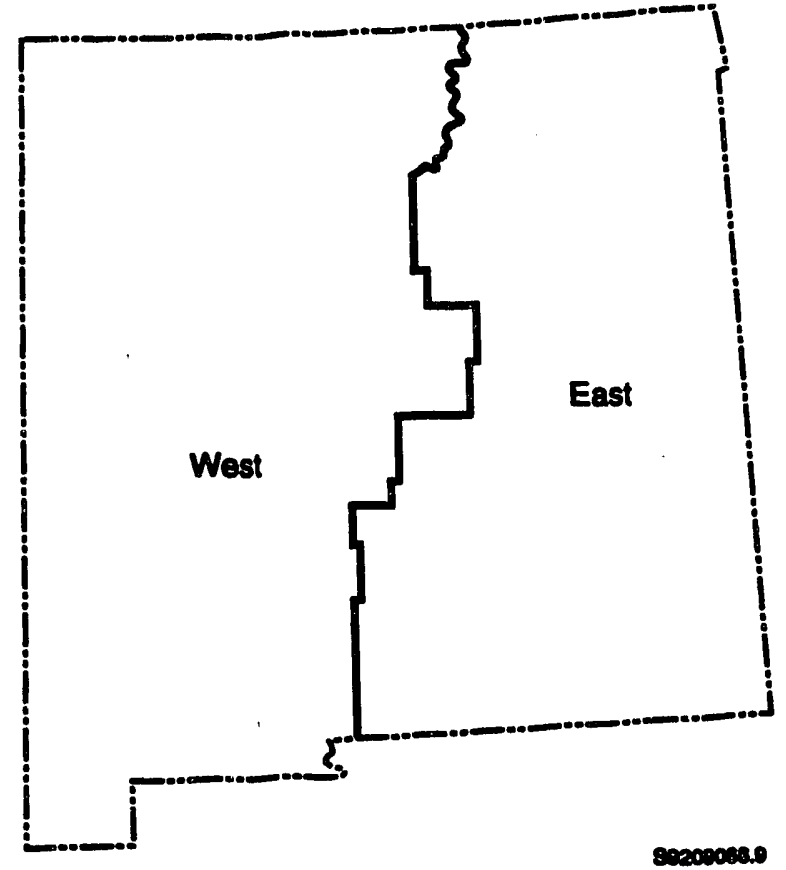

FIGURE 3.6. New Mexico Petroleum Production Regions

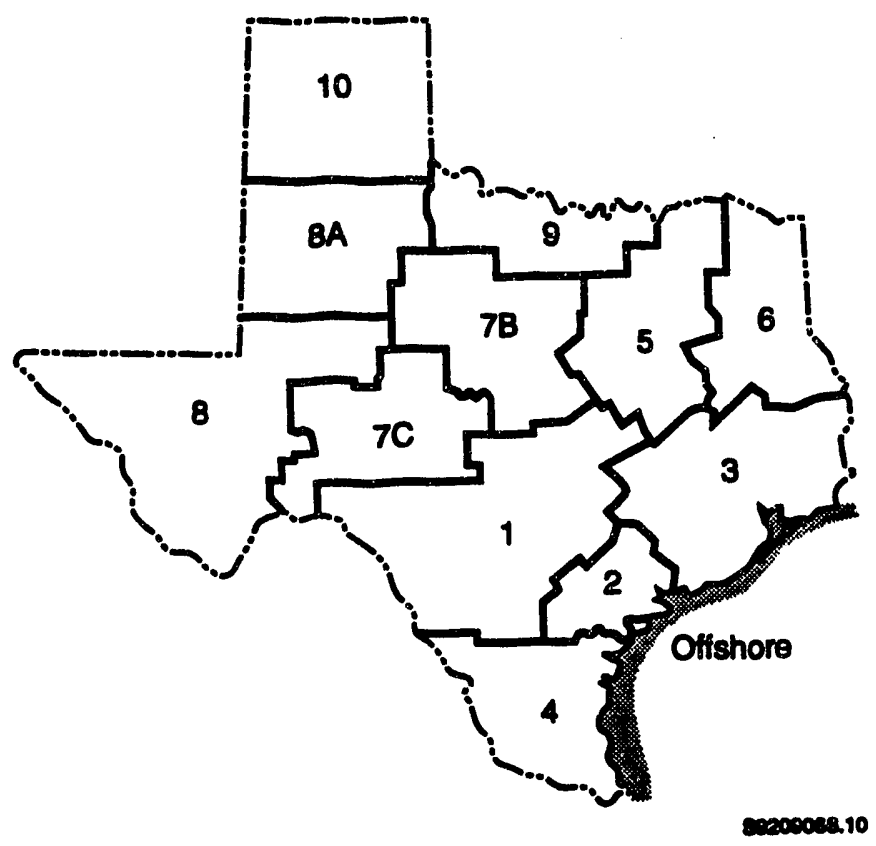

FIGURE 3.7. Texas Petroleum Production Regions 


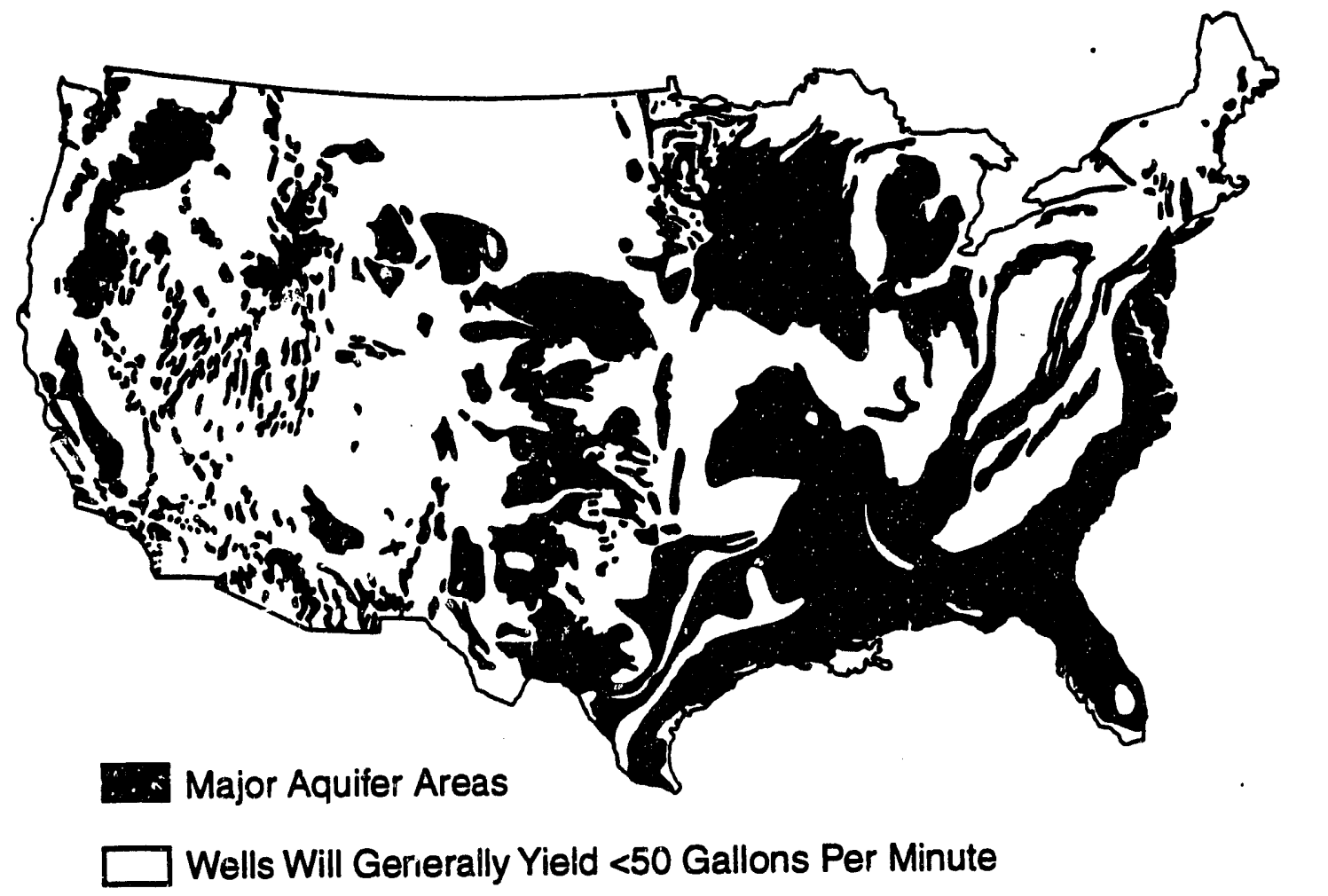

\section{FIGURE 3.8. Major U.S. Aquifers}

To reduce the storage volume requirements and buayant drive, the $\mathrm{CO}_{2}$ should be siored as a supercritical fluid with a density close to that of water. Both pressure and temperature increase with depth. Unfortunately, higher temperatures will require e::en higher pressures to minimize the buoyant force. The depths required for $\mathrm{CO}_{2}$ disposal are generally at least a few thousand feet. Most expioration and characterization at these depths have been performed for $0 i\}$ and gas. Very little is known about non-petroleum reservoirs at these depths, which makes $\mathrm{CO}_{2}$ disposal in deep aquifers a risky proposition.

Aquifers are never homogeneous. A simple alluvial aquifer system will often have hydraulic conductivities ranging through several orders of magnitude within a few meters, particularly in the vertical direction. This variability significantly reduces the sweep efficiency of the injection wel?. This problem would be made worse by the viscous fingering of the two fluids 
$\left(\mathrm{CO}_{2}\right.$ and water). For $\mathrm{CO}_{2}$ disposal, nonhomogeneous hydraulic conductivity could significantly limit the effective aquifer disposal capacity as well as the allowable injection rate.

$\mathrm{A} \mathrm{CO}_{2}$ disposal system would require a large aquifer that would confine the $\mathrm{CO}_{2}$ for several hundred years. By their existence, gas and oil reservoirs provide evidence of long-term confinement; however, such long-term confinement is much more speculative for aquifers.

Natural aquifer waters generally have a $\mathrm{pH}$ of about 8 , which $\mathrm{CO}_{2}$ injection will reduce. A probable moderate drop in the $\mathrm{pH}$ to about 5 could cause increased weathering of the aquifer matrix. Geochemical impacts would have to be analyzed on a case-by-case basis.

Aquifers have only recently been given serious attention as a possible disposal location for $\mathrm{CO}_{2}$. Much of this work has been conducted in The Netherlands (e.g., van Engelenburg and Blok 1992; van der Meer 1992) where preliminary feasibility studies (particularly van Engelenburg and Blok 1992) have yielded cautious optimism. The authors of this study do not share that optimism, particulariy for the Uniced States, where the geology is much more complex than that of The Netherlands. The technical issues described above make $\mathrm{CO}_{2}$ disposal in aquifers significantly riskier than disposal in either the deep ocean or depleted oil and gas reservoirs. Therefore, the potential cost of aquifer disposal for comparison with disposal in the ocean or depleted oil and gas reservoirs was not calculated at this time.

Despite these currently perceived risks, aquifers have the potential to provide low-cost $\mathrm{CO}_{2}$ disposal for the majority of U.S. fossil-fired power plants and warrant further investigation of their technical, environmental, and economic feasibility. 


\subsection{TRANSMISSION}

Transmitting $\mathrm{CO}_{2}$ to the disposal point can be a significant part of the overall cost of control, depending on the distance. In this analysis, where the power $\mathrm{plant}$ and $\mathrm{CO}_{2}$ recovery technology are held constant, the range of impact on power generation costs and $\mathrm{CO}_{2}$ control costs is due entirely to differences in the transmission distance. With the prospective transmission distance ranging from less than $100 \mathrm{mi}$ up to about $2000 \mathrm{mi}$, differences in transmission costs may have a significant bearing on the regional efficacy of implementing $\mathrm{CO}_{2}$ capture at fossil-fired power plants.

\subsection{IRANSMISSION DISTANCE}

Calculating the transmission distance requires identifying the prospective disposal points and source points (the power plants). The locations of prospective disposal points in deep ocean water or depleted oil and gas (DOG) reservoirs were identified in Section 3. This section of the report describes the assumptions used for establishing the locations of the power plants and calculating the transmission distance.

Many factors affect the siting of coal-fired power plants, especially at the local level. However, when examined at the state or regional level, two factors stand out: the demand for power and the availability of coal. Thus, most coal-fired power plants are located in well-populated states with significant coal resources. Coal and electricity transmission costs are obviousiy important siting factors. Proximity to potential $\mathrm{CO}_{2}$ disposal points and $\mathrm{CO}_{2}$ transmission costs may become an important factor in the future. Many other factors, such as shifting demographics, will also contribute to future siting decisions.

In this study, the $\mathrm{GCC}$ plants with $\mathrm{CO}_{2}$ recovery were assumed to be sited at the same location as current PC power plants with generating capacities greater than about 100 MWe. Note that future plants need not be physically located at exactly the same $\mathrm{place}$ in order for the results of this analysis to be valid. Rather, a physical distribution of coal-fired plants similar to the 
current distribution would be sufficient. The actual locations of current sites merely provide a convenient data base for measuring the prospective $\mathrm{CO}_{2}$ transmission distances.

The specific procedure was to identify the location and generating capacity of all coal-fired power plants with a generating capacity greater than 100 MWe (McGraw-Hill 1989; EIA 1991a). The sum of the coal-fired generating capacity identified was assumed to be replaced with an equal generating capacity supplied by multiple GCC plants with $\mathrm{CO}_{2}$ recovery as described in Section 2. As noted above, the new plants were assumed to be located at current $\mathrm{plant}$ sites. The number of units per site was set to match (with rounding to the nearest whole unit) the current generating capacity at the site. The resultant number of GCC generating units is identified for each state in Figure 4.1.

With the source points and disposal points identified, the design and cost of the transmission network depends on the degree of integration or independence among the plants. At one extreme, each generating unit could have its own pipeline running directly from the unit to the disposal point. At the other extreme, every unit in the country could be connected to a common piping network, or at least to regional networks. The latter approach would likely be significantly less expensive, as $\mathrm{CO}_{2}$ from several units could be combined into larger trunk lines, allowing economy-of-scale benefits in pipeline construction. However, the transmission costs estimated on th.s basis would be valid only if $\mathrm{CO}_{2}$ capture was implemented at all of the units included in the network. Implementation at fewer plants would likely lead to higher transportation costs because the network would be limited. In addition, pipeline economies-of-scale might not be great. The pipe diameter required for a single unit (18 in.) is already quite large (particularly for operating pressures in excess of 1200 psia), so larger diameter pipes may not offer any significant economies-of-scale. Network construction also generates a significant cost allocation problem, which makes $i$ extremely difficult to calculate the marginal cost of $\mathrm{CO}_{2}$ control for each unit. For these reasons, 


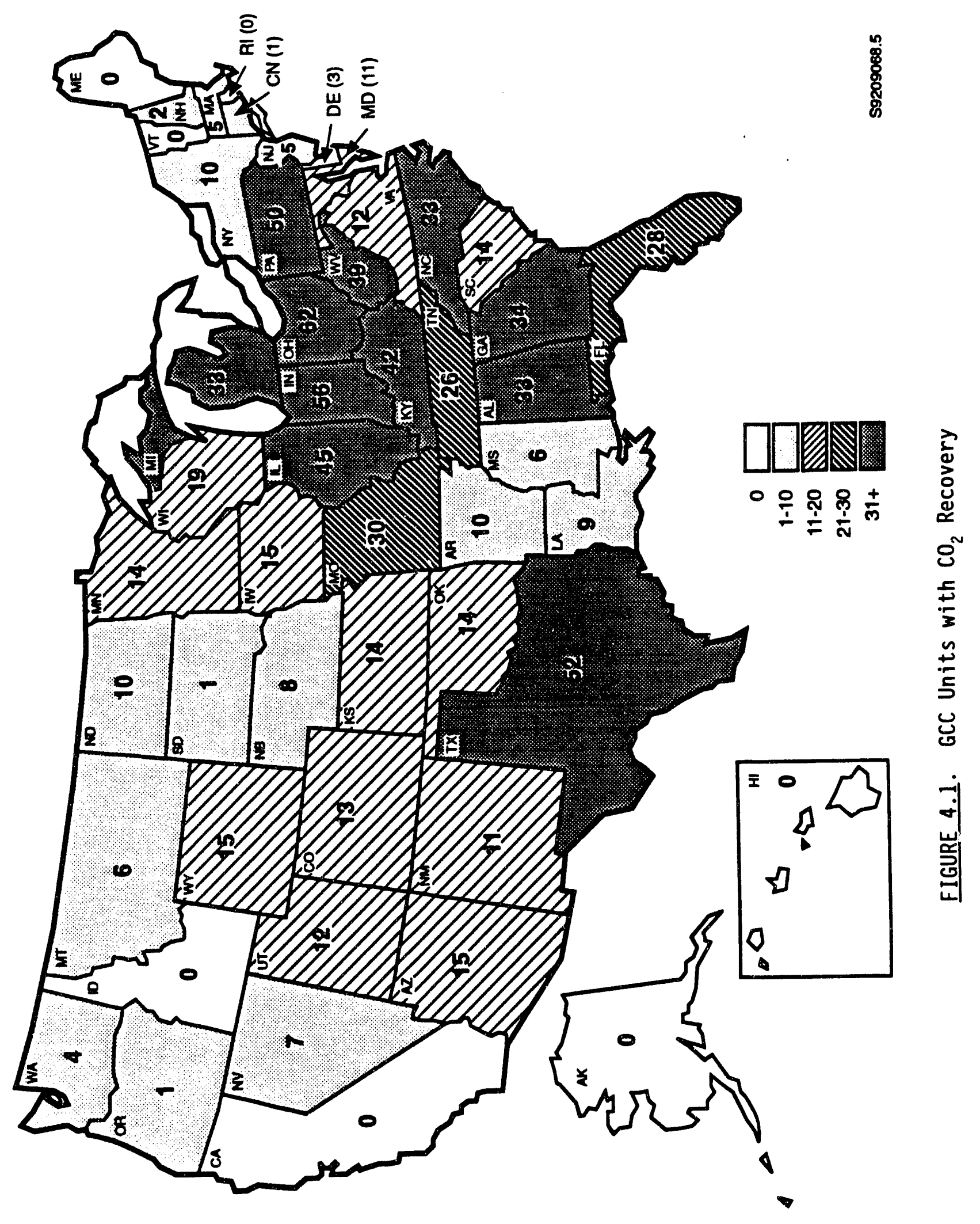

4.3 
each unit was assumed to have its own pipeline connecting to a disposal point. The costs derived from this design assumption should represent an upper bound on the actual costs.

Three transmission lengths were calculated for each power plant, representing disposal in the ocean at a depth of $500 \mathrm{~m}$ or $3000 \mathrm{~m}$, or disposal in a depleted oil and gas reservoir. Total mileage was segregated into overland and undersea portions. Overland "airline" distance was multiplied by 1.17 to account for expected deviations from a perfectly straight path. This factor was established by comparing airline miles and highway miles between several major cities, as published in the OAG Desktop Flight Guide (Official Airline Guides 1992) and Rand McNally Road Atlas (Rand McNally and Company 1990), respectively. Undersea mileage was not multiplied by this factor. Separation into overland and undersea portions was also important for distinguishing expected costs per mile of pipe.

The disposal point in the ocean was assumed to be the location with $500-\mathrm{m}$ or $3000-\mathrm{m}$ deep water that was closest to the power plant in question. A relatively small (compared to the entire pipeline) diffuser section is presumed to discharge the $\mathrm{CO}_{2}$ into the water. In contrast, disposal in depleted oil and gas reservoirs is complicated by their non-uniform and disperse nature. The $\mathrm{CO}_{2}$ flow from a single $\mathrm{GCC}$ unit would require distribution from a trunk line to multiple wells, the number depending on the characteristics of the depleted wellfield. For example, in their evaluation of $\mathrm{CO}_{2}$ capture and disposal from an IGCC plant, Hendriks, Blok and Turkenburg (1990) estimate that disposal of $487,000 \mathrm{~kg} / \mathrm{hr}$ of $\mathrm{CO}_{2}$ would require 15-20 wells. In the ir evaluation of a larger IGCC plant, Shell Internationale (1990) estimates that only' 6 wells would be required to dispose of $625,000 \mathrm{~kg} / \mathrm{hr}$ of $\mathrm{CO}_{2}$. By comparisor, the reference $\mathrm{CO}_{2}$ recovery unit defined in Section 2 produces $370,000 \mathrm{~kg} / \mathrm{hr}$ of $\mathrm{CO}_{2}$. Both of the above references assume that $\mathrm{CO}_{2}$ injection will commence immediately after production is terminated. Hence, all existing collection equipment is assumed to be available for use as $\mathrm{CO}_{2}$ distribution equipment. The implied assumption in both studies is that the equipment is appropriate, without modification, for $\mathrm{CO}_{2}$ disposal. 
Complete availability and applicability of residual oil/gas collection equipment for use as $\mathrm{CO}_{2}$ distribution equipment represents the best possible situation. A more rigorous analysis of $\mathrm{CO}_{2}$ distribution requirements and the availability and applicability of residual wellfield equipment is needed, but was beyond the scope of this study. Therefore, the simplifying assumption employed in the above two references was used in this study as wel1. Thus transmission costs to depleted oil and gas wells may be underestimated, especially compared with transmission to ocean disposal points.

The total potential $\mathrm{CO}_{2}$ disposal volume by state or substate region was presented in section 3. In recognition of the $\mathrm{CO}_{2}$ distribution concerns noted above, one-half of the potential disposal volume in each region was assumed to be infeasible for $\mathrm{CO}_{2}$ disposal because of the disperse nature of the available volume within a formation. Even so, half of the potential total was adequate for disposing all $\mathrm{CO}_{2}$ from all $830 \mathrm{GCC}$ units for 40 years. For the purposes of calculating the length of the transmission pipeline, the disposal volume available in each region was presumed to exist at the geographic center of the region. Because of the limited disposal volume available in each region, a filling strategy was necessary to determine the applicable disposal location for each unit. In general, disposal locations were assigned to GCC units so as to minimize the incremental transmission distance, i.e., the unit and disposal location with the shortest possible transmission distance were paired first, followed by the pair with the next shortest possible transmission distance, and so on.

Summary statistics describing the resultant pipeline lengths are presented in Table 4.1 and $r$ igure 4.2. The prospective transmission distance varies from practically zero (for a GCC unit sitting on top of a depleted oil and gas reservoir) to nearly $2000 \mathrm{mi}$. The average transmission distance is about $700 \mathrm{mi}$ for disposal in DOG reservoirs or ocean water at a $3000-\mathrm{m}$ depth; disposal at a 500-m depth reduces the average transmission distance by about $100 \mathrm{mi}$. If both ocean and DOG reservoir disposal are available, the average transmission distance drops to about $400 \mathrm{mi}$. The dispersion of transmission 
TABLE 4.1. Transmission Distance Summary

\begin{tabular}{|c|c|c|c|}
\hline & \multicolumn{2}{|c|}{ Transmission Distance, } & Miles \\
\hline Disposal Location & Minimum & Average & Maximum \\
\hline 500-m-deep ocean & 76 & 583 & 1425 \\
\hline 3000-m-deep ocean & 155 & 670. & 1538 \\
\hline DOG reservoirs & 24 & 694 & 1960 \\
\hline $\begin{array}{l}500 \text {-m-deep ocean or DOG } \\
\text { reservoirs, whichever is closer }\end{array}$ & 24 & 373 & 970 \\
\hline $\begin{array}{l}3000 \text {-m-deep ocean or DOG } \\
\text { reservoirs, whichever is closer }\end{array}$ & 24 & 408 & 1042 \\
\hline
\end{tabular}

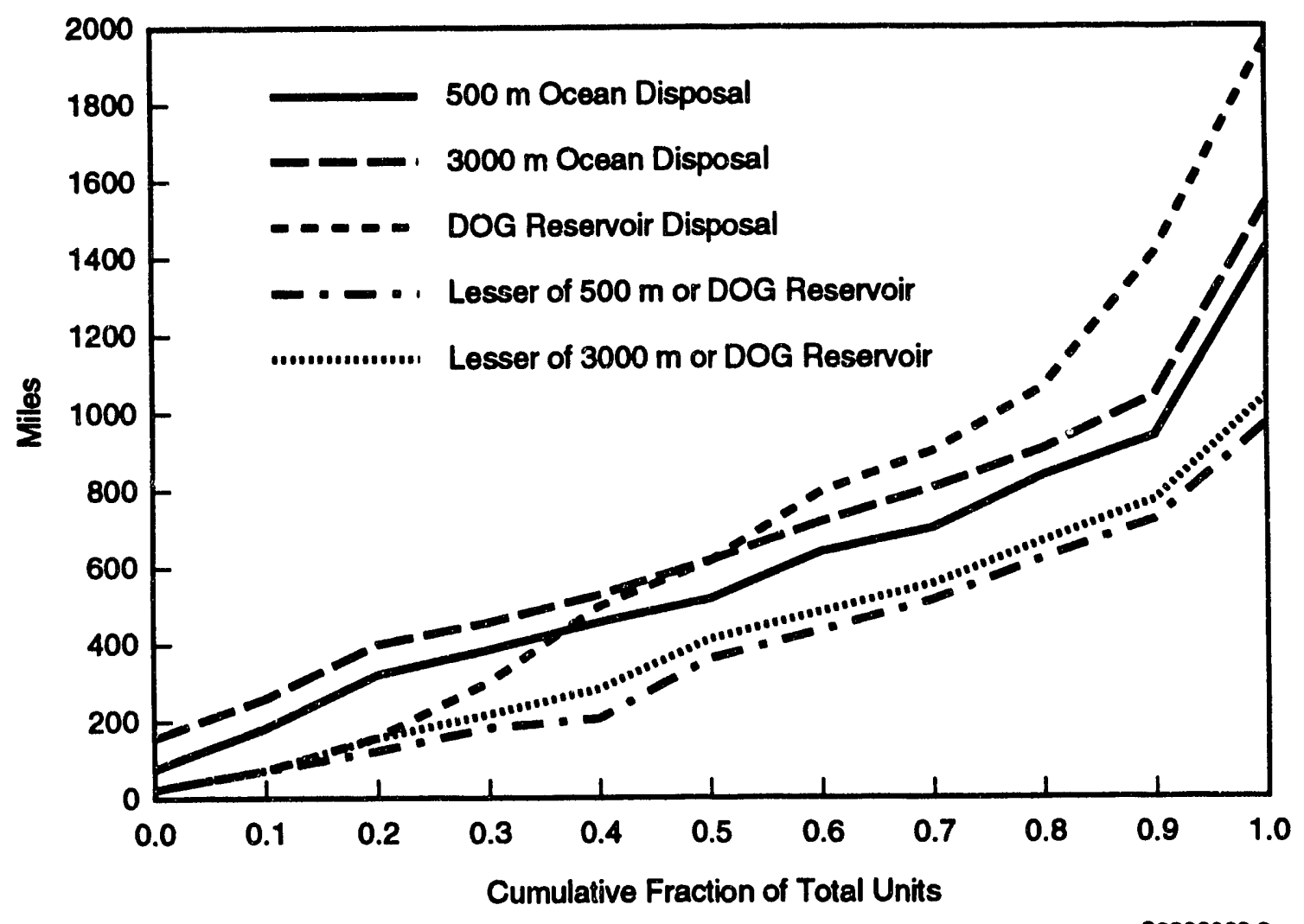

FIGURE 4.2. Transmission Distance Summary 
distances is greatest for disposal in DOG reservoirs: about $20 \%$ of the units have transmission distances less than $150 \mathrm{mi}$, but another $20 \%$ have transmission distances greater than $1050 \mathrm{mi}$.

\subsection{PIPELINE DESIGN AND COST}

Selection of the pipe diameter involves a tradeoff between the size and cost of the pipe and the size and cost of the compression equipment required to overcome frictional losses plus the cost of power to run the compressors. Smaller diameters reduce the cost of the pipe, but increase compression costs and vice-versa. An appropriate pipe diameter was determined from $\mathrm{CO}_{2}$ pipeline design data developed in two previous studies (Decker 1986; Anada et al. 1982). In Decker, an actual $\mathrm{CO}_{2}$ pipeline running from Southeastern Colorado to West Texas had a flow density of $1.05 \mathrm{MMSCFD} /$ in. $^{2}$ of pipe cross sectional area. Pipe designs developed in Anada et a1. had flow densities averaging $0.65 \mathrm{MMSCFD} / \mathrm{in}^{2}$. Pressure loss was not an issue in the system described by Decker, which had a significant elevation drop, so the design rule-of-thumb derived from Anada et al. was used. The resulting pipe diameter required for each GCC plant with $\mathrm{CO}_{2}$ recovery was 18 in.

Calculation of the pressure drop through the pipe is complicated because of the compressible, non-ideal nature of $\mathrm{CO}_{2}$ and its quickly changing fluid properties near the critical point design conditions. Overall pressure and temperature changes were calculated by integrating over simultaneous evaluations of temperature and pressure changes for sequential pipeline segments. The minimum pipeline pressure was set at 1200 psia as described in Section 2. Recompression would occur whenever pipeline pressure falls to this 1evel. The maximum pressure was set at 1800 psia based on design assumptions used in Anada et a1. (1982) and Smelser and Booras (1990). In general, a higher exit pressure would be expected to increase the required pipe wall thickness, but the required pipe diameter would decrease as the density of $\mathrm{CO}_{2}$ increases. $A$ higher pressure ratio would al so increase the compressor power required per unit of pressure added if non-intercooled compression was used. The size and frequency of compression stations are additional factors that would need to be 
considered in a more detailed piping analysis. A maximum pressure of 1800 psia was felt to be a reasonable assumption based on the two studies cited.

At each station $\mathrm{CO}_{2}$ was assumed to be compressed from 1200 psia to 1800 psia. Initial compression at the GCC unit also requires aftercooling to reduce the temperature of $\mathrm{CO}_{2}$ entering the pipeline to $100^{\circ} \mathrm{F}$. The exit temperature after recompression is already below $100^{\circ} \mathrm{F}$ (due to a lower inlet temperature), so aftercooling is not needed. During transport in buried pipelines, the $\mathrm{CO}_{2}$ will gradually $\mathrm{cool}$ as heat is transferred to the surrounding soil. Soil temperatures will obviously vary with location and time of year. An average soil temperature of $60^{\circ} \mathrm{F}$ was assumed based on data from U.S. Geological Survey maps. The pressure drop per unit length of pipe at $100^{\circ} \mathrm{F}$ and 1200 psia is nearly double that at $60^{\circ} \mathrm{F}$ and $1800 \mathrm{psia}$, so an accurate determination of the expected temperature and pressure conditions is important.

Heat transfer and pressure drop equations governing the design of the pipeline are presented in Appendix $B$. The results of the overland pipeline analysis are summarized in Table 4.2. Pressure drop per mile declines as temperature and pressure drop over the length of the pipe, averaging $3.07 \mathrm{psia} / \mathrm{mi}$ for the first segment and $2.70 \mathrm{psia} / \mathrm{mi}$ for the last segment. The entrance conditions shown are applicable for initial compression at the power plant, where cooling water allows intercooling between compression stages and final aftercooling to $100^{\circ} \mathrm{F}$. Subsequent recompression from 1200 psia to $1800 \mathrm{psia}$, with a compressor inlet temperature near $60^{\circ} \mathrm{F}$, would yield a compressor exit

TABLE 4.2 Overiand Pipeline Temperature and Pressure Profile

\begin{tabular}{|c|c|c|c|c|}
\hline & \multicolumn{2}{|c|}{ Temperature, ${ }^{\circ} \mathrm{F}$} & \multicolumn{2}{|c|}{ Pressure, psia } \\
\hline Pipe Segment & Entrance & Exit & Entrance & Exit \\
\hline $0-60 \mathrm{mi}$ & 100.0 & 83.6 & 1800 & 1616 \\
\hline $60-120 \mathrm{mi}$ & 83.6 & 72.0 & 1616 & 1447 \\
\hline $120-180 \mathrm{mi}$ & 72.0 & 65.9 & 1447 & 1284 \\
\hline $180-210 \mathrm{mi}$ & 65.9 & 64.1 & 1284 & 1203 \\
\hline
\end{tabular}


temperature of about $70^{\circ} \mathrm{F}$. Therefore, the average pressure loss per mile after the first 210 miles was assumed to be 2.70 psia. Additional discussion of the compressor sizing is presented later in this section.

The pressure drop relationships described above were applied to overland pipelines and did not take into account any elevation loss between the power plant and the ocean shore. Thus, the estimated overland pipeline pressure drop may be conservatively high. The impact of elevation drop was specifically considered for the undersea pipelines, however.

Two fundamental requirements govern the undersea pipeline sizing:

1) the exit pressure must be greater than the static head of the ocean at the injection point and 2) pressure throughout the pipeline must be greater than the local liquid-vapor equilibrium pressure (to avoid two-phase flow problems), which varies as the $\mathrm{CO}_{2}$ temperature adjusts to the local ocean temperature. At the temperatures prevalent in deep ocean water, the pressure in the pipeline can be significantly lower than 1200 psia and still avoid two-phase flow.

An initial analysis showed that the $\mathrm{CO}_{2}$ would $\mathrm{cool}$ to the ocean water temperature within the first several hundred meters of the pipeline. Ocean temperatures off the U.S. coasts vary considerably depending on the location, time of year, and depth. Data from Thurman (1986) were used to develop the following temperature profile that is roughly representative of average summer conditions for U.S. coastal waters: $23^{\circ} \mathrm{C}$ at the surface, $11^{\circ} \mathrm{C}$ at $500 \mathrm{~m}$ and $2^{\circ} \mathrm{C}$ at $3000 \mathrm{~m}$. The average offshore pipeline distances were $93 \mathrm{mi}$ to $500 \mathrm{~m}$ and $172 \mathrm{mi}$ to $3000 \mathrm{~m}$. The minimum $\mathrm{CO}_{2}$ exit pressure (ocean static pressure) is $5.13 \mathrm{MPa}$ at $500 \mathrm{~m}$ and $30.3 \mathrm{MPa}$ at $3000 \mathrm{~m}$.

The undersea pipeline analysis indicated that the required exit pressures for $500-\mathrm{m}$ and $3000-\mathrm{m}$ discharge would be exceeded with an entrance pressure of 1200 psia (the minimum pressure allowed in the overland pipeline) without any additional compression stations. In fact, the diameter of an undersea pipeline discharging at $500 \mathrm{~m}$ could be reduced to $14 \mathrm{in}$., while the diameter of an undersea pipeline discharging at $3000 \mathrm{~m}$ could be reduced to 16 in. 
We11 pressures for DOG reservoirs were also evaluated to determine if the minimum overland pipeline pressure of 1200 psia would be adequate or if additional compression would be required at the well head. As described in Section 2, DOG reservoir pressure was assumed to increased linearly with depth at rate of about 30 bars per $1000 \mathrm{ft}$. Temperature rise and frictional loss would be negligible as the $\mathrm{CO}_{2}$ flowed down the injection well, while pressure increases dramatically with the drop in elevation. At all depths up to at least $9000 \mathrm{ft}$, the $\mathrm{CO}_{2}$ pressure was calculated to be greater than the prevailing reservoir pressure. Therefore, additional compression at the well head would not be required.

Pipeline costs were estimated based on recent actual construction costs reported in the 0il and Gas Journal (True 1989a; True 1990) for onshore and offshore oil and gas pipelines. Regression analysis was applied to pipeline cost data for pipelines with 12- to 24-in. diameters and lerigths greater than $10 \mathrm{mi}$ to predict construction costs for onshore and offshore applications. No pipelines have currently been laid at depths greater than about $600 \mathrm{~m}$. Therefore, the offshore data were assumed to apply to disposal at $500 \mathrm{~m}$ only. Pipelines from $500 \mathrm{~m}$ to $3000 \mathrm{~m}$ were assumed to cost an additional $50 \%$. For additional information on deep water pipe-laying techniques that could potentially be applied to $3000-m$ depths, the reader is referred to Timmermans (1984a, 1984b, 1989), True (1989b), and Stoll (1986). Pipeline unit capital costs and sizing assumptions are summarized in Table 4.3. Annual pipeline 08M was set at $2.25 \%$ of initial capital, based on data in Matchak et a1. (1984).

Compression power requirements and costs were calculated based on conditions presumed to exist at the power plant and subsequent recompression stations. In both cases, the inlet pressure was assumed to be 1200 psia, the minimum pipeline operating pressure. At the power plant, supplementary compression from 1200 to 1800 psia was based on prior intercooling of the $\mathrm{CO}_{2}$ to $100^{\circ} \mathrm{F}$ in a water-cooled heat exchanger. As previously discussed, $\mathrm{CO}_{2}$ in the pipeline was calculated to $\operatorname{cool}$ to a temperature of about $64^{\circ} \mathrm{F}$ for a presumed soil temperature of $60^{\circ} \mathrm{F}$. Hence, recompression occurs at a lower entering temperature. 
TABLE 4.3. Pipeline Size and Cost Assumptions

Pipe Diameter, in.

12

14

16

18

20

22

24
Pipeline Costs, 1000 s of Mid-1990 \$/Mile

Offshore offshore

Onshore to $500 \mathrm{~m}$

520

580

650

710

770

830

890
500-3000 m

780

870

975

1065

1155

1245

1335

Note: Onshore pipeline: 18-in. diameter

Offshore pipeline to $500 \mathrm{~m}: 14-\mathrm{in}$. diameter

Offshore pipeline to $3000 \mathrm{~m}: 16$-in. diameter

The theoretical compressor power was calculated using Equation 4.1 (Perry and Green 1984). For the temperature and pressure conditions described above, the theoretical compressor power is 1.21 MWe for supplemental compression at the power $\mathrm{plant}$, but only 0.54 MWe for subsequent recompression. The key difference is the compressibility factor, which drops from 0.45 to 0.22 as the temperature drops from $100^{\circ} \mathrm{F}$ to $64^{\circ} \mathrm{F}$ at $1200 \mathrm{psia}$. This example demonstrates the extreme variability of $\mathrm{CO}_{2}$ fluid properties near ambient temperatures. These properties must be considered very carefully in any design analysis.

$$
k W=(M / 1000) * k /(k-1) * z * R * T_{1}^{*}\left[\left(P_{2} / P_{1}\right)^{(k-1) / k}-1\right]
$$

where $\mathrm{kW}=$ kilowatts

$$
\begin{aligned}
M & =\text { mass flow rate, } \mathrm{kg} / \mathrm{s} \\
k & =C_{p} / C_{v}=1.3 \text { for } \mathrm{CO}_{2} \\
z & =\text { non-ideal gas compressibility factor } \\
R & =\text { ideal gas constant }=8314 / \mathrm{MW} \mathrm{J/kg*K} \\
M W & =\text { gas molecular weight }=44 \text { for } \mathrm{CO}_{2} \\
T_{1} & =\text { inlet temperature, } \mathrm{K}
\end{aligned}
$$




$$
\begin{aligned}
& P_{1}=\text { inlet pressure } \\
& P_{2}=\text { outlet pressure }
\end{aligned}
$$

Actual compressor power was calculated by applying an $80 \%$ efficiency factor for the combined compressor and motor to the theoretical power figures noted above. Based on the pipeline pressure drop data presented earlier, the power consumed in transporting $\mathrm{CO}_{2}$ is $7.2 \mathrm{~kW} / \mathrm{mi}$ for the first $210 \mathrm{mi}$ and $3.1 \mathrm{~kW} / \mathrm{mi}$ thereafter.

Unique compressor unit cost estimates were developed for initial and $\therefore \quad$ supplemental compression and subsequent recompression, reflecting the different size and economies-of-scale associated with the two applications. Initial supplemental compression to 1800 psia (or less for pipelines less than $210 \mathrm{mi}$ long) would be accomplished in an integrated, multi-stage compressor. The expected unit cost for this application was set equal to that presented in Smelser and Booras (1990), updated to mid-1990 dollars. The unit cost for recompression was estimated based on the relative size of the two applications and on compressor cost-scaling data presented in Garrett (1989). The resultant capital cost assumptions were $\$ 1,541,000 /$ MWe and $\$ 3,019,000 /$ MWe (of compressor power) for initial compression and recompression, respectively, which includes a $2 \%$ allowance for ancillary cooling system equipment. Annual 0\&M was set at $3 \%$ of capital per data in Matchak et a1. (1984). 


\subsection{SYSTEM RESULTS}

Complete system cost and performance characteristics were developf $d$ for each of the 329 unique power plant locations. These data were used to calculate the levelized energy cost (LEC) in $\$ / \mathrm{kWh}$ and levelized $\mathrm{CO}_{2}$ control cost (LCCC) in $\$ / M g$. Levelized cost analysis combines initial cost, annually recurring cost, and system performance characteristics with financial parameters to produce a single figure of merit (the LEC or LCCC) that is economically correct and can be used to compare the projected energy and $\mathrm{CO}_{2}$ control costs of alternative nlants. The specific methodology employed was that defined in Brown et al. (1987), which is consistent with the "required revenue" approach recommended by the Electric Power Research Institute in their Technical Assessment Guide (EPRI 1989). The specific financial assumptions employed are listed in Table 5.1. The majority of these were taken from the Iechnical 4ssessment Guide. Exceptions are the price year, first year of operation, and net salvage value, which were assumed by PNL for this tudy, and the fuel price escalation rate, which was taken from the Annual Energy Outlook (EIA 1992).

IABLE 5.1. Financial Assumption:

\begin{tabular}{lc} 
& Assumption \\
\hline & \\
After-tax nominal discount rate & $9.82 \%$ \\
General inflation rate & $5.00 \%$ \\
Capital infiation rate & $5.00 \%$ \\
Operation and maintenance inflation rate & $5.00 \%$ \\
Fuel (coal) inflation rate & $6.70 \%$ \\
Investment tax credit & $0.00 \%$ \\
Property tax and insurance rate & $2.00 \%$ \\
Combined state and federal tax rat: & $38.0 \%$ \\
Plant economic life & 30 years \\
Plant depreciable life & 20 years \\
Plant construction period & 3 years \\
Price year & 1990 \\
First year of operation & 2000 \\
Annual power production capacity factor & $65.0 \%$ \\
Net salvage value at end of life & 0
\end{tabular}




\subsection{LEC AND LCCC CALCULATION}

Although LEC calculations are a standard part of utility economic analysis additional discussion of the two economic "figures of merit" is warranted, particulariy in regard to the LCCC figure. As noted above, LEC calculations combine the cost and performance characteristics of a power plant into a single, equitably comparable figure. While this is important for the comparison of any two power plants, the LEC approach is crucial to evaluating most $\mathrm{CO}_{2}$ recovery and disposal concepts where cost has typically increased significantly, while performance has decreased significantly (because of increased parasitic power consumption). These effects are correctly captured in the LEC calculation, where both increased annualized costs and decreased annual net power output cause the LEC for a plant with $\mathrm{CO}_{2}$ recovery to increase relative to the LEC for a reference $\mathrm{plant}$ without $\mathrm{CO}_{2}$ recovery and disposal.

The LCCC figure expresses the annualized cost of $\mathrm{CO}_{2}$ control per unit of $\mathrm{CO}_{2}$. The correct calculation of this figure must focus on the incremental increase in cost and the incremental decrease in $\mathrm{CO}_{2}$ emission relative to a reference $\mathrm{plant}$. The product of interest from a power plant is electricity. Hence, incremental cost and emission are best measured per kWh, in order to ensure a fair comparison of power plants producing different amounts of electrical energy. Thus, the illcremental cost is the difference in LEC $(\$ / \mathrm{kWh})$ between the $\mathrm{plant}$ with $\mathrm{CO}_{2}$ recovery and disposal and the reference plant. Similarly, the incremental emission is the difference in $\mathrm{CO}_{2}$ emission per $\mathrm{kWh}$ $(\mathrm{Mg} / \mathrm{kWh})$ between the reference $\mathrm{plant}$ and the $\mathrm{plant}$ with $\mathrm{CO}_{2}$ recovery and disposal. The $\mathrm{LCCC}(\$ / \mathrm{Mg})$ equals the incremental cost $(\$ / \mathrm{kWh})$ divided by the incremental decrease in $\mathrm{CO}_{2}$ emission $(\mathrm{Mg} / \mathrm{kWh})$.

If the expression defined above seems obvious, consider two calculations that may appear logical at first, but are seen to be inferior upon inspection. One alternative would be to annualize the incremental capital and operation and maintenance costs and use this figure for the incremental cost. Unfortunately, this approach ignores any decrease in plant performance that would provide an additional increase in the incremental cost of electricity. Another alternative would be to use the amount of $\mathrm{CO}_{2}$ captured and disposed as 
the incremental emission reduction. This too would be incorrect because the amount of $\mathrm{CO}_{2}$ captured and disposed is generally greater than the reduction in emission per $\mathrm{kWh}$, which is the relevant figure. The difference arises from the change in $\mathrm{plant}$ performance or heat rate. Additional parasitic power consumption (i.e., power consumed within the boundaries of the power plant) associated with the typical $\mathrm{CO}_{2}$ recovery plant causes an increase in the heat rate $(\mathrm{Btu} / \mathrm{kWh})$ and the amount of fuel burned and $\mathrm{CO}_{2}$ generated. Thus, it is possible, even with less than $100 \% \mathrm{CO}_{2}$ recovery, to capture and dispose of more $\mathrm{CO}_{2}$ than is generated in the reference $p$ ? ant. Obviously, the figure of interest is the reduction in emission and not the amount captured and disposed. If either or both of the alternative approaches are used, the cost of $\mathrm{CO}_{2}$ capture and disposal will be understated.

\subsection{LEC AND LCCC RESULTS}

The LEC for the reference GCC power plant described in Section 2 (without $\mathrm{CO}_{2}$ recovery and disposal) was calculated to be $\$ 0.0631 / \mathrm{kWh}$. The LEC rises to $\$ 0.0839 / \mathrm{kWh}$ when $\mathrm{CO}_{2}$ recovery is included. The corresponding LCCC is $\$ 27.15 / \mathrm{Mg}$. This $33 \%$ increase in LEC would apply for a power plant located at the disposal point, a situation that might occur for $\mathrm{CO}_{2}$ disposed of in DOG reservoirs. Although ocean platform power plants have been proposed and would al so el iminate transportation costs, increases in other plant construction costs would likely offset the transportation advantage.

Summary statistics describing the range and distribution of LECS and LCCCs when $\mathrm{CO}_{2}$ transmission is included with recovery are presented in Tables 5.2 and 5.3 and Figures 5.1 through 5.4. Figures 5.1 and 5.2 show how LEC and LCCC vary with the cumulative fraction of the total number of power plants (830). Figures 5.3 and 5.4 have expressed cumulative power plants in terms of cumulative $\mathrm{CO}_{2}$ emission reductions. Not surprisingly, the trends for both are similar to that described earlier for transmission distance. LECS vary from about 8.5 to $14.5 \mathrm{\$} / \mathrm{kWh}$, while LCCCs range from about 30 to $105 \mathrm{\$} / \mathrm{Mg}$. The average LEC is about $10.5 \$ / \mathrm{kWh}$ for disposal in DOG reservoirs or 3000-m-deep ocean water; disposal in 500-m-deep ocean water reduces the average LEC by about $0.5 \$ / \mathrm{kWh}$. The average LCCC for disposal in DOG 
TABLE 5.2. LEC Summary

\begin{tabular}{|c|c|c|c|}
\hline \multirow[b]{2}{*}{ Disposal Location } & \\
\hline & Minimum & Average & Maximum \\
\hline 500-m-deep ocean & 0.0863 & 0.1015 & 0.1265 \\
\hline 3000-m-deep ocean & 0.0902 & 0.1064 & 0.1332 \\
\hline DOG reservoirs & 0.0846 & 0.1047 & 0.1433 \\
\hline $\begin{array}{l}500 \text {-m-deep ocean or DOG } \\
\text { reservoir, whichever is closer }\end{array}$ & 0.0846 & 0.0951 & 0.1134 \\
\hline $\begin{array}{l}3000 \text {-m-deep ocean or DOG } \\
\text { reservoir, whichever is closer }\end{array}$ & 0.0846 & 0.0970 & 0.1183 \\
\hline
\end{tabular}

TABLE 5.3. LCCC Summary

\begin{tabular}{lcccc}
\multicolumn{1}{c}{ Disposal Location } & & Minimum & Average & Maximum \\
\hline 500 -m-deep ocean & 30.27 & 50.15 & 82.94 \\
3000 -m-deep ocean & 35.38 & 56.57 & 91.73 \\
DOG reservoirs & 28.10 & 54.38 & 104.98 \\
$\begin{array}{l}500 \text {-m-deep ocean or DOG } \\
\text { reservoir, whichever is closer }\end{array}$ & 28.10 & 41.83 & 65.70 \\
$\begin{array}{l}3000 \text {-m-deep orean or DOG } \\
\text { reservoir, whichever is closer }\end{array}$ & 28.10 & 44.24 & 72.13
\end{tabular}

reservoirs or $3000-\mathrm{m}$-deep ocean is about $\$ 55 / \mathrm{Mg}$; disposal in 500 - $\mathrm{m}$-deep ocean water reduces the average $\mathrm{LCCC}$ by about $\$ 5 / \mathrm{Mg}$. If both ocean and DOG reservoir disposal are available, the average LEC drops to about $9.6 \mathrm{\$} / \mathrm{kWh}$, while the average LCCC drops to about $\$ 43 / \mathrm{Mg}$. The dispersion of LECS and LCCCS is greatest for disposal in DOG reservoirs. For example, about $20 \%$ of the units have LECs less than $9 \$ / \mathrm{kWh}$, but another $20 \%$ have LECs greater than $11.6 \$ / \mathrm{kWh}$.

The LEC and LCCC figures presented for disposal in DNG reservoirs do not include any potential credit for enhanced recovery of oil or natural gas. Shell Internationale (1990) projected little net economic benefit from 

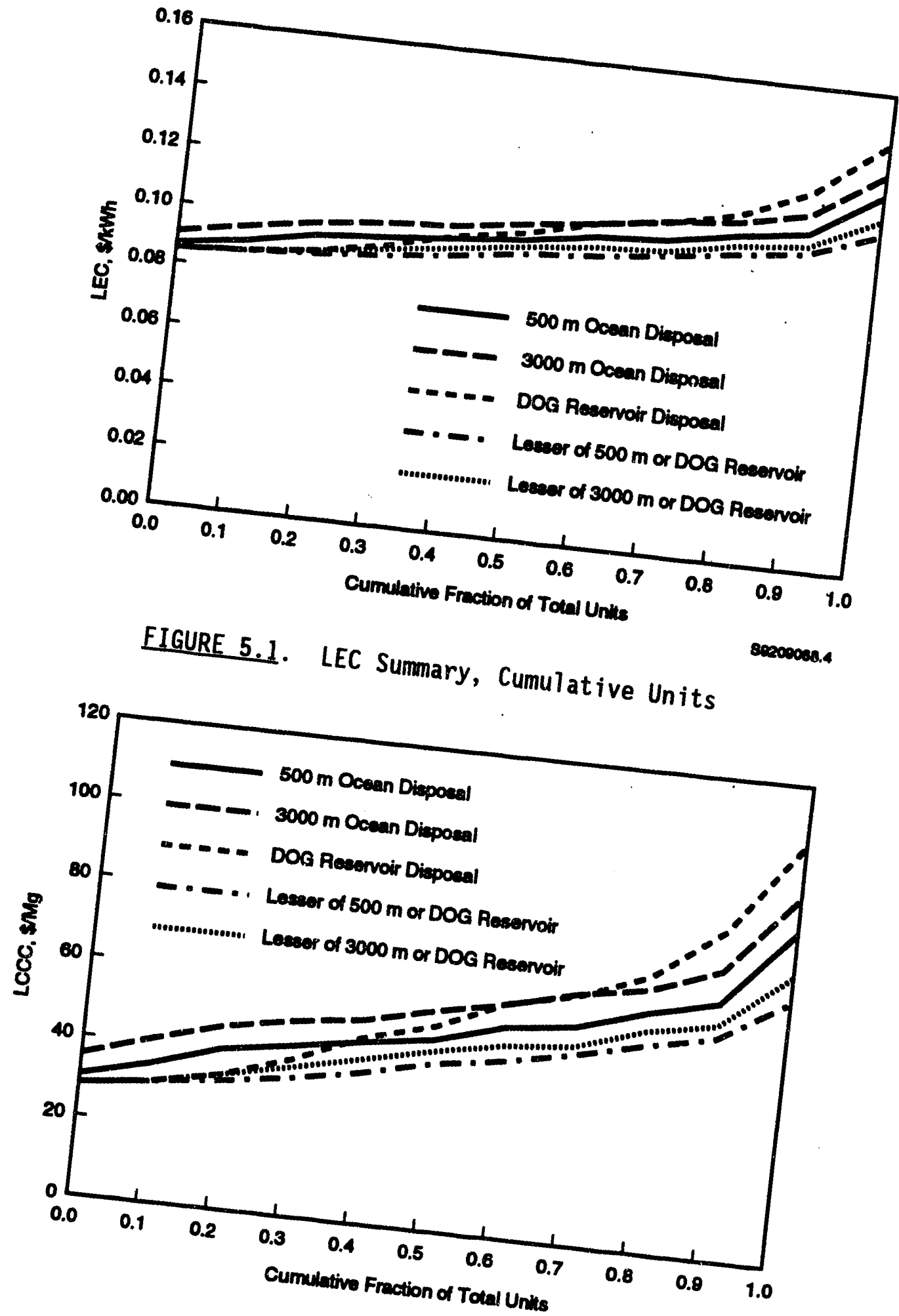

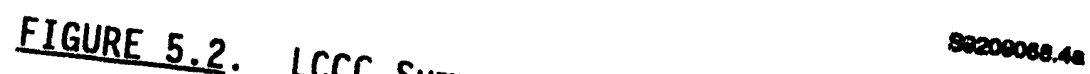

LCCC Summary, Cumulative Units 


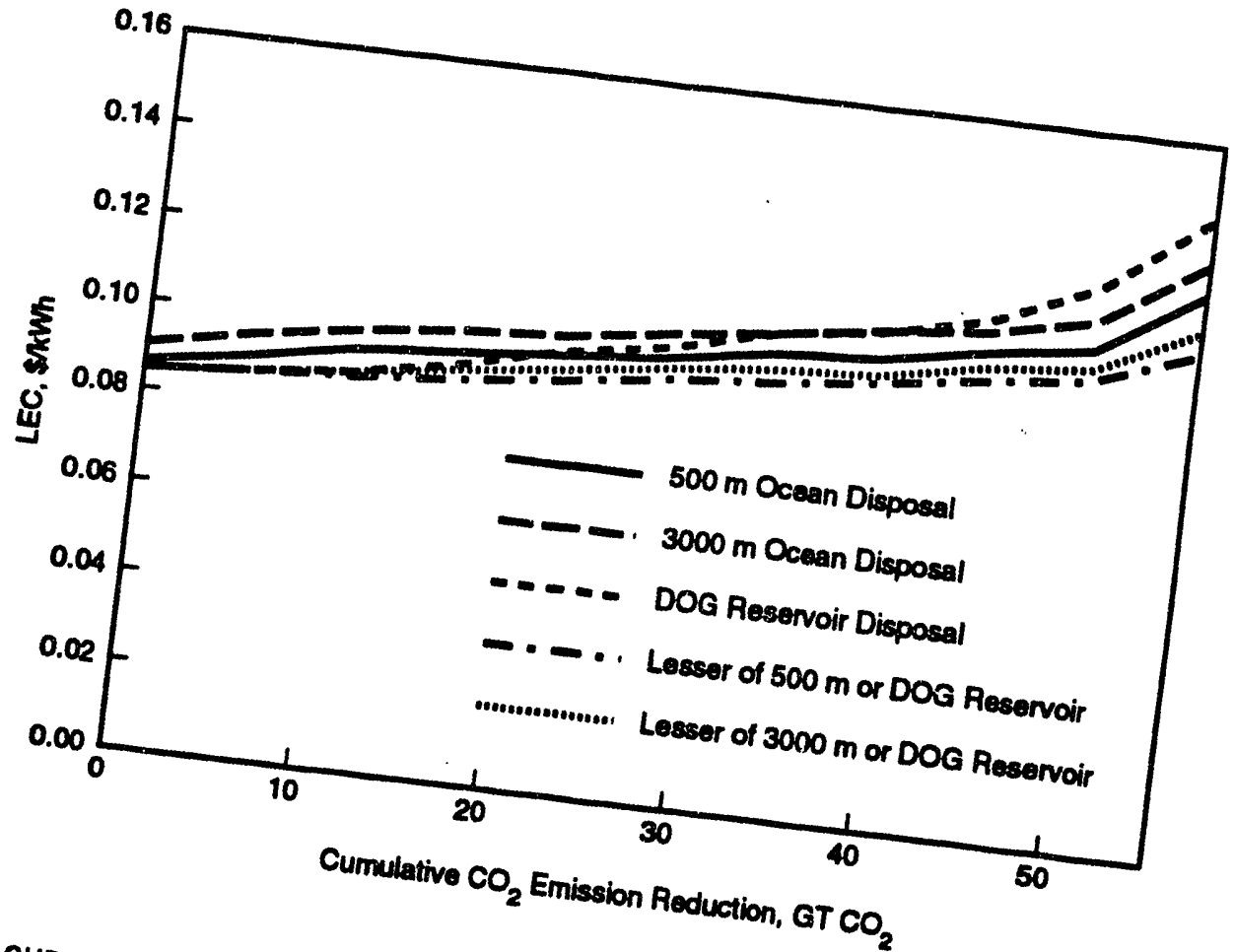

FIGURE 5.3. LEC

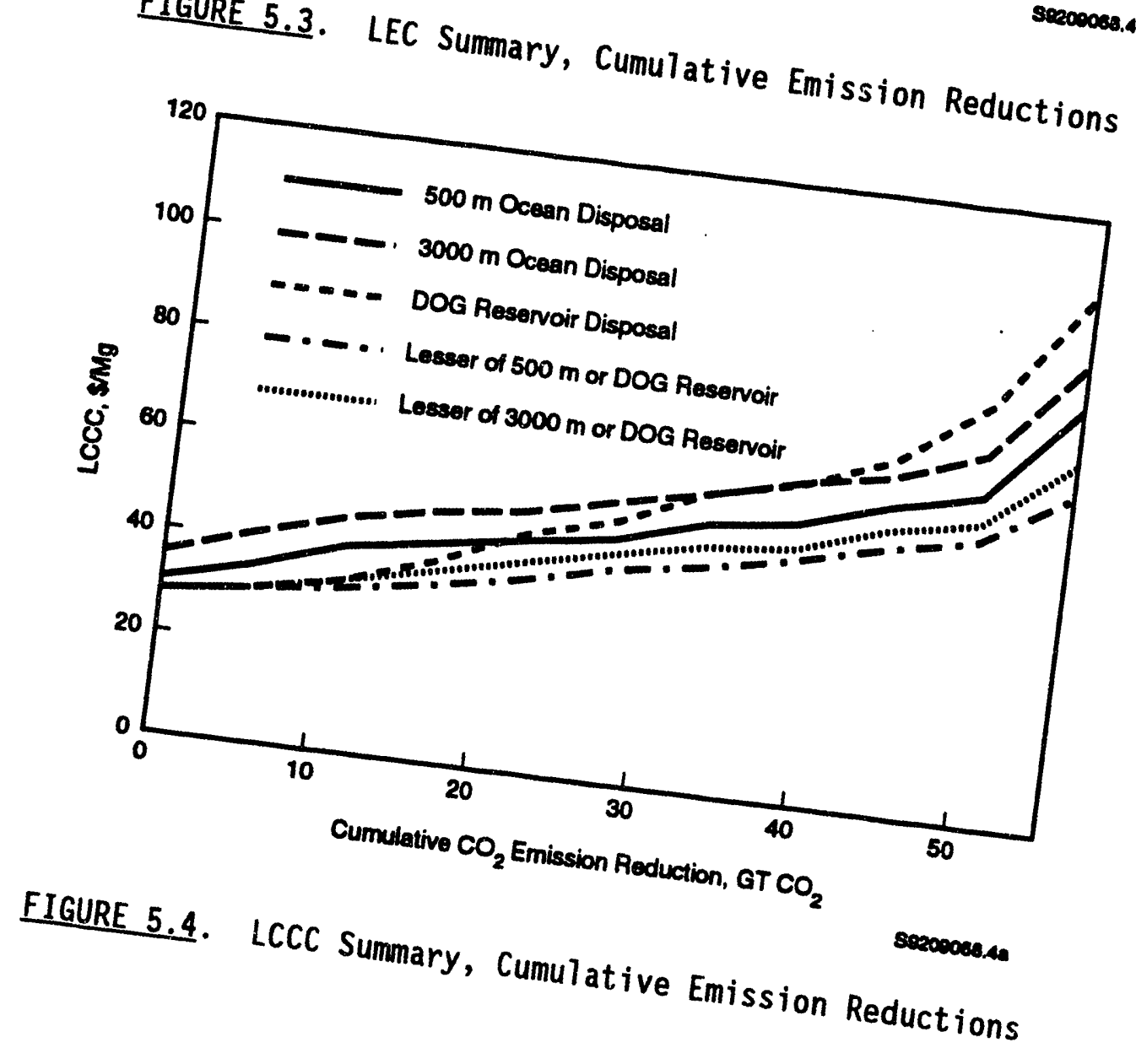

5.6 
injecting $\mathrm{CO}_{2}$ into Dutch gas fields prior to normal closure of the field. Injection of $\mathrm{CO}_{2}$ into partially depleted oil fields would probably have a significant positive economic benefit that would reduce the net cost of recovery and disposal in some cases. 


\subsection{CONCLUSIONS AND RECOMMENDATIONS}

Ocean disposal of $\mathrm{CO}_{2}$ offers essentially unlimited capacity, but such disposal is distant from most U.S. coal-fired power plant locations and presents environmental concerns in the vicinity of the disposal point. Depleted $0 i 1$ and gas reservoirs are also distant from most U.S. coal-fired power plants. Although they have a more limited disposal capacity than the ocean, DOG reservoirs were calculated to have a potential capacity more than double that required to dispose of all $\mathrm{CO}_{2}$ from $830 \mathrm{GCC}$ power plants (380-MWe each) for a period of 40 years. The existence of $0 i 1$ and gas reservoirs provides "proof" that $\mathrm{CO}_{2}$ can be confined for the long term in these formations.

In contrast, aquifer disposal has great potential in terms of large capacity and low cost, but is believed to be significantly riskier. Key concerns are lack of geologic knowledge about aquifers at depths adequate for $\mathrm{CO}_{2}$ disposal; geochemical impacts from decreased water $\mathrm{pH}$; and long-term confinement; which is unproven for nonpetroleum formations. The technical, environmental, and economic feasibility of aquifer disposal for the Unitied States should be investigated more thoroughly.

Carbon dioxide recovery at GCC plants increased the LEC by about one third relative to a reference $\mathrm{GCC} \mathrm{plant}$ without $\mathrm{CO}_{2}$ recovery. The transmission distance is the key factor affecting $\mathrm{CO}_{2}$ control costs. The LEC with $\mathrm{CO}_{2}$ recovery and transmission increased by one third to more than a factor of two, depending on the transmission distance, which ranged from about 25 to nearly $2000 \mathrm{mi}$. While $\mathrm{CO}_{2}$ recovery and disposal would likely be too expensive to implement on a national basis, regional or site-specific applications may be competitive with other $\mathrm{CO}_{2}$ control strategies. Credit for potential enhanced oil recovery benefits in depleted oil reservoir applications (not included in this study) would further improve economic attractiveness.

The significant impact of transmission on the cost-effectiveness of $\mathrm{CO}_{2}$ recovery and disposal suggests that several key assumptions made in this study are worthy of further examination:

1. $\mathrm{CO}_{2}$ properties vary dramatically within the range of ambient temperatures that might be encountered by a $\mathrm{CO}_{2}$ pipeline. For example, 
when $\mathrm{CO}_{2}$ is recompressed from 1200 to $1800 \mathrm{psia}$, the power required at a $100^{\circ} \mathrm{F}$ inlet temperature is approximately double that required at a $60^{\circ} \mathrm{F}$ inlet temperature. The impact of locational and seasonal variation in ambient temperature on pipeline design and performance should be considered.

2. Investment in $\mathrm{CO}_{2}$ distribution equipment within an 0 il and gas reservoir was not included in this study, but should be rigorously evaluated before this disposal option is seriously considered.

3. Each GCC unit was presumed to have its own pipeline from the power plant to the disposal point. Combining the $\mathrm{CO}_{2}$ flow from several units or power plants into an integrated network may have significant economic benefit.

4. Specific material requirements for $\mathrm{CO}_{2}$ pipelines should be investigated to determine if typical oil and gas pipeline costs are a good proxy for $\mathrm{CO}_{2}$ pipeline costs.

5. The elevation drop in overland pipelines should be included in the evaluation of recompression requirements.

The costs of $\mathrm{CO}_{2}$ control for the GCC power plant should be compared with other control options, such as increased efficiency of energy supply and end use equipment, reforestation, and carbon taxes. The cost of $\mathrm{CO}_{2}$ control for other fossil fuels and combustion technologies should also be evaluated to complete the development of a $\mathrm{CO}_{2}$ control "supply curve" for U.S. electric utilities. Finally, as advances in $\mathrm{CO}_{2}$ recovery technology occur, the results of this study should be updated. 


\section{APPENDIX A}

\section{CALCULATIONS OF CO 2 STORAGE CAPACITY}


APPENDIX A

\section{CALCULATIONS OF $\mathrm{CO}_{2}$ STORAGE CAPACITY}

The general approach for calculating the potential cumulative $\mathrm{CO}_{2}$ storage capacity was presented in Section 3.2. Calculational details are presented in this appendix.

\section{A. $1 \mathrm{CO}_{2}$ STORAGE CAPACITY RESULTING FROM OIL PRODUCTION}

DOE production statistics from 1988 (EIA 1990) for the lower 48 states serve as the base production data for all capacity calculations, as well as the base from which future production is projected (see Table A.1). The crude oil production values include direct oil production and lease condensate production. Lease condensate is oil that condenses from gas streams at wells largely producing natural gas. The DOE crude oil production statistics do not include volumes of liquids recovered at natural gas processing plants. These liquids are included in volumes of natural gas production that are reported by DOE. The cumulative production values presented in Table A.l include all recorded historical U.S. production. Both 1988 and cumulative production volumes are measured at standard petroleum industry conditions $\left(60^{\circ} \mathrm{F}\right.$, $14.73 \mathrm{psia}$ ) and given in stock tank barrels (42 U.S. gal).

The DOE data shown in Table A.1 provide the foundation for estimating $\mathrm{CO}_{2}$ storage capacity resulting from oil production through 1988 . Storage capacity resulting from oil production occurring in the years 1989 through 2030 must come from forecast data. However, DOE data publications do not make pruduction forecasts beyond the year 2010. To incorporate a longer time frame into the analysis, production forecasts developed for use in the National Energy Strategy (NES) (DOE 1991) were used (see Table A.2).

The NES production data for 1988 do not directly match the 1988 DOE production data. This discrepancy is probably due to differences in production data accounting. To compensate for this difference, the production trend for 
IABLE A.1. 1988 DOE Crude 0i1 Production Data (millions of stock tank barrels)

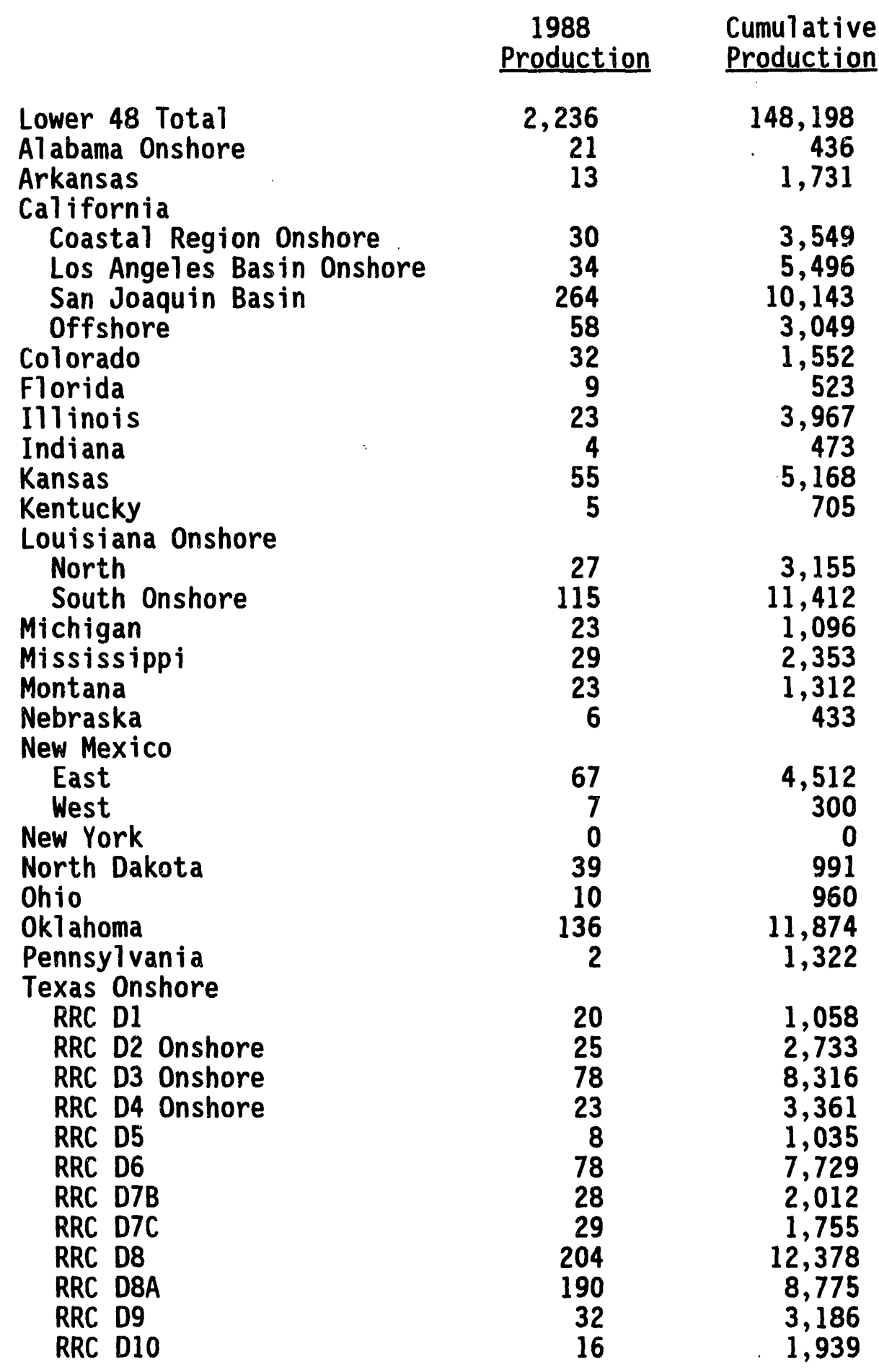


TABLE A.1. (Contd)

\section{$1988 \quad$ Cumulative \\ Production Production}

Utah

West Virginia

Wyoming

Misc.

Gulf of Mexico Louisiana Offshore

Texas Offshore

$\begin{array}{rr}33 & 1,016 \\ 3 & 553 \\ 112 & 5,931 \\ 6 & 329 \\ 290 & 9,268 \\ 29 & 312\end{array}$

Note: Maps identifying those regions that are not states (e.g., RRC D1, which stands for Railroad Commission District) were presented in Figures 3.4 through 3.7.

TABLE A.2. NES Crude 0i1 Production Forecasts (millions of stock tank barrels)

\begin{tabular}{|c|c|c|c|c|c|c|}
\hline & $\begin{array}{l}\text { Daily } \\
\text { Lower } 48\end{array}$ & $\begin{array}{c}\text { Daily } y^{(a)} \\
\text { EOR } \\
\end{array}$ & $\begin{array}{c}\text { Daily }{ }^{(b)} \\
\text { NGL }\end{array}$ & $\begin{array}{l}\text { Daily } \\
\text { Total }\end{array}$ & $\begin{array}{l}\text { Annual } \\
\text { Total } \\
\end{array}$ & $\begin{array}{c}\text { Annual } \\
\text { Change (\%) }\end{array}$ \\
\hline $\begin{array}{l}1985 \\
1986^{(c)} \\
1987(c) \\
1988^{(c)} \\
1989 \\
1990 \\
1995 \\
2000 \\
2005 \\
2010 \\
2015 \\
2020 \\
2025 \\
2030\end{array}$ & $\begin{array}{l}6.7 \\
6.4 \\
6.0 \\
5.7 \\
5.3 \\
5.0 \\
4.5 \\
4.2 \\
3.9 \\
3.4 \\
3.0 \\
2.6 \\
2.0 \\
1.4\end{array}$ & $\begin{array}{l}0.5 \\
0.5 \\
0.5 \\
0.5 \\
0.5 \\
0.5 \\
0.6 \\
0.7 \\
0.9 \\
1.1 \\
1.1 \\
1.0 \\
1.0 \\
0.9\end{array}$ & $\begin{array}{l}1.6 \\
1.6 \\
1.6 \\
1.6 \\
1.6 \\
1.5 \\
1.7 \\
1.9 \\
1.7 \\
1.6 \\
1.6 \\
1.1 \\
0.9 \\
0.6\end{array}$ & $\begin{array}{l}8.8 \\
8.5 \\
8.1 \\
7.8 \\
7.4 \\
7.0 \\
6.8 \\
6.8 \\
6.5 \\
6.1 \\
5.7 \\
4.7 \\
3.9 \\
2.9\end{array}$ & $\begin{array}{l}3219 \\
3091 \\
2964 \\
2836 \\
2701 \\
2555 \\
2482 \\
2482 \\
2373 \\
2227 \\
2081 \\
1716 \\
1424 \\
1059\end{array}$ & $\begin{array}{c}-- \\
- \\
- \\
- \\
-0.048 \\
-0.054 \\
-0.029 \\
0.000 \\
-0.044 \\
-0.062 \\
-0.066 \\
-0.175 \\
-0.170 \\
-0.256\end{array}$ \\
\hline
\end{tabular}

(a) EOR refers to enhanced oil recovery.

(b) NGL refers to natural gas 1 iquids (includes lease condensates).

(c) The NES presented data for 1985, 1989, 1990, 1995, 2000, etc. Production values for 1986,1987 , and 1988 are interpolated.

the years 1988 through 2030 from the NES was applied to the 1988 DOE production data. The application of the NES trend to the DOE data on a national production basis is shown in Figure A.1. Table A.3 applies the NES production trend (shown in Table A.2 as the percentage of annual change) to the 1988 DOE 


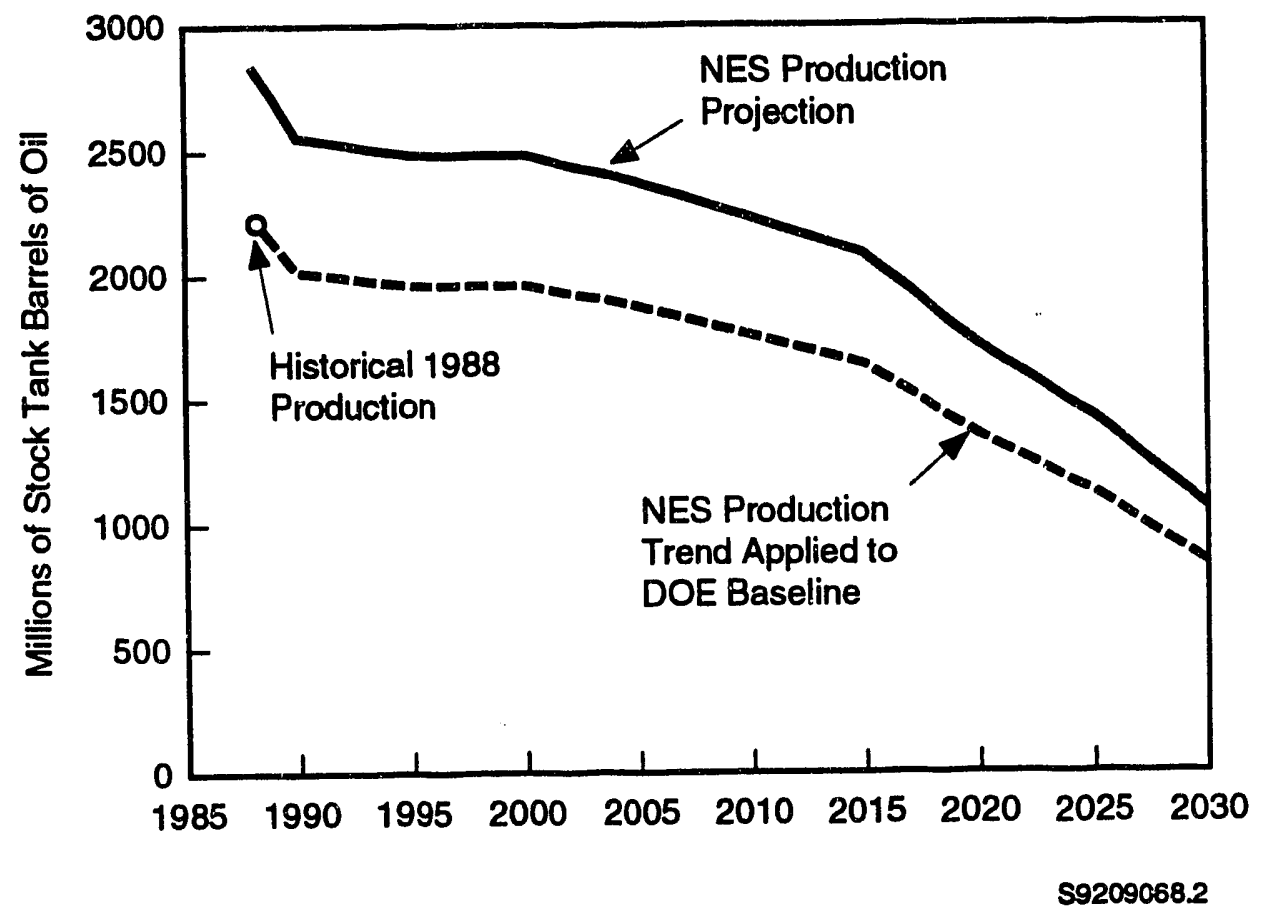

FIGURE A.1. Application of NES Production Forecast to 1988 DOE Production Data

production data. The application of this trend assumes that all geographical regions in the lower 48 states would undergo the same relative increases and decreases in production. In all likelihood, there would be some regional shifting over time; however, regional projections through the year 2030 are unavailable.

Based on the calculated regional production data shown in Table A.3 and the cumulative production data (through 1988) shown in Table A.1, cumulative production by year through the year 2030 was calculated (see Table A.4).

The gas component of oil production is accounted for within the gas production estimates; thus for every stock tank barre 1 produced, 42 gal of void is created within the reservoir. This assumes that $0 i 1$ is a non-compressible fluid. That is, reservoir pressure does not cause a gallon of surface oil to have significantly less volume within the reservoir. In reality, there is 


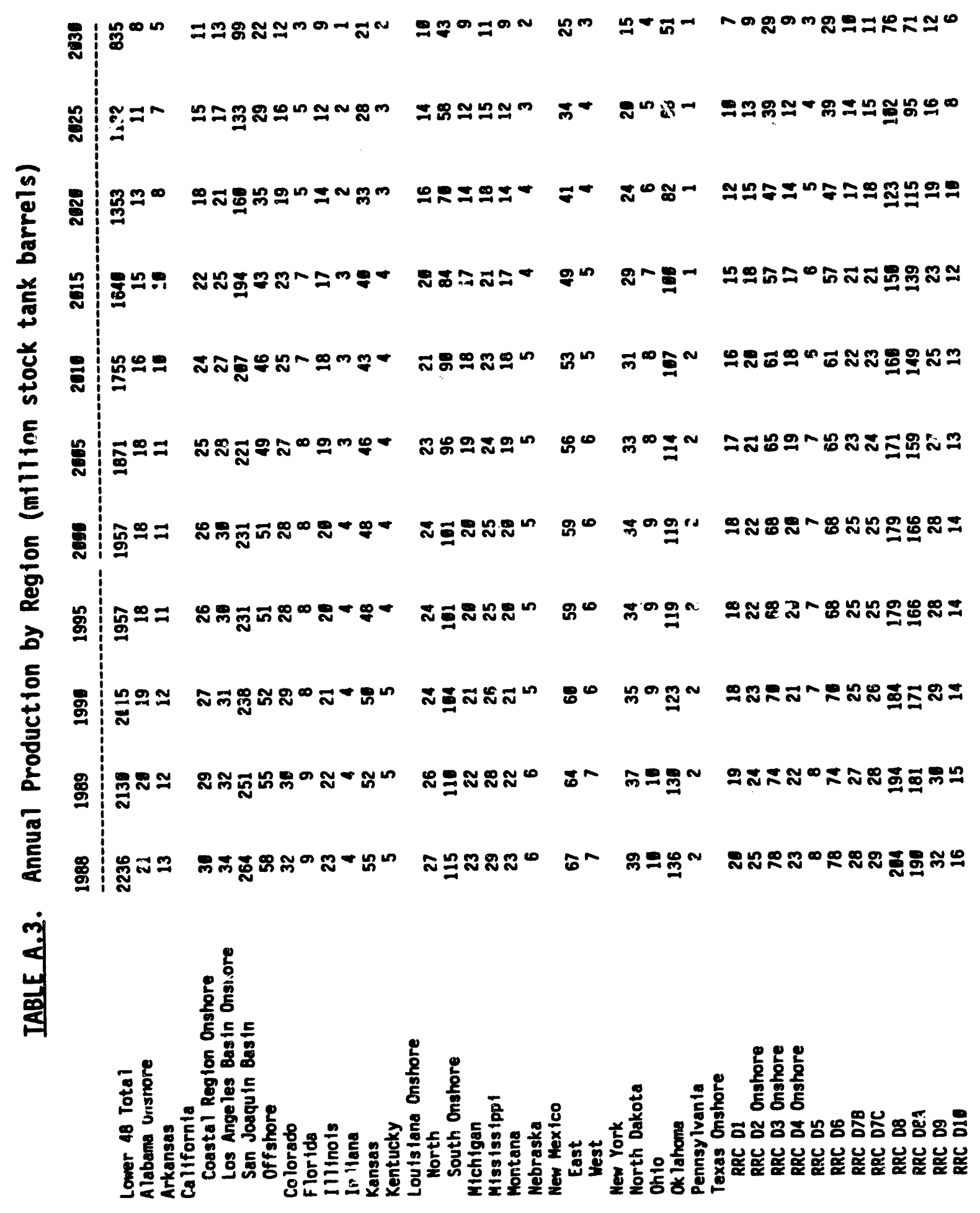

A. 5 


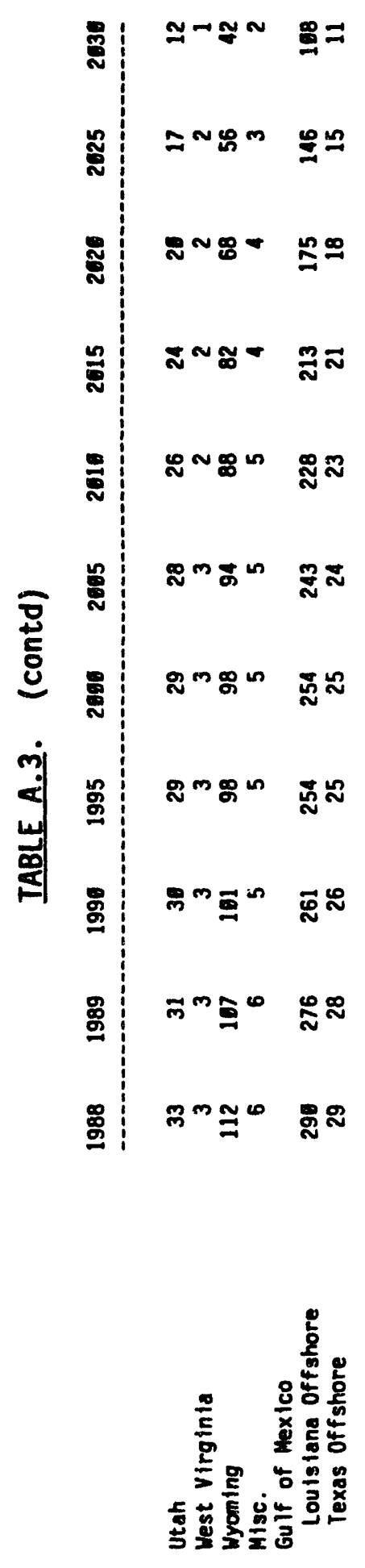

A. 6 


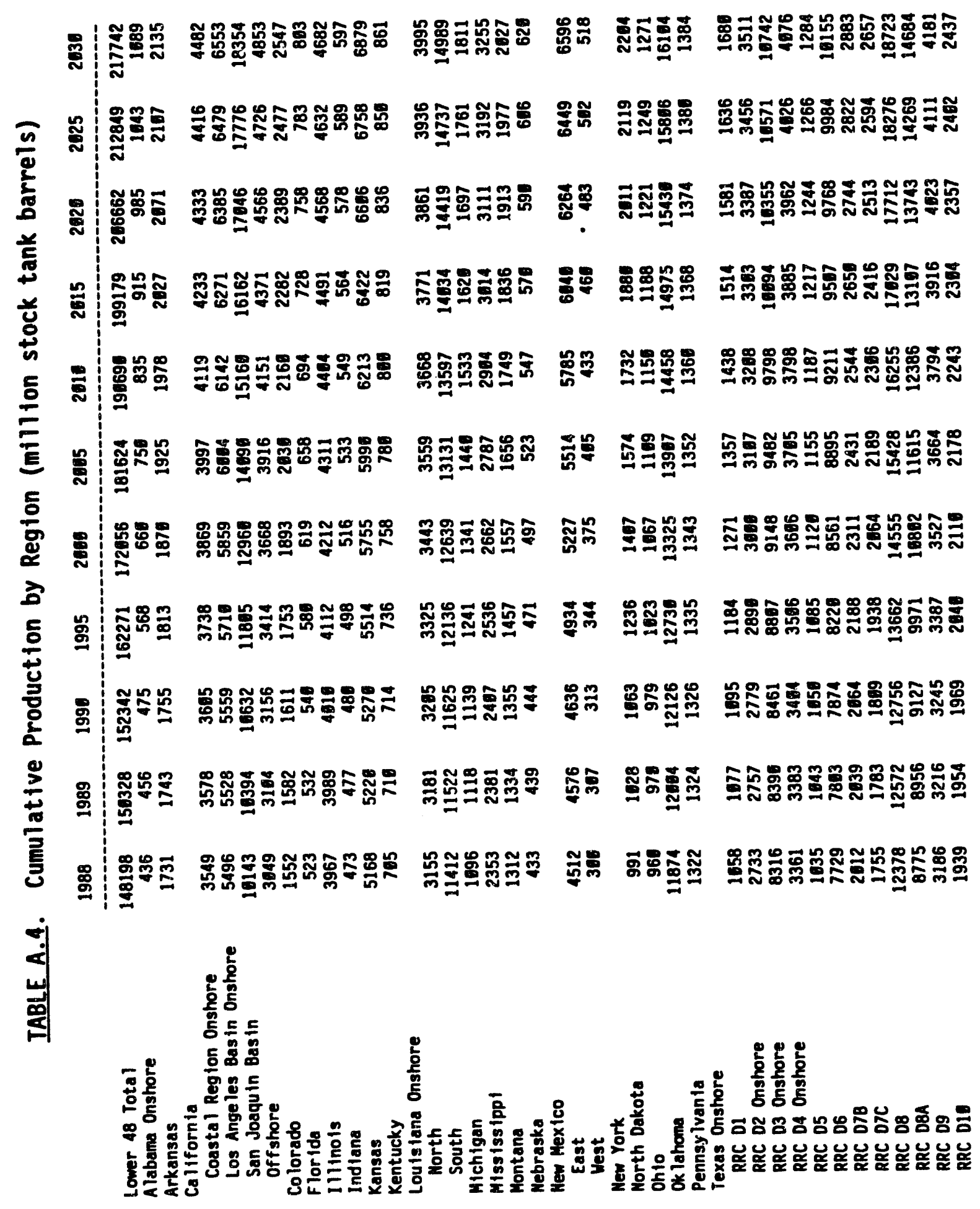

A. 7 


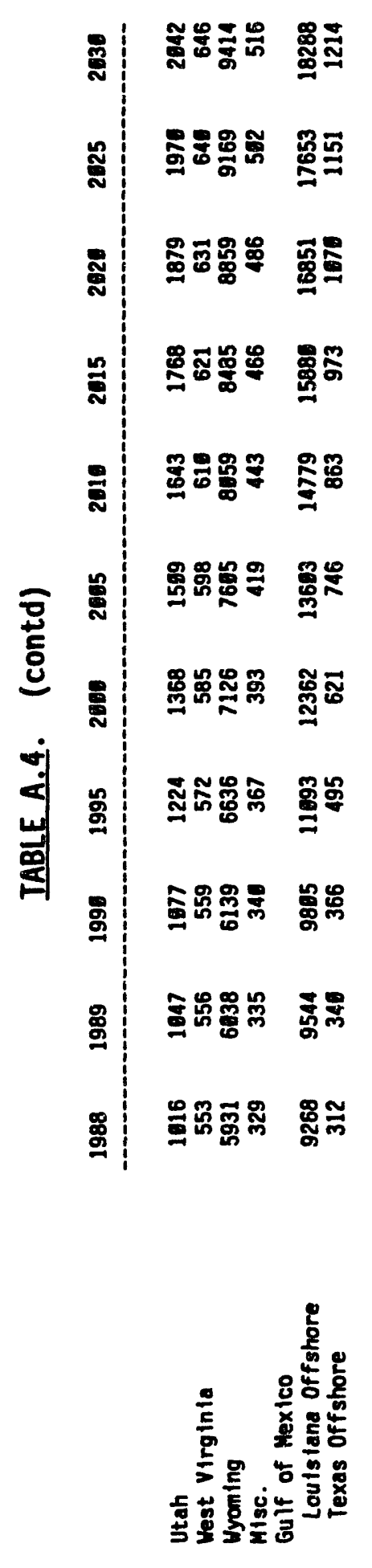

A. 8 
some compressibility. In addition, as the oil is produced, the reservoir overburden pressure, typically 1 psi per $\mathrm{ft}$ of depth, causes the void volume to shrink slightly.

The next step of the analysis was to develop a profile of depth versus capacity for each region shown in Table A.4. This profile is important because pressure and temperature change dramatically with depth, and the amount of $\mathrm{CO}_{2}$ that can be stored is highly dependent on the storage temperature and pressure. A more simplified approach of assuming an average temperature and pressure is not appropriate, as the relationship between $\mathrm{CO}_{2}$ storage volume and temperature and pressure is not linear.

To develop the depth profile, producing rate (i.e., barrels per year) versus depth was assumed to be a good proxy for available storage volume by depth. This assumption implies that if 10 barrels of oil are produced above $5000 \mathrm{ft}$ in a year and 90 barrels are produced below $5000 \mathrm{ft}$ in the same year, then $10 \%$ of all available storage volume exists above $5000 \mathrm{ft}$. This assumption appears to be reasonable although imperfect, as production versus depth undoubtably changes over time with early historical production focused on shallow reservoirs and current production moving toward deeper and deeper reservoirs. As DOE's evaluation of producing rate versus depth is published intermittently, the most recent DOE analysis of 1974 data (EIA 1978) was selected as the basis for this analysis. Data summarized from the DOE analysis are presented in Table A.5. Because the DOE analysis of 1974 data uses slightly different regions than the 1988 DOE production data (see Table A.1), it was necessary to "map" the 1974 regional data into the 1988 set of regions. The notes in the last coiumn of Table A.5 detail this mapping exercise.

The producing rate data in Table A.5 were combined with the cumulative production data presented in Table A.4 to calculate cumulative storage volume 


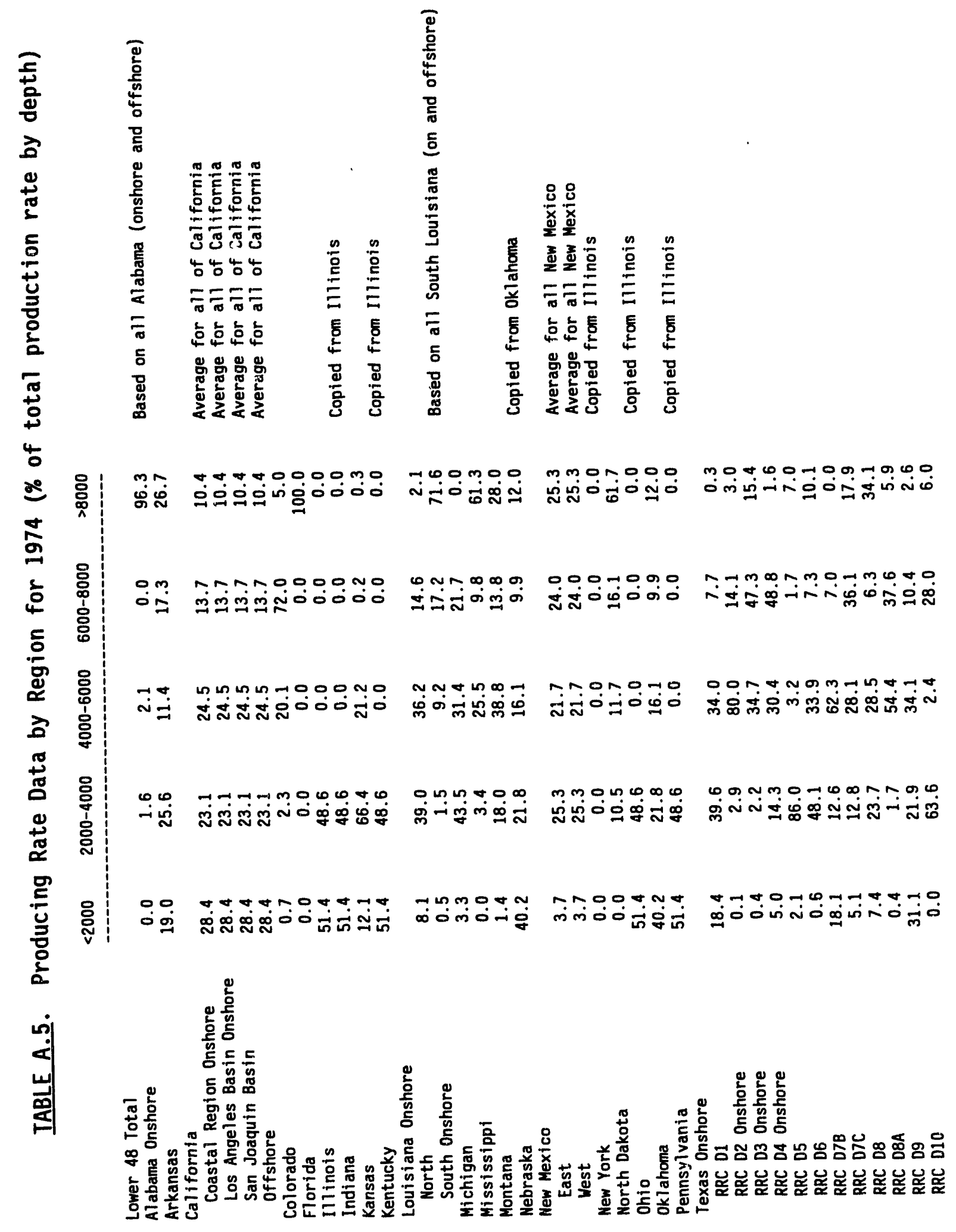

A. 10 

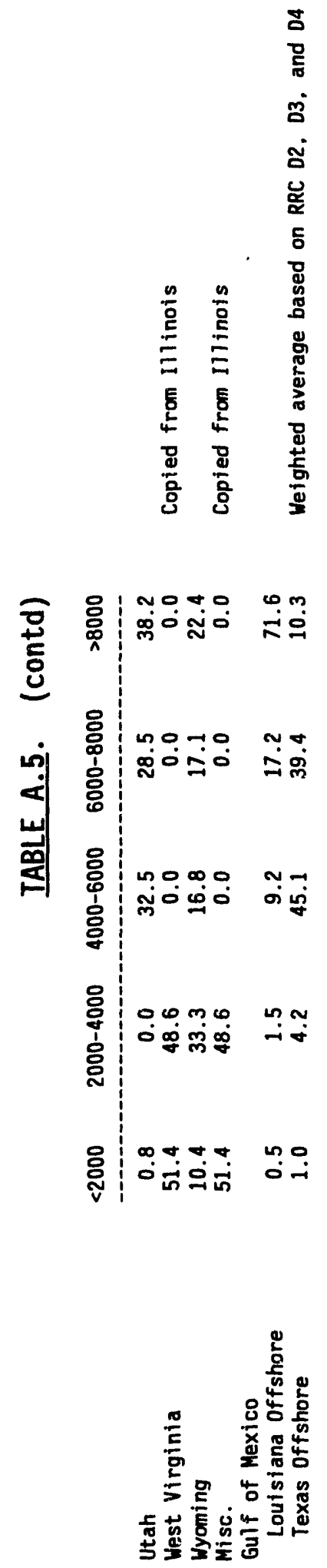

A. 11 
by region, year, and depth. The following is an example of the type and form of data generated from this calculation:

Texas RRC D1; Year 2030

\begin{tabular}{cc}
\hline Depth $^{(a)}$ & Volume \\
\hline$<2000$ & 1.4 \\
$2000-4000$ & 3.0 \\
$4000-6000$ & 2.5 \\
$6000-8000$ & 0.6 \\
$>8000$ & 0.0
\end{tabular}

(a) $\mathrm{ft}$
(b) millions of stock tank barrels
per year (at $42 \mathrm{gal}$ per barre1)

Next, an average temperature and an average pressure gradient were assumed and used to estimate reservoir temperature and pressure at each depth interval. Worldwide, reservoir pressure--the pressure in the pores--is normally about equal to the static pressure caused by a column of fluid that extends to the surface. The water gradient is usually about 0.433 to $0.5 \mathrm{psi} / \mathrm{ft}$ (Amyx, Bass and Whiting 1960; S7ider 1983). For this analysis, a conservative pressure gradient of $0.433 \mathrm{psi} / \mathrm{ft}$ is assumed. For temperature calculations, a mean surface temperature of $60^{\circ} \mathrm{F}(519.7 \mathrm{R})$ is assumed, with a gradient of $1^{\circ} \mathrm{F}$ per $100 \mathrm{ft}$. Based on these gradients, the example data for the Texas RRC D1 region (year 2030) can be enhanced to create the following depth profile:

\begin{tabular}{|c|c|c|c|}
\hline \multicolumn{4}{|c|}{ Year $2030^{(a)}$} \\
\hline Depth (feet) & Volume $e^{(0)}$ & Temperature (R) & Pressure (psia) \\
\hline $\begin{array}{c}<2000 \\
2000-4000 \\
4000-6000 \\
6000-8000 \\
>8000\end{array}$ & $\begin{array}{r}7.6 \times 10^{6} \\
17.0 \times 10^{6} \\
14.0 \times 10^{6} \\
3.4 \times 10^{6} \\
0.0\end{array}$ & $\begin{array}{l}529.7 \\
549.7 \\
569.7 \\
589.7 \\
609.7\end{array}$ & $\begin{array}{r}447.73 \\
1313.73 \\
2179.73 \\
3045.73 \\
3911.73\end{array}$ \\
\hline
\end{tabular}

(a) Data are assumed to represent depths of 1000,3000,5000,7000, and $9000 \mathrm{ft}$, which are the midpoints of the indicated depth intervals.

(b) Converted from millions of stock tank barrels per year (at 42 gal per barrel) to annual cubic feet using $5.615 \mathrm{ft}^{3} /$ barre 1 . 
For each depth interval, year and region, a theoretical $\mathrm{CO}_{2}$ storage capacity can be estimated from the above data using the following equation:

$$
\mathrm{CO}_{2}, \mathrm{ft}^{3}=358.4 \mathrm{n}=358.4 \mathrm{P}_{\mathrm{R}} \mathrm{V}_{\mathrm{R}} / \mathrm{z}_{\mathrm{R}} \mathrm{RT} \mathrm{R}_{\mathrm{R}}
$$

where: $n=1 \mathrm{~b} \cdot \mathrm{mole}$ of $\mathrm{CO}_{2}$ at $32^{\circ} \mathrm{F}, 14.73$ psia

$P=$ reservoir pressure, psia

$V=$ reservoir volume, $\mathrm{ft}^{3}$

$z=$ compressibility factor

$R=$ gas constant $=10.731 \mathrm{~b} \cdot \mathrm{mole}-\mathrm{R} / \mathrm{psia}-\mathrm{ft}^{3}$

$T=$ reservoir temperature, degrees Rankine

The compressibility factor, "z-factor," changes dramatically with temperature and pressure as illustrated by the following data:

\begin{tabular}{|c|c|c|}
\hline \multicolumn{3}{|c|}{$\mathrm{CO}_{2}$ Compressibility Data } \\
\hline$z$-factor & Temperature (R) & Pressure (psia) \\
\hline $\begin{array}{l}0.814 \\
0.234 \\
0.365 \\
0.442 \\
0.543\end{array}$ & $\begin{array}{l}529.7 \\
549.7 \\
569.7 \\
589.7 \\
609.7\end{array}$ & $\begin{array}{r}447.73 \\
1313.73 \\
2179.73 \\
3045.73 \\
3911.73\end{array}$ \\
\hline
\end{tabular}

Table A.6 presents a summary of the theoretical $\mathrm{CO}_{2}$ storage capacity by region and year, summed over ali depth intervals.

\section{A.2 $\mathrm{CO}_{2}$ STORAGE CAPACITY RESULTING FROM NATURAL GAS PRODUCTION}

As with the oil scenario, (a) storage capacity generated by natural gas production is based on DOE production statistics from 1988 (EIA 1990) for the lower 48 states (see Table A.7). The DOE natural gas production values

(a) The phrase "oil scenario" refers to the analysis (presented in the preceding section of this paper) of $\mathrm{CO}_{2}$ storage capacity resulting from crude oil production. 


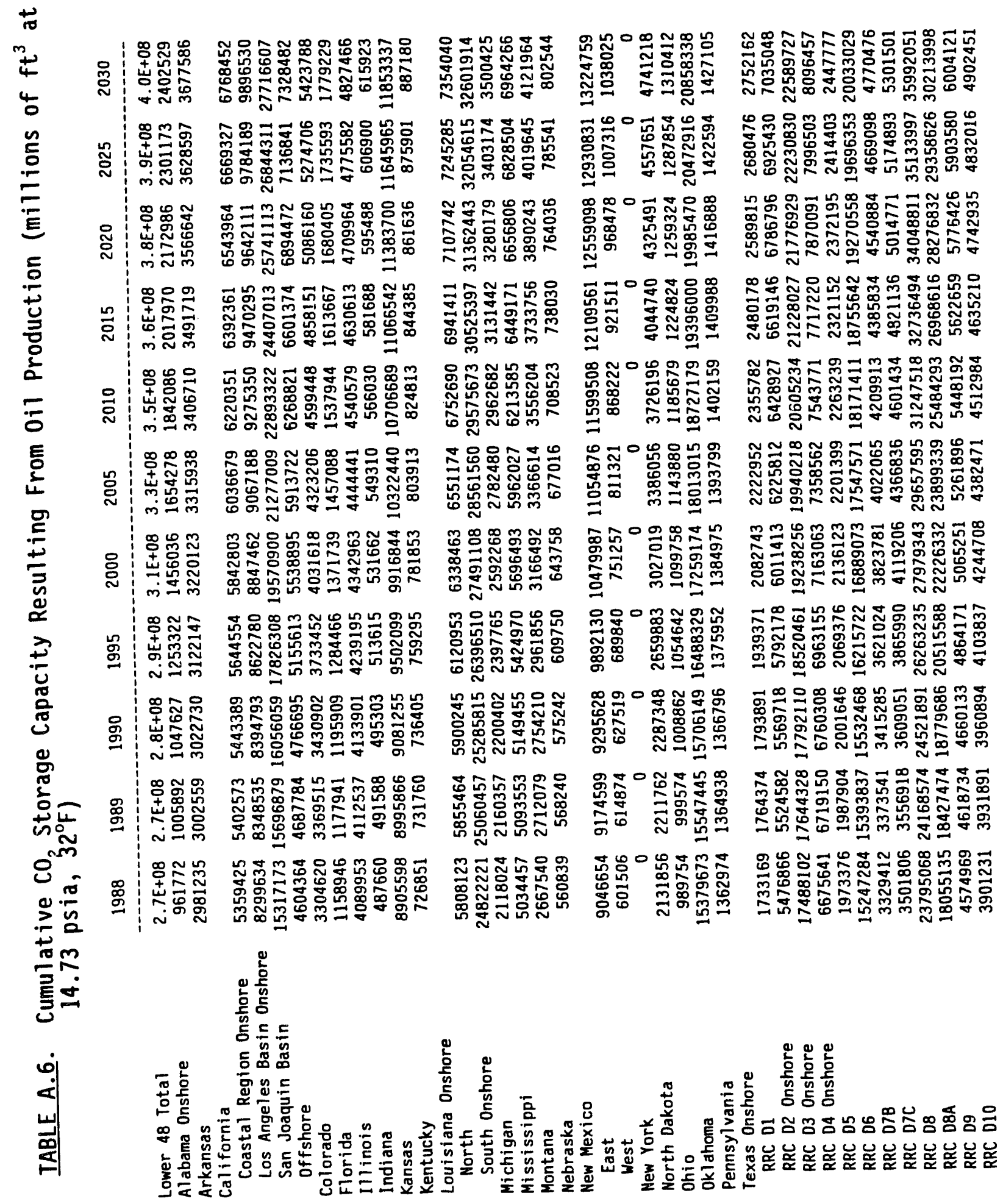




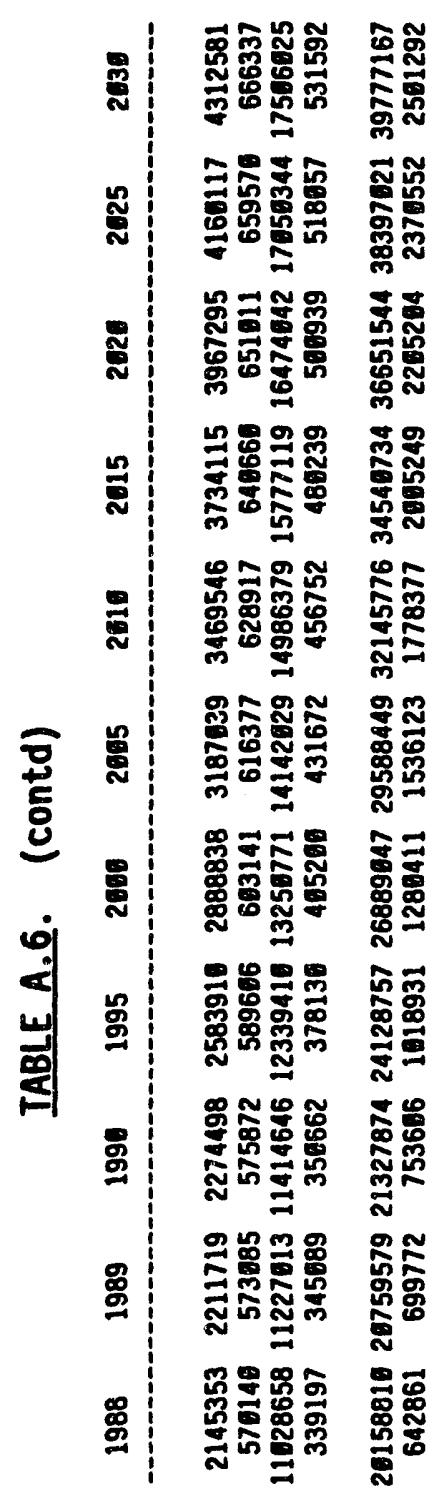

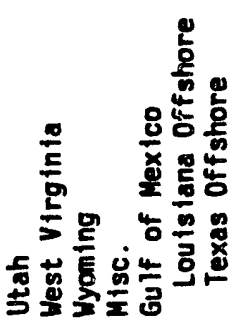

A. 15 
TABLE A.7. 1988 DOE Gas Production Data (billions of standard cubic feet)

Lower 48 Total
Llabama Onshore
Arkansas
California
Coastal Region Onshore
Los Angeles Basin Onshore
San Joaquin Basin
Offshore
Colorado
Florida
IIlinois
Indiana
Kansas
Kentucky
Louisiana Onshore
North
South Onshore
Michigan
Mississippi
Montana
Nebraska
New Mexico
East
West
New York
North Dakota
Ohio
Oklahoma
Pennsylvania
Texas Onshore
RRC D1
RRC D2 Onshore
RRC D3 Onshore
RRC D4 Onshore
RRC D5
RRC D6
RRC D7B
RRC D7C
RRC D8
RRC D8A
RRC D9
RRC Dlo

Production Production
754,767

1,230

5,703

5,359

4,369

17,566

2,145

6,404

540

0

28,178

3,926

27,289

92,697

3,052

7,778

1,465

416

367

20,090

15,929

727

$69 \quad 1,452$

$132 \quad 6,834$

2,183

162

70,861

10,348

168

353

557

1,244

177

433

131

294

826

101

126

579
4,272
23,312
52,061
54,132
4,390
21,199
4,412
9,397
40,927
5,883
4,934
47,972 
IABLE A.7. (Contd)

\begin{tabular}{lcc} 
& $\begin{array}{c}1988 \\
\text { Production }\end{array}$ & $\begin{array}{r}\text { Cumulative } \\
\text { Production }\end{array}$ \\
\cline { 2 - 3 } & 60 & 2,935 \\
Utah Virginia & 182 & 16,661 \\
West Virginia & 581 & 14,620 \\
Wyoming & 32 & 2,285 \\
Misc. & & \\
Gulf of Mexico & 3,479 & 96,914 \\
Louisiana Offshore & 1,345 & 14,519 \\
Texas Offshore & &
\end{tabular}

Note: Maps identifying those regions that are not states (e.g., RRC D1, which stands for Railroad Commission District 1) were presented in Figures 3.4 through 3.7.

include the energy equivalent of natural gas liquids recovered at natural gas processing plants. The production values do not include lease condensates that are accounted for in oil production volumes reported by DOE. The cumulative production values presented in Table A.7 include all recorded historical U.S. production. Both 1988 and cumulative production volumes are measured at standard conditions (i.e., 60 $\mathrm{F}, 14.73$ psia).

The DOE data shown in Table A.7 provide the foundation for estimating $\mathrm{CO}_{2}$ storage capacity. Similar to the approach used in the oil scenario, estimates of storage capacity resulting from natural gas production from 1989 through 2030 are based on NES forecast data (DOE 1991). These data are presented in Table A.8.

The production trend for the years 1988 through 2030 from the NES was applied to the 1988 DOE production data (see Figure A.2) on a national production basis. Table A.9 applies the NES production trend (shown in Table A.8 as the percentage of annual change) to the 1988 DOE production data.

Based on the calculated regional production data shown in Table A.9 and the cumulative production data (through 1988) shown in Table A.7, cumulative production by year through the year 2030 was calculated (see Table A.10). All figures in Tables A.9 and A.10 are expressed in billion standard cubic feet. 
IABLE A.8. NES Natural Gas Production Forecasts (trillions of standard cubic feet)

Annual
Lower 48 $\begin{gathered}\text { Annual } \\ \text { Change (\%) }\end{gathered}$

$\begin{array}{llc}1985 & 16.4 & -.- \\ 1986^{(a)} & 16.7 & -.- \\ 1987^{(a)} & 16.9 & --- \\ 1988^{(a)} & 17.1 & 0.013 \\ 1989 & 17.3 & 0.012 \\ 1990 & 17.4 & 0.006 \\ 1995 & 18.8 & 0.080 \\ 2000 & 20.8 & 0.106 \\ 2005 & 19.5 & -0.063 \\ 2010 & 18.5 & -0.051 \\ 2015 & 19.4 & 0.049 \\ 2020 & 18.4 & -0.052 \\ 2025 & 18.1 & -0.016 \\ 2030 & 16.5 & -0.088\end{array}$

(a) The NES presented data for the years 1985, 1989, 1990, 1995, 2000 , etc. Production values for 1986,1987 , and 1988 are interpolated.

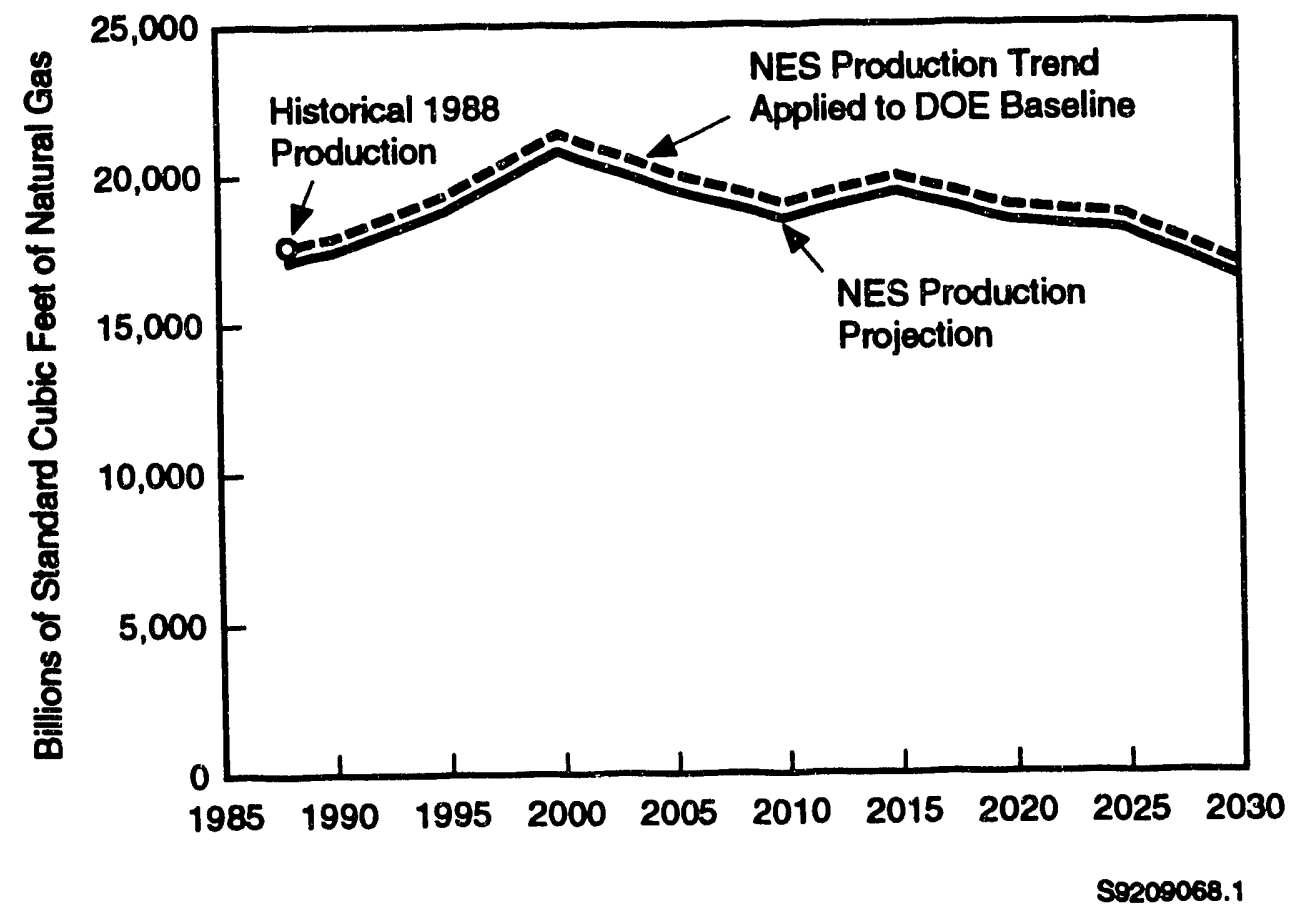

FIGURE A.2. Application of NES Production Forecast to 1988 DOE Natural Gas Production Data 


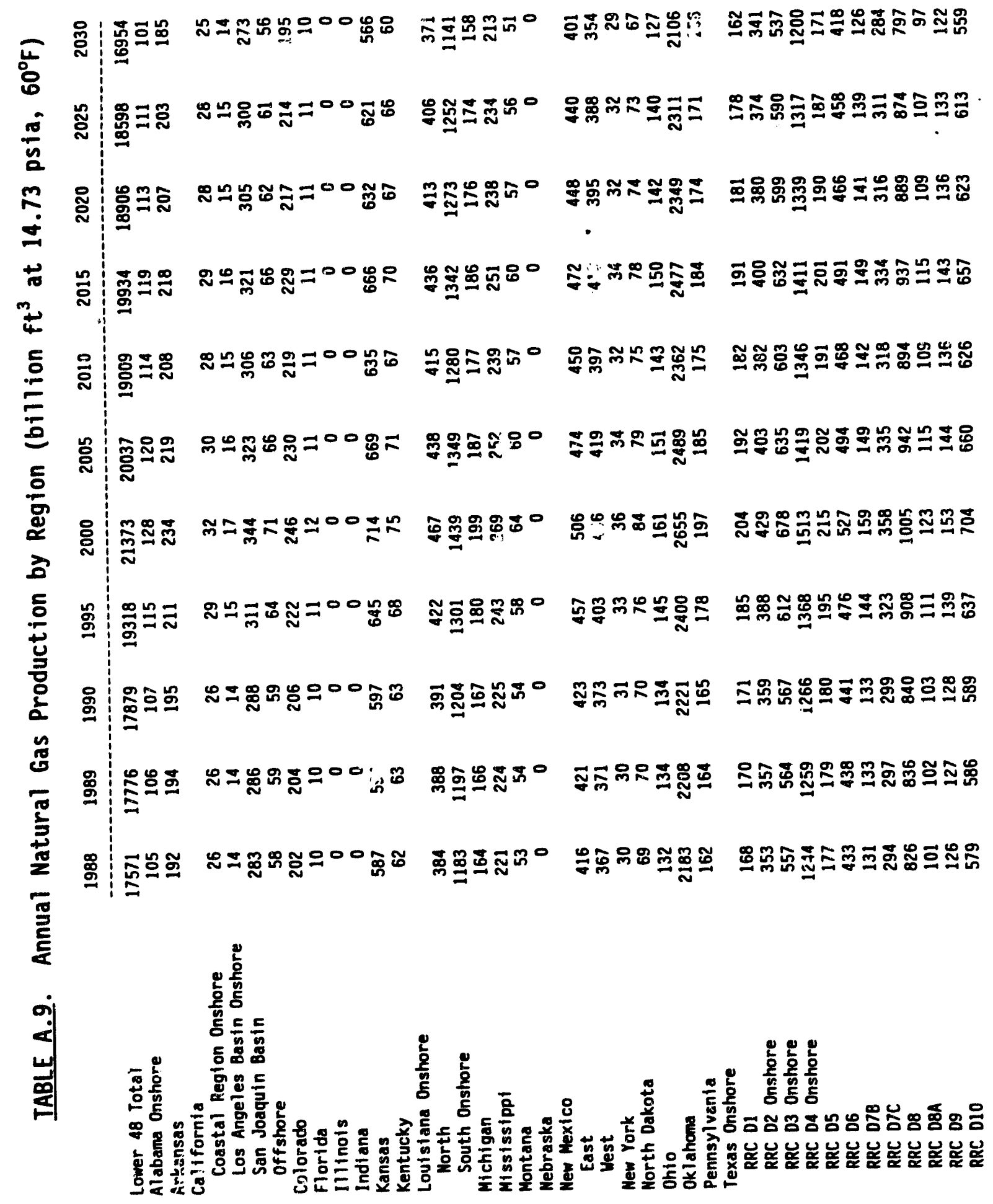




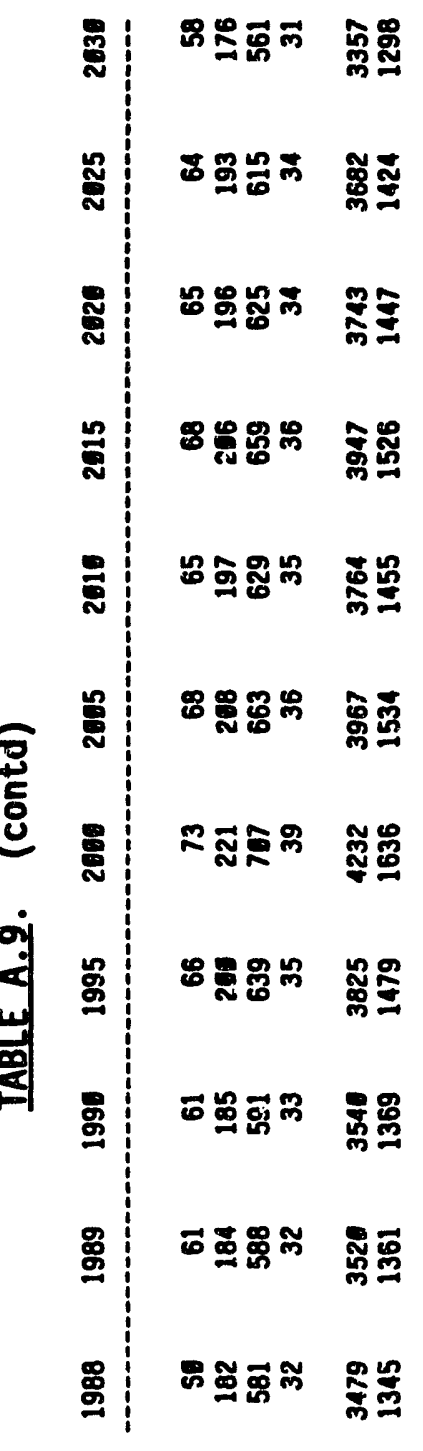

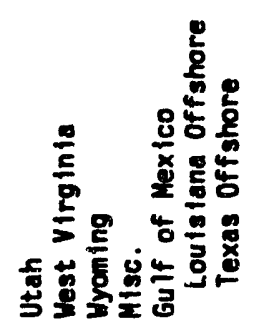




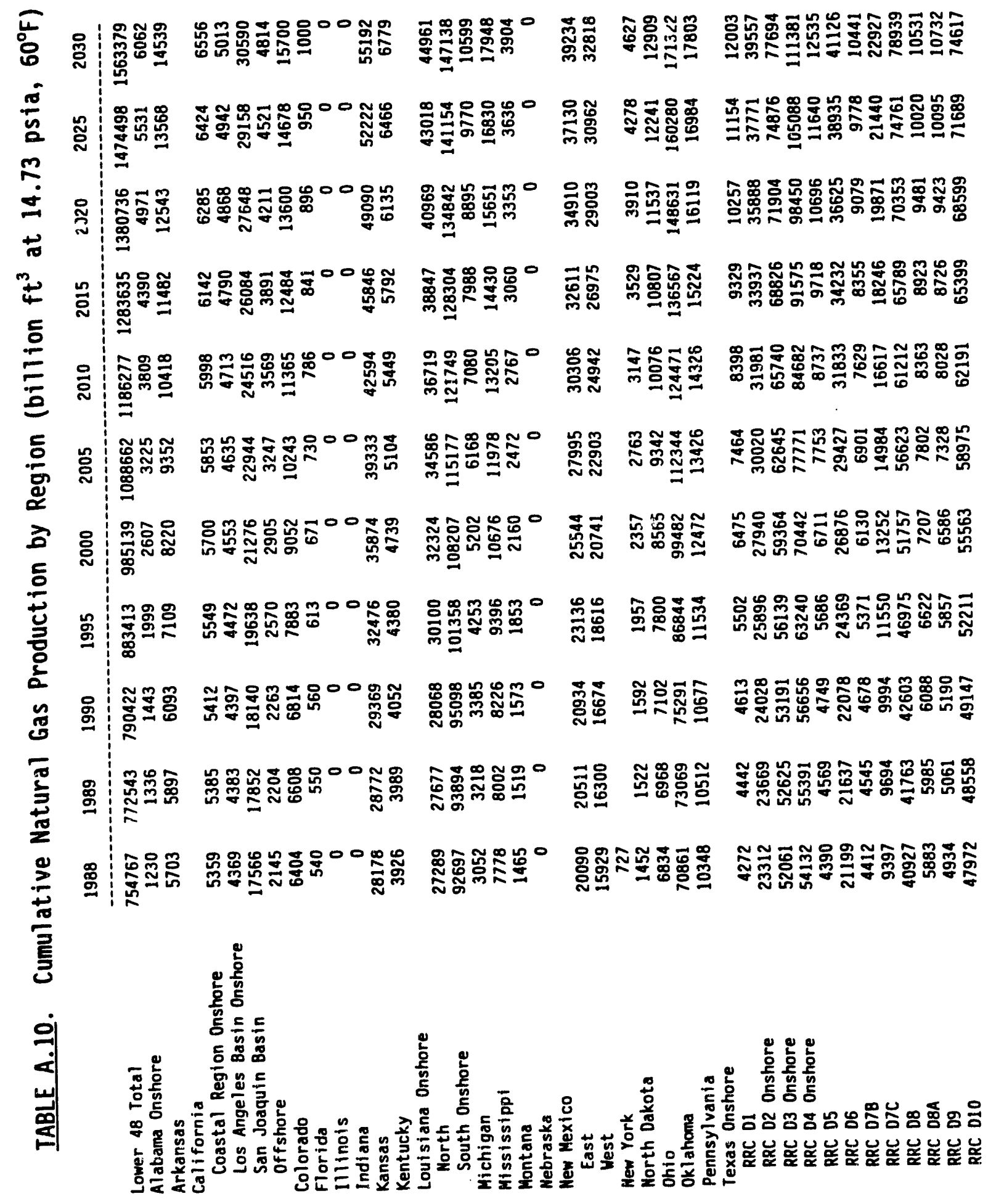




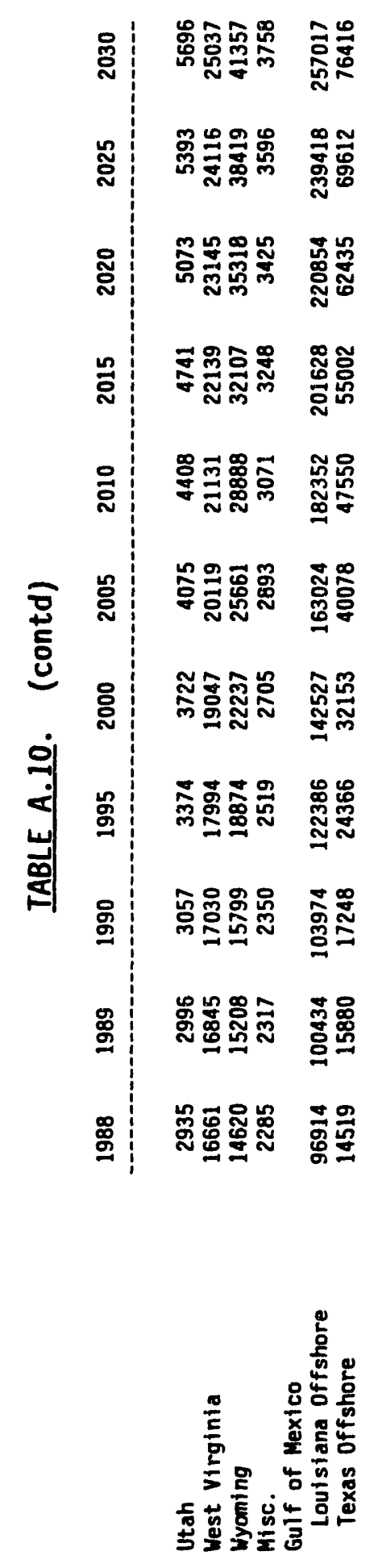


Similar to the oil scenario, the next step of the analysis was to develop a profile of depth versus capacity for each region. Unfortunately, a producing rate profile similar to that presented in Table A.5 for crude 0 il is not available for gas. Consequently, the crude oil profile was assumed to apply equally well to natural gas. Implicit in this assumption is that gas will be produced at the same general depths and have a production volume that is proportional to the volume of crude oil produced at that same depth. This implication is not entirely correct, but should be adequate for the purposes of this analysis.

The producing rate data in Table A.5 were combined with the cumulative production data presented in Table A.10 to calculate cumulative storage volume by region, year, and depth. The following is an example of the type and form of data generated from this calculation.

\section{Texas RRC D1; Year 2030}

\begin{tabular}{|c|c|c|}
\hline Dep & (a) & Volume ${ }^{(b)}$ \\
\hline $\begin{array}{r}<20 \\
2000 \\
4000 \\
6000 \\
>80\end{array}$ & $\begin{array}{l}000 \\
000 \\
000 \\
0\end{array}$ & $\begin{array}{r}29.8 \\
64.2 \\
55.1 \\
12.5 \\
0.5\end{array}$ \\
\hline $\begin{array}{l}\text { (a) } \\
\text { (b) }\end{array}$ & & $60^{\circ} \mathrm{F}$ \\
\hline
\end{tabular}

Following this, the average temperature gradient of $1^{\circ} \mathrm{F}$ per $100 \mathrm{ft}$ and the average pressure gradient of $0.433 \mathrm{psi} / \mathrm{ft}$ were applied to the depth profile.

Natural gas production is expressed in cubic feet at standard conditions. Natural gas is highly compressible; consequently, unlike the oil scenario where the production of a barrel of oil was assumed to create one barrel (i.e., $42 \mathrm{gal}$ ) of void volume in the reservoir, a standard $\mathrm{ft}^{3}$ of gas produced at the surface creates a much smaller reservoir void volume because the gas is highly compressed while in its original reservoir space. The compressibility of the natural gas is adjusted for through the following equation:

$$
V_{R}=P_{s c} V_{s c} z_{R} T_{R} / z_{s c} T_{s c} P_{R}
$$


where: $V_{R}=$ reservoir void volume, $\mathrm{ft}^{3}$

$V_{s c}=$ gas volume at standard conditions, $\mathrm{ft}^{3}$

$P_{R}=$ reservoir pressure, psia

$P_{\text {sc }}=$ standard pressure, 14.73 psia

$T_{R}=$ reservoir temperature, Rankine

$T_{s c}=$ standard temperature, 520 Rankine

$Z_{R}=$ compressibility factor at $T_{R}$ and $P_{R}$

$z_{s c}=$ compressibility factor at $520 R$ and 14.73 psia $=1$

Because reservoir temperature, pressure, and, consequently, the compressibility factor change for each depth interval, the reservoir void volume must be independently calculated for each depth, year and region.

While the compressibility factors for $\mathrm{CO}_{2}$ can be obtained from tables published in a variety of chemical engineering handbooks, compressibility factors for natural gas must be calculated. Natural gas is a blend of hydrocarbon gases that varies from reservoir to reservoir with an infinite number of gas compositions possible. As a result, standard tables for all blends of natural gas are not available.

To calculate natural gas compressibility factors, the pseudocritical temperature and pressure for the gas must first be calculated. (a) This calculation can be accomplished using the following relationships:

$$
\begin{aligned}
& \text { Pseudocritical pressure }=P_{p c}=709.604-58.718 * \text { gas gravity } \\
& \text { Pseudocritical temperature }=T_{p c}=170.491-307.344 * \text { gas gravity }
\end{aligned}
$$

(a) Pseudocritical temperature and pressure relate to the physical characteristics of the constituent hydrocarbons in the natural gas and the nearness of the actual temperature and pressure to the critical point of each respective constituent hydrocarbon. For further explanation, the reader is referred to texts (e.g., Ikoku 1984 or McLain 1973) that discuss multi-phase gas systems. 
The gas gravity (i.e., the molecular weight of the gas relative to the molecular weight of the air) is assumed to be 0.7 , which is representative of many natural gases. This assumption results in pseudocritical properties of

$$
\begin{aligned}
& P_{p c}=668.5 \\
& T_{p c}=385.6
\end{aligned}
$$

The next step is to calculate the pseudo-reduced pressure and temperature:

$$
\begin{aligned}
& P_{p r}=P / P_{p c} \\
& T_{p r}=T / T_{p c}
\end{aligned}
$$

$P$ and $T$ are the absolute pressure (psia) and absolute temperature (Rankine) at which the $z$-factor is required (Ikoku 1984). These pseudo-reduced values can be indexed on a chart to find the z-factor (see Figure A.3). The z-factors for natural gas with a specific gravity of 0.7 at each depth interval (and corresponding absolute temperatures and pressures) are as follows:

\section{Natural Gas Compressibility Data}

\begin{tabular}{ccc}
\multirow{2}{*}{-factor } & Temperature (R) & Pressure (psia) \\
\cline { 3 - 3 } 0.91 & 529.7 & 447.73 \\
0.80 & 549.7 & 1313.73 \\
0.76 & 569.7 & 2179.73 \\
0.81 & 589.7 & 3045.73 \\
0.85 & 609.7 & 3911.73
\end{tabular}




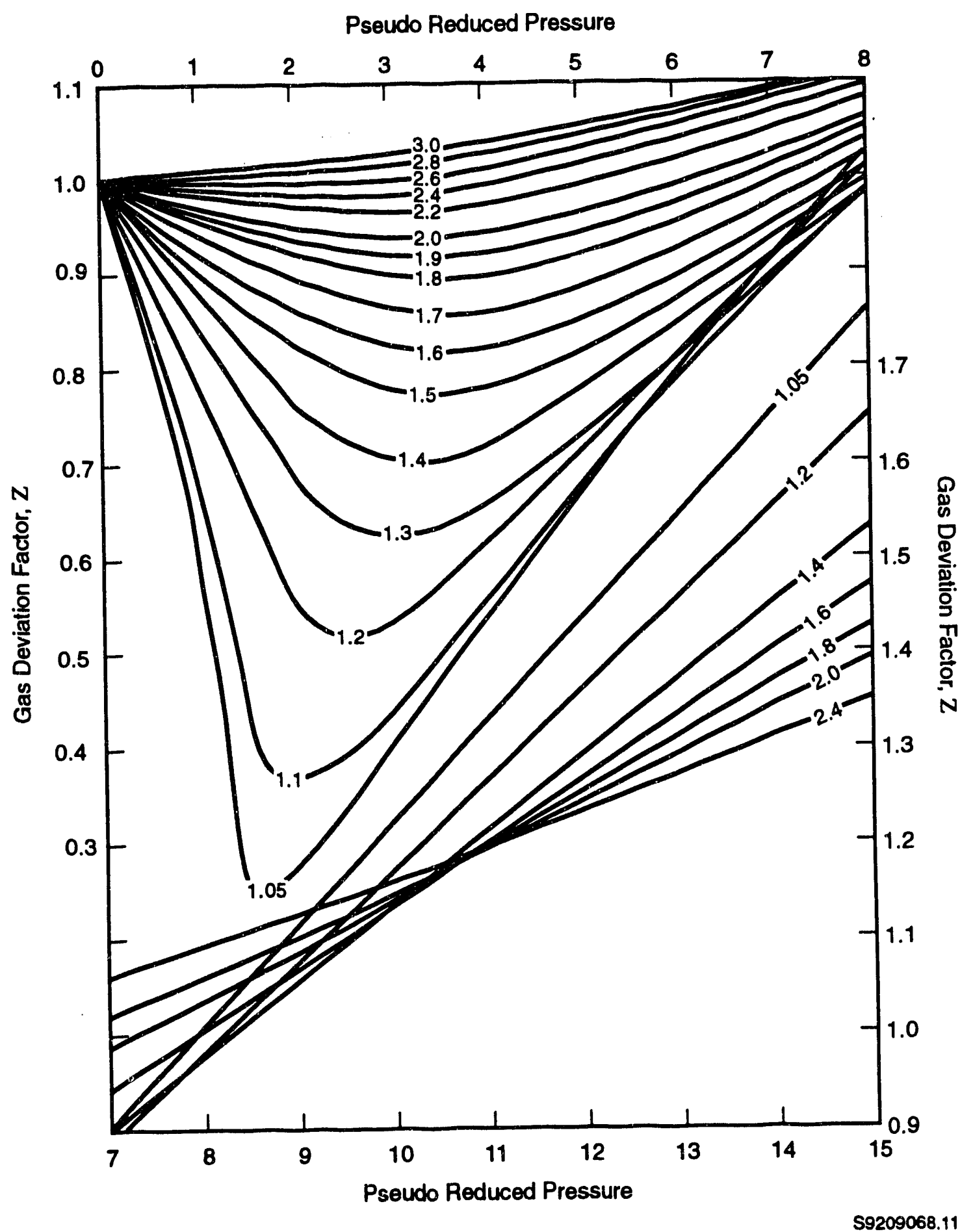

FIGURE A.3. Z-factor chart for natural gases (after Ikoku 1984) 
Based on the calculated reservoir void volume (i.e., $\mathrm{V}_{\mathrm{R}}$ ), the volume of $\mathrm{CO}_{2}$ (measured at $32^{\circ} \mathrm{F}$ and $14.73 \mathrm{psia}$ ) that can stored in the void volume can be calculated.

$$
\mathrm{CO}_{2}, \mathrm{ft}^{3}=358.4 \mathrm{n}=358.4 \mathrm{P}_{\mathrm{R}} \mathrm{V}_{\mathrm{R}} / \mathrm{Z}_{\mathrm{R}} \mathrm{RT} \mathrm{R}_{\mathrm{R}}
$$

where: $n=1 \mathrm{~b} \cdot$ mole of $\mathrm{CO}_{2}$ at $32^{\circ} \mathrm{F}, 14.73 \mathrm{psia}$

$P_{R}=$ reservoir pressure, psia

$V_{R}=$ reservoir void volume, $\mathrm{ft}^{3}$

$Z_{R}=$ compressibility factor at $T_{R}$ and $P_{R}$

$T_{R}=$ reservoir temperature, Rankine

$R=$ gas constant $=10.73 \mathrm{lb} \cdot \mathrm{mole}-\mathrm{R} / \mathrm{psia}-\mathrm{ft}^{3}$

As described in the oil scenario discussion, the compressibility factors for $\mathrm{CO}_{2}$ are as follows:

\begin{tabular}{|c|c|c|}
\hline \multicolumn{3}{|c|}{$\mathrm{CO}$ Comoressibility } \\
\hline$z$-factor & Pressure (psia) & Temperature $(R)$ \\
\hline $\begin{array}{l}0.814 \\
0.234 \\
0.365 \\
0.442 \\
0.543\end{array}$ & $\begin{array}{l}529.7 \\
549.7 \\
569.7 \\
589.7 \\
609.7\end{array}$ & $\begin{array}{r}447.73 \\
1313.73 \\
2179.73 \\
3045.73 \\
3911.73\end{array}$ \\
\hline
\end{tabular}

Table A.11 presents a summary of the theoretical $\mathrm{CO}_{2}$ storage capacity by region and year summed over all depth intervals.

\section{A.3 TOTAL $\mathrm{CO}_{2}$ STORAGE CAPACITY RESULTING FROM ALL PETROLEUM PRODUCTION}

The estimates for $\mathrm{CO}_{2}$ storage capacity resulting from crude oil production (see Table A.6) and natural gas (see Table A.11) can be summed to estimate a total theoretical $\mathrm{CO}_{2}$ storage capacity resulting from all petroleum production through the year 2030, including historical production. Table A.12 presents the final results by region and year. 


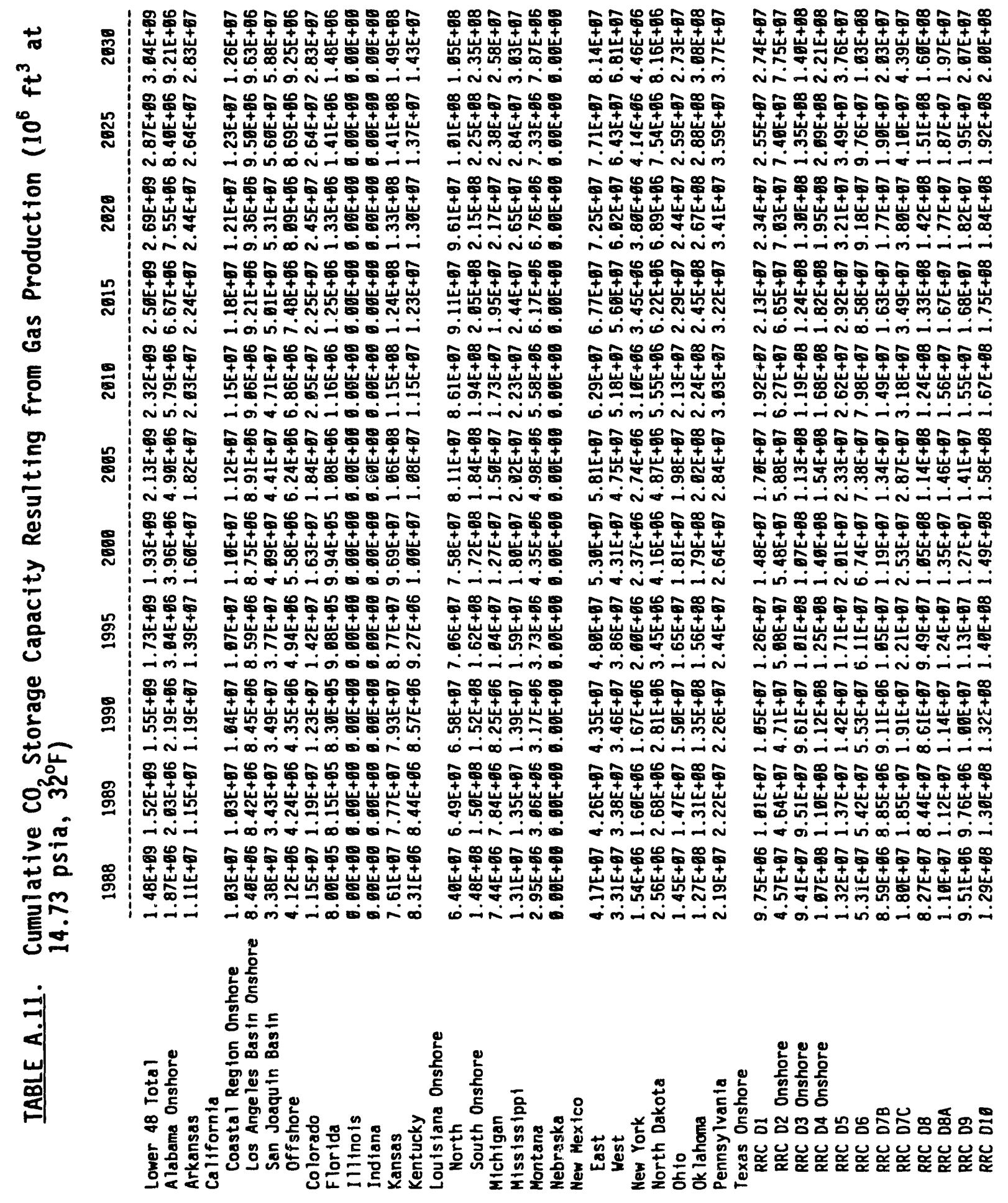




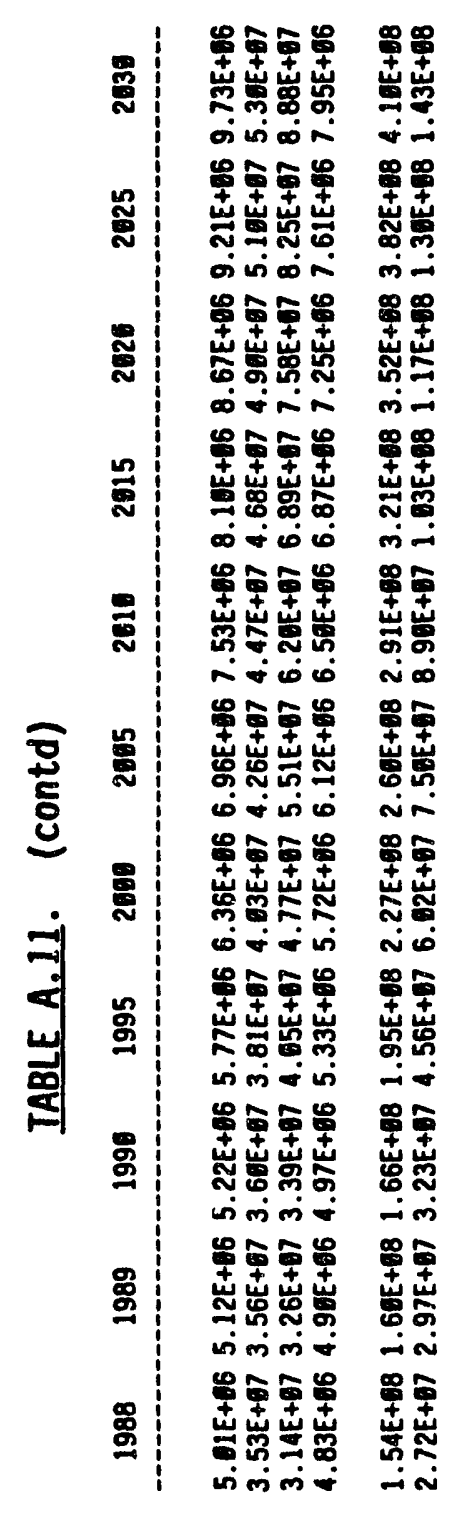

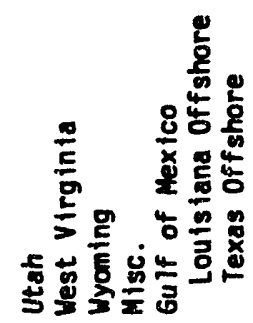


In addition, some analysts may be interested in the total void volume present in the reservoir that accommodates the stored $\mathrm{CO}_{2}$. As described earlier in this appendix, the void volume is an interim result in the calculational process. Table A.13 presents the void volume resulting from crude oil production, and Table A.14 presents similar information for natural gas production. 


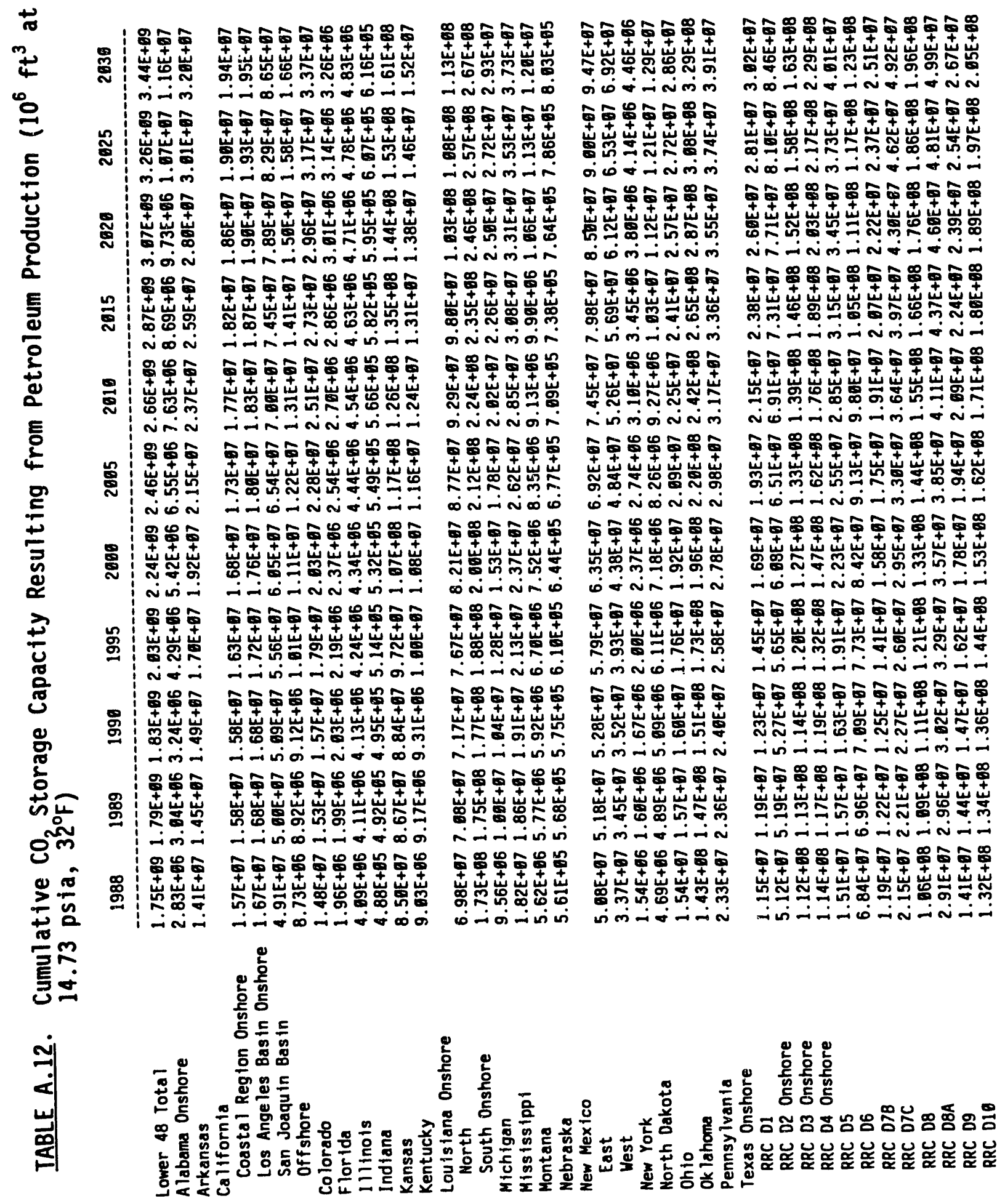




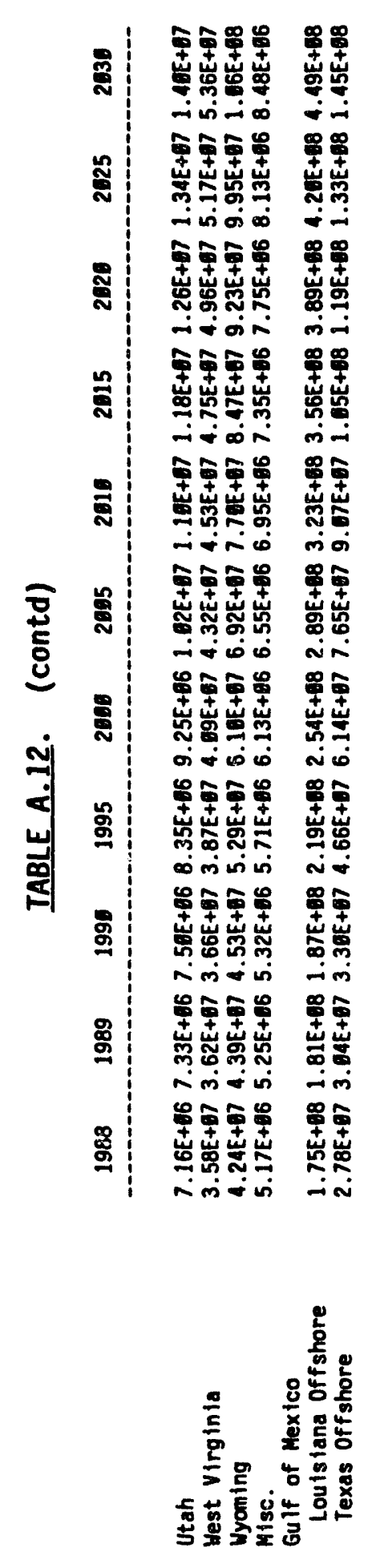

\section{A. 32}




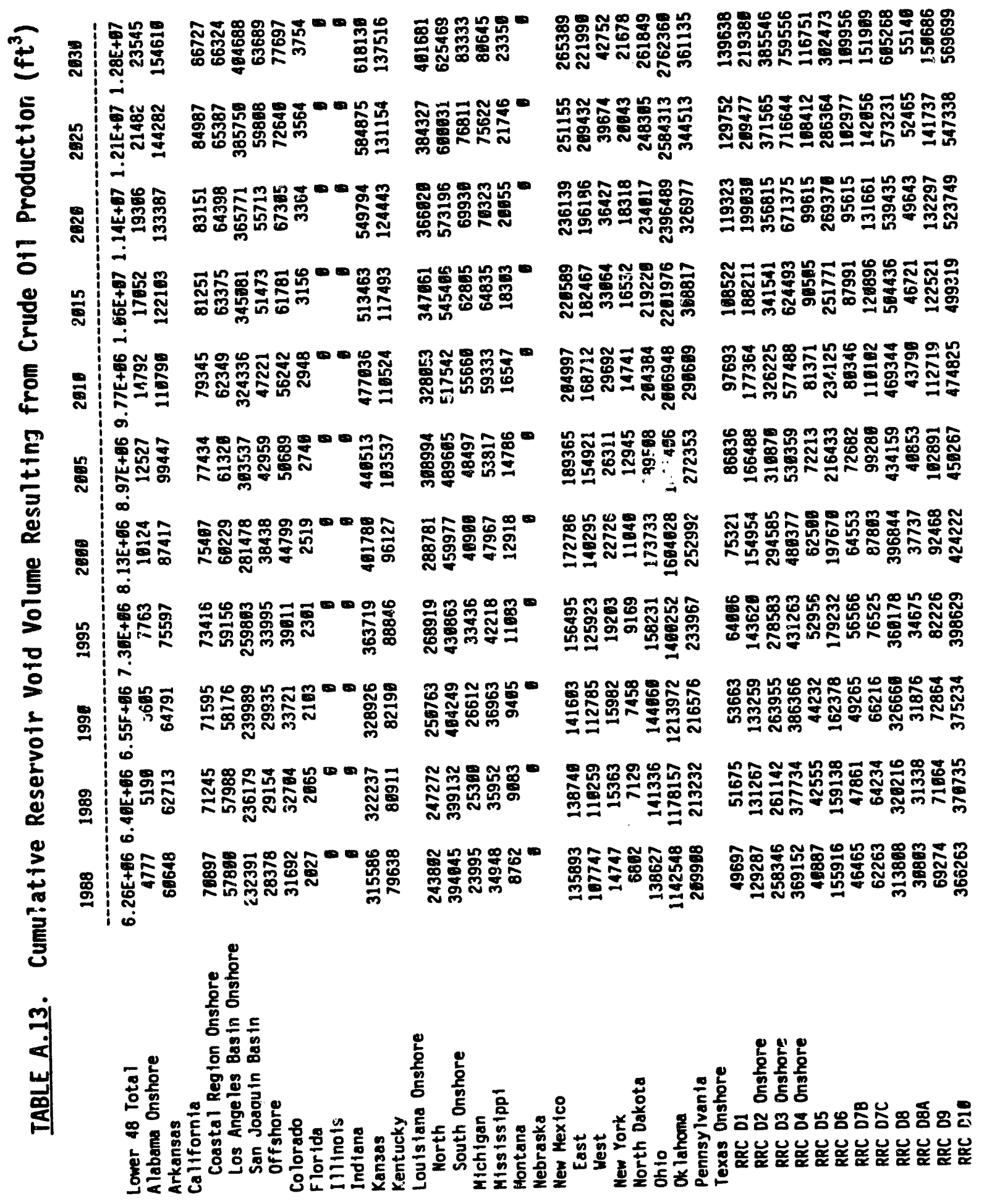



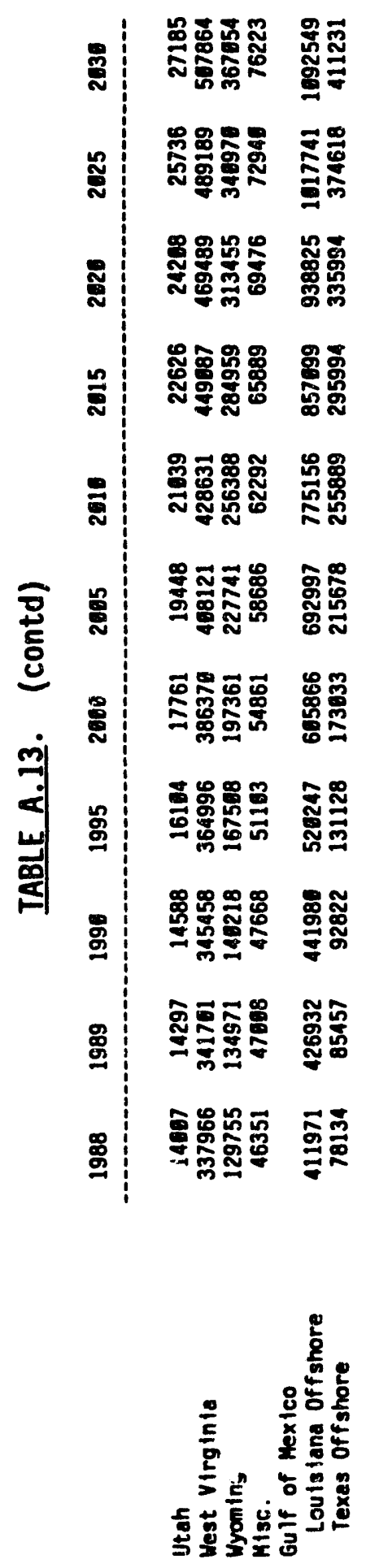

A. 34 


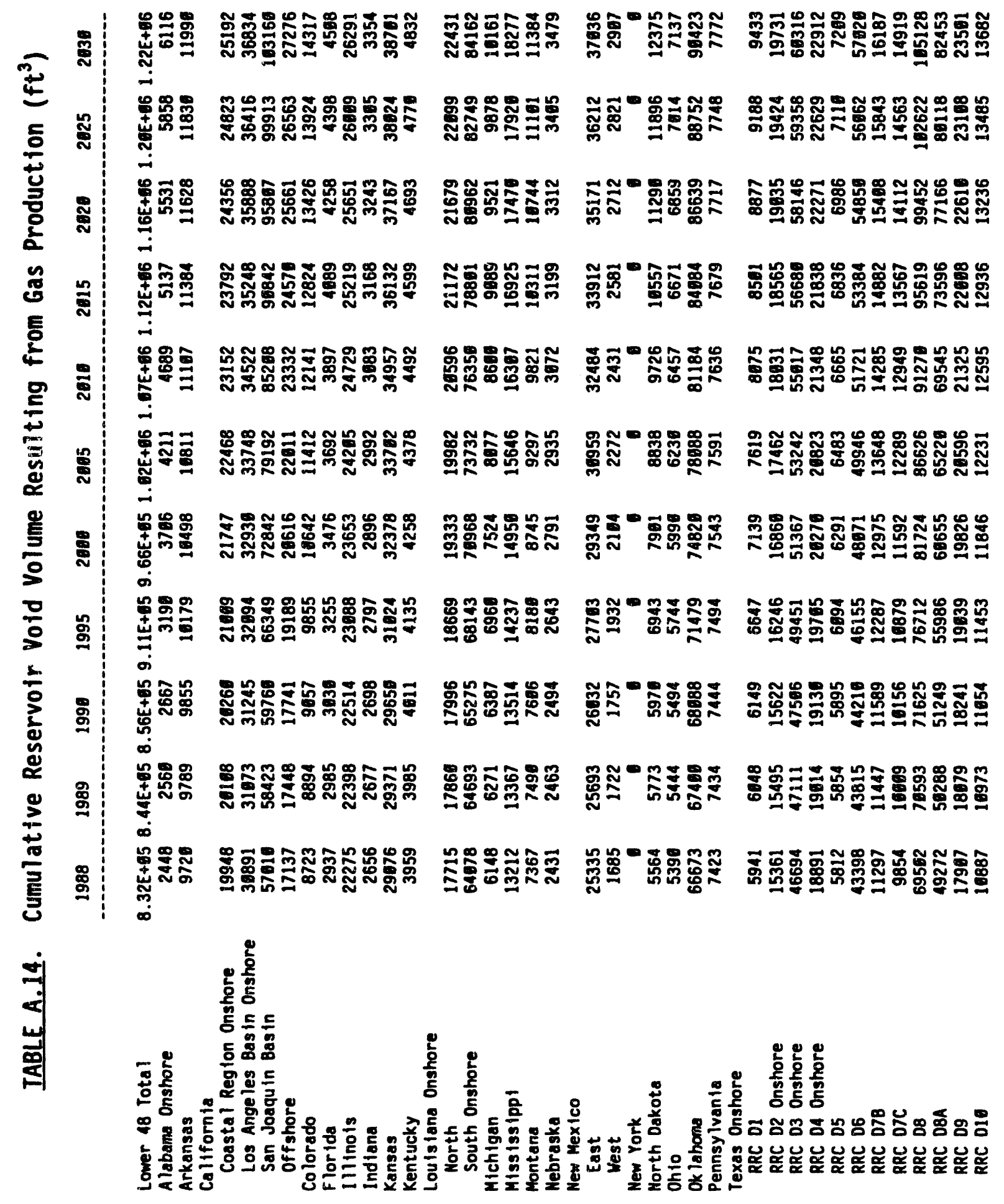




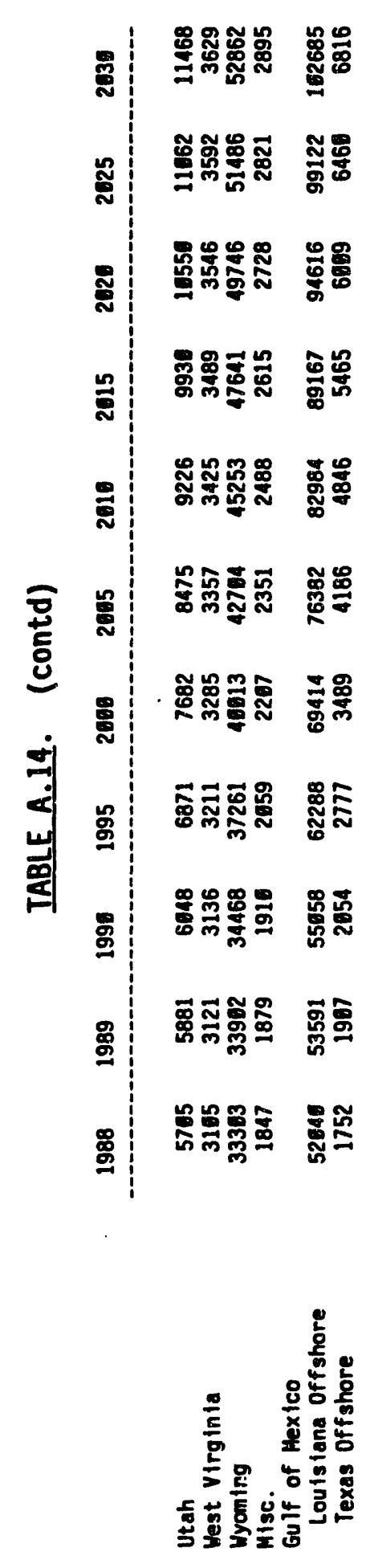




\section{APPENDIX B}

\section{PIPELINE DESIGN DETAILS}




\section{APPENDIX B}

\section{PIPELINE DESIGN DETAILS}

Heat transfer and pressure drop equations used for designing the $\mathrm{CO}_{2}$ transmission pipelines are presented in this appendix. Equations for overland transmission are presented first. Modifications required for ocean transmission follow.

The Darcy-Weisbach formula (Equation B.1) was used for calculating the head loss due to friction. The pressure loss is simply the head loss multiplied by the fluid density. While this equation is normally used for calculating head loss for incompressible flow, reasonable accuracy can be obtained by averaging the fluid properties at the inlet and outlet of the pipe if the overall pressure (density) change is 1ess than 40\% (Crane 1986). If the overall pressure (density) change is greater than $40 \%$, the Darcy-Weisbach formula can still be used if applied consecutively to sufficiently small segments of the pipe.

$$
h_{1}=f L v^{2} / 2 D g
$$

where $h_{1}=$ head loss

$f=$ friction factor

$L=$ pipe length

$v=$ fluid velocity

D = pipe diameter

$\mathbf{g}=$ acceleration of gravity

The $\mathrm{CO}_{2}$ exit temperature per segment of pipe was determined by equating the change in enthalpy of the $\mathrm{CO}_{2}$ with the heat transfer through the pipe wal1 as defined by Equations B.2 and B.3.

$$
Q=m^{*} C_{p}^{*}\left(T_{C 2}-T_{C 1}\right)
$$

B. 1 
where $Q$ =heat transfer per pipe segment

$$
\begin{aligned}
m= & \mathrm{CO}_{2} \text { mass flow rate } \\
C_{p}= & \text { average } \mathrm{CO}_{2} \text { heat capacity } \\
T_{\mathrm{C} 2}= & \mathrm{CO}_{2} \text { exit temperature } \\
T_{\mathrm{C} 1}= & \mathrm{CO}_{2} \text { inlet temperature } \\
& Q=U^{*} \mathrm{~A}^{*}\left[\left(\mathrm{~T}_{\mathrm{C} 1}-T_{\mathrm{S} 1}\right)-\left(\mathrm{T}_{\mathrm{C2}}-\mathrm{T}_{\mathrm{S} 2}\right)\right] /\left\{\ln \left[\left(\mathrm{T}_{\mathrm{C} 1}-\mathrm{T}_{\mathrm{S} 1}\right) /\left(T_{\mathrm{C} 2}-T_{\mathrm{S} 2}\right)\right]\right\}
\end{aligned}
$$

where $U=$ overall heat transfer coefficient

$$
A=\text { reference heat transfer area }
$$

$T_{S 1}=$ soil temperature at pipe segment inlet

$T_{S 2}=$ soil temperature at pipe segment exit

The overall heat transfer rate for a pipe segment is equal to the reciprocal of the sum of the individual heat transfer resistances, as indicated in Equation B.4. Equations B.5, B.6, and B.7 define the internal convective resistance, the conductive resistance through the pipe wall, and the external conductive resistance.

$$
U * A=1 /\left(R_{1}+R_{2}+R_{3}\right)
$$

where $R_{1}=$ internal heat transfer resistance

$$
R_{2}=\text { pipe wall heat transfer resistance }
$$$$
R_{3}=\text { external heat transfer resistance }
$$

$$
R_{1}=1 /\left(h_{i} * A_{i}\right)
$$

where $h_{i}=$ inside heat transfer coefficient

$$
A_{i}=\text { inside surface area }
$$

$$
R_{2}=\ln \left(r_{0} / r_{i}\right) /\left(2 * p i * k_{p}^{*} L\right)
$$

\section{B.2}


where $r_{0}=$ outside pipe radius

$r_{i}=$ inside pipe radius

$k_{p}=$ pipe wall thermal conductivity

$L=$ pipe segment length

$$
R_{3}=\cosh ^{-1}\left(D / r_{0}\right) /\left(2 * p i * k_{s}^{*} L\right)
$$

where $D=$ pipe depth from ground surface to pipe centerline

$$
k_{s}=\text { soil thermal conductivity }
$$

The internal heat transfer coefficient was estimated using the DittusBoelter equation (Welty, Wicks and Wilson 1976) for forced convection for internal flow under turbulent conditions (Equation B.8).

$$
N u_{d i}=h_{i} D_{i} / k_{c}=0.023 * \operatorname{Re}_{d i}{ }^{0.8} \operatorname{Pr}_{c} 0.3
$$

where $\mathrm{Nu}_{\mathrm{di}}=$ Nusselt number based on inside pipe diameter

$D_{i}=$ inside pipe diameter

$k_{c}=$ thermal conductivity of $\mathrm{CO}_{2}$

$\operatorname{Re}_{\mathrm{di}}=$ Reynolds number based on inside pipe diameter

$\operatorname{Pr}_{\mathrm{C}}=\operatorname{Prandt} 1$ number of $\mathrm{CO}_{2}$

Note that exponent on the Prandt 1 number equals 0.3 if fluid in pipe is being cooled; 0.4 if being warmed.

The calculational procedure requires the following nested iterative solution to solve simultaneously for the exit $\mathrm{CO}_{2}$ pressure and temperature for a pipe segment, given entrance conditions:

1. Assume exit temperature.

2. Assume exit pressure.

3. Look up entrance and exit fluid properties.

4. Calculate average fluid properties. 
5. Calculate frictional head loss and elevation head gain.

6. Compare calculated exit pressure to assumed exit pressure.

7. Repeat steps 2-6 until calculated pressure equals assumed pressure.

8. Calculate overall heat transfer coefficient (U).

9. Calculate overall heat transfer rate.

10. Calculate exit temperature.

11. Compare calculated exit temperature to assumed exit temperature.

12. Repeat steps 1-11 until calculated temperature equals assumed temperature.

An analysis of heat transfer between $\mathrm{CO}_{2}$ and the ocean water was conducted by modifying the external resistance equation (Equation B.7) to reflect a convective heat transfer mode. Equation B.9 describes the external convective resistance. The external heat transfer coefficient was estimated using the McAdams equation (We]ty, Wicks and Wilson 1976) for forced convection for external cross flow (Equation B.10). Forced (rather than natural) external convection was presumed, due to ocean currents.

$$
R_{3}=1 /\left(h_{0} * A_{0}\right)
$$

Where $h_{0}=$ outside heat transfer coefficient

$A_{0}=$ outside surface area

$$
N u_{d o}=h_{o} D_{o} / k_{w}=0.02629 * \operatorname{Re}_{d i}{ }^{0.805 * P r_{w}}{ }_{w}^{0.333}
$$

Where $\mathrm{Nu}_{\mathrm{do}}=$ Nusselt number based on outside pipe diameter

$$
\begin{aligned}
D_{0} & =\text { outside pipe diameter } \\
k_{w} & =\text { therma } 1 \text { conductivity of sea water } \\
\operatorname{Re}_{d i} & =\text { Reynolds number based on inside pipe diameter } \\
\operatorname{Pr}_{w} & =\text { Prandt } 1 \text { number of sea water }
\end{aligned}
$$

\section{B. 4}


The 12-step iterative procedure described above for overland pipes was repeated for ocean pipes.

B.5 


\section{REFERENCES}

Anada, H., D. King, A. Seskus, M. Fraser, and J. Sears, 1982. Feasibility and Economics of By-Product $\mathrm{CO}_{2}$ Supply for Enhanced 0 il Recovery. DOE/MC/08333-3. Science Applications, Inc. and West Virginia University, Morgantown, West Virginia.

Amyx, J., D. M. Bass, and R. L. Whiting. 1960. Petroleum Reservoir Engineering: Physical Properties. McGraw-Hill, New York.

Blok, K., W. C. Turkenburg, C. A. Hendriks, and M. Steinberg, ed. 1992.

Proceedings of the First International Conference on Carbon Dioxide Removal. Pergamon Press, Oxford, England.

Brown, D. R., J. A. Dirks, M. K. Drost, G. E. Spanner, and T. A. Williams. 1987. An Assessment Methodology for Thermal Energy Storage Evaluation.

PNL-6372, Pacific Northwest Laboratory, Richland, Washington.

Crane Company. 1986. Flow of Fluids Through Valves, Fittings, and Pipes.

New York.

Decker, L. C. 1986. "Sheep Mountain $\mathrm{CO}_{2}$ Line Fills Out West Texas EOR Grid." 0il and Gas Journal 84(20):57-60,62.

DOE. See U.S. Department of Energy.

Electric Power Research Institute (EPRI). 1989. Technical Assessment Guide. EPRI P-6587-L. Palo Alto, California.

Energy Information Administration (EIA). 1978. Depth and Producing Rate Classification of Domestic Oil Reserves, 1974. U.S. Department of Energy, Washington, D.C.

Energy Information Administration (EIA). 1990. U.S. $0 i 1$ and Gas Reserves by Year of Field Discovery. DOE/EIA-0534, U.S. Department of Energy, Washington, D.C.

Energy Information Administration (EIA). 1991a. Inventory of Power Plants in the United States 1990. DOE/EIA-0095, U.S. Department of Energy, Washington, D.C.

Energy Information Administration (EIA). 1991b. 0i1 and Gas Field Code Master List 1991. DOE/EIA-0370, U.S. Department of Energy, Washington, D.C.

Energy Information Administration (EIA). 1992. Annual Energy Outlook 1992. DOE/EIA-0383, U.S. Department of Energy, Washington, D.C.

Garrett, D. E. 1989. Chemical Engineering Economics. Van Nostrand Reinhold, New York. 
Hamilton, L. D. 1989. "A Systems Approach to a Technology-based Response to the Greenhouse Gas Issue." Presented at IEA/OECD Seminar: Energy Technologies for Reducing Emissions of Greenhouse Gases. Paris, France.

Hendriks, C. A., K. Blok, and W. C. Turkenburg. 1990. Technology and Cost of Recovering and Storing Carbon Dioxide from an Integrated Gasifier, Combined Cycle Plant. Ministry of Housing, Physical Planning and Environment, Air Directorate, Leidschendam, The Netherlands.

Horn, F. L. and M. Steinberg. 1982. Possible Storage Sites for Disposal and Environmental Control of Atmospheric Carbon Dioxide. BNL 51597, Brookhaven National Laboratory Associated Universities, Inc., Upton, New York.

Ikoku, C. I. 1984. Natural Gas Production Engineering. John Wiley \& Sons, New York.

Matchak, T. A., A. D. Rao, V. Ramanathau, and M. T. Sander. 1984. Cost and Performance for Commercial Applications of Texaco-Based Gasification-

Combined-Cycle Power Plants. EPRI AP-3486. Prepared for the Electric Power Research Institute, Palo A7to, California, by Fluor Engineers, Inc., Irvine, California.

McGraw-Hi11. 1989. Electrical World Directory of Electric Utilities, 97th Edition. New York.

McLain, W. D. 1973. The Properties of Petroleum Fluids. PennWell Publishing Company, Tulsa, Oklahoma.

Official Airline Guides. 1992. OAG Desktop Flight Guide. Oak Brook, Illinois.

Perry, R. and D. W. Green, ed. 1984. Chemical Engineers' Handbook, Sixth Edition. McGraw-Hill Book Company, New York.

Rand McNally and Company. 1990. Rand McNally Road Atlas 1990. New York.

Reilly, R. W., D. R. Brown, and H. D. Huber. 1981. Aquifer Thermal Energy Storage Costs with a Seasonal Heat Source. PNL-4135, Pacific Northwest Laboratory, Richland, Washington.

Shell Internationale. 1990. Carbon Dioxide Disposal from Coal Based Combined Cycle Power Stations in Depleted Gas Fields in the Netherlands. Ministry of Housing, Physical Planning and Environment, Air Directorate, Leidschendam, The Netherlands.

S1ider, H. C. 1983. Worldwide Practical Petroleum Reservoir Engineering Methods. PennWell Publishing Company, Tulsa, Oklahoma. 
Smelser, S. C. and G. S. Booras. 1990. "An Engineering and Economic Evaluation of $\mathrm{CO}_{2}$ Removal from Fossil Fuel-Fired Power Plants." Presented at the 9th Annual ${ }^{2}$ EPRI Conference on Gasification Power Plants. Electric Power Research Institute, Palo Alto, California.

Steinberg, M., J. Lee and S. Morris. 1991. An Assessment of CO Greenhouse Gas Mitigation Technologies. BNL 46045, Brookhaven National Laboratory, Upton, New York.

Stol1, J. E. 1986. "Installing the 'Jugular Vein' for Offshore 0 il Production." Surveyor 20(3):2-10.

Thurman, H. V. 1986. Introductory Oceanography. Merrill Publishing Company, Columbus, Ohio.

Timmermans, W. J. 1984a. "Designing Pipelines for Extreme Water Depths." 0il and Gas Journal 82(51):78-82.

Timmermans, W. J. 1984b. "Pipe-Joining Techniques for Deepwater Lines." 0il and Gas Journal 82(52):57-58.

Timmermans, W. J. 1989. "Technology for Larger Deepwater Pipelines Lags Behind Industry's Development Plans." 0il and Gas Journal 87(18):68-78.

True, W. R. 1989a. "Pipeline Economics." 0il and Gas Journal 87(48):41-66.

True, W. R. 1989b. "Laying, Repairing Deepwater Gulf Lines Chaillenges Operators." 0il and Gas Journal 87(50):56-61.

True, W. R. 1990. "Pipeline Economics." Oil and Gas Journal 88(48):41-63. U.S. Department of Energy. 1991. National Energy Strategy. 061-00-00754-7, Government Printing Office, Washington, D.C. 20402.

van der Meer, L.G.H. 1992. "Investigations Regarding the Storage of Carbon Dioxide in Aquifers in the Netherlands." Proceedings of the First International Conference on Carbon Dioxide Removal. Pergamon Press, Oxford, England.

van Engelenburg, B. C. W. and K. Blok. 1992. Prospects for the Disposal of Carbon Dioxide in Aquifers. G-91006, University of Utrecht, Utrecht, The Netherlands.

Welty, J. R., C. E. Wicks, and R. E. Wilson. 1976. Fundamentals of Momentum, Heat, and Mass Transfer, Second Edition. John Wiley and Sons, New York. 

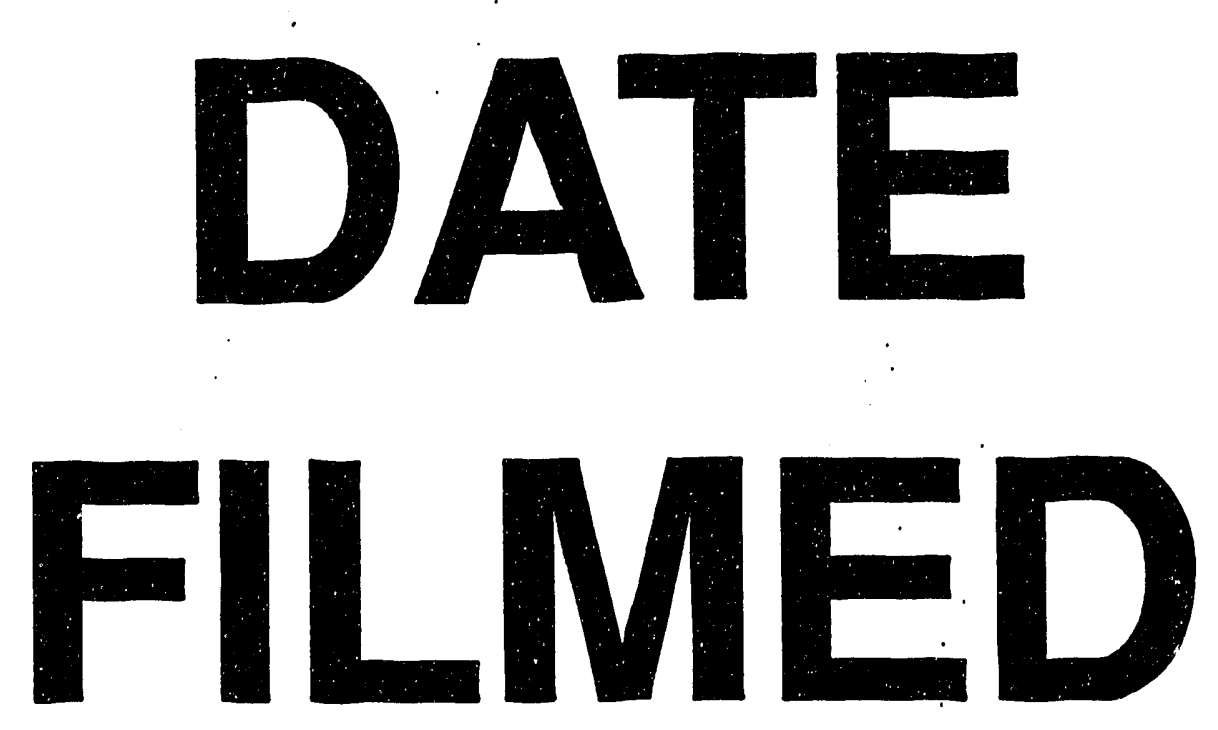

$9 / 16 / 93$
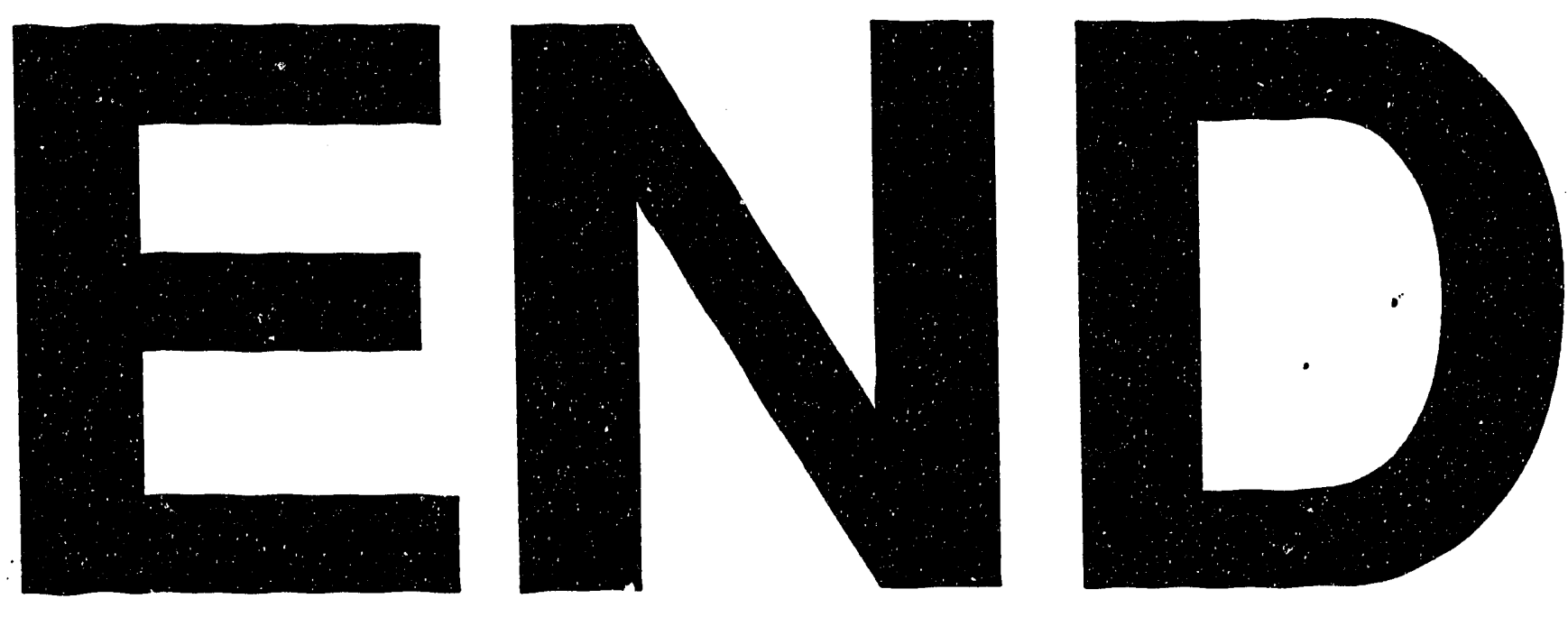